$12 / 1 / 195850$

\title{
Advanced Manufacturing: \\ Technology and International Competitiveness
}

February 1995
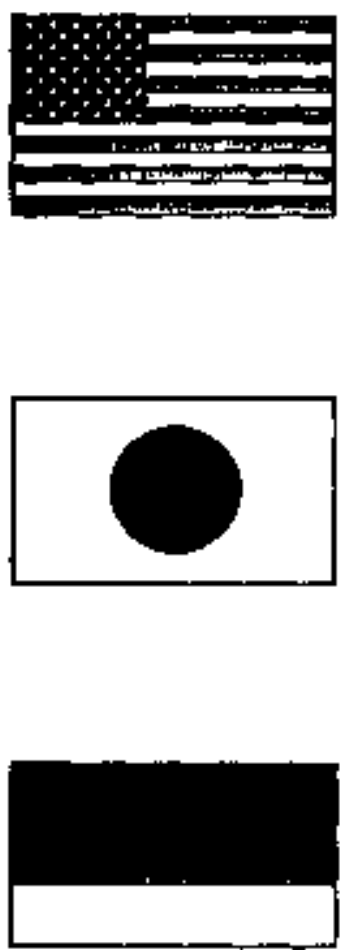


\title{
Advanced Manufacturing: Technology and International Competitiveness
}

\author{
Aleta Tesar, Author
}

February 1995

This report has been prepared by the Lawrence Livermore National Laboratory, Nonproliferation, Arms Control, and International Security Directorate. The views expressed are those of the project personnel and not necessarly those of the

Directorate or Laboratory.

\section{Disclaimar}

This document was prepared as an account of work sponsored by an agency of the United States Government. Neither the United States Government nor the University of Callfornia nor any of theit employees makes any warranty, express or implied, or assumes any legal liability or responsibility for the accuracy, completeness, or usefulness of any information, apparatus, product, or process disclosed, or represents that its use would not infringe on privately owned rights. Reference herein to any speclific cornmercial products, process or service by trade name, trademark, manufacturer, or otherwise, does not necessarily constitute or imply its endorsement, recommendation, or tavoring by the United States Govemment or the University of California. The views and opinions of authors expressed herein do not necessarily state of reflect those of the United Stales Government or the University of Califomia and shall not be used for advertising or product endorsement purposes.

Work performed under the auspices of the U.S. Department of Energy by Lawrence Livernore National Laboratory under Contract W-4705-Eng*48.

For additional copies of this document, please FAX a written request to (510) $422-4563$. 


\section{DISCLAIMER}

Portions of this document may be illegible in electronic image products. Images are produced from the best available original document. 


\section{Contents}

\section{Preface}

Part 1: Human Capital

Part 2: Manufacturing Initiatives

Part 3: Component Technology R\&D 


\section{Preface}

This work examines the role of advanced technologies in manufacturing competitiveness. Germany, Japan, and the United States are compared as the manufacturers in these nations continue to lead the world in production, technology development, and trade. As global infrastructure, information exchange, and markets evolve, the nature of manufacturing in these three countries is rapidly changing. Competitive manufacturers are responding to both technical and economic pressures. Their success is based on how efficiently they can adjust to these pressures. Through comparisons, the similarities in Human Capital issues (Part 1), Research Initiative strategies (Part 2), and Manufacturing Technology R\&D goals (Part 3) for all three nations become clear. It also follows that the ability of manufacturers to effectively implement and utilize technology innovations impacts a country's manufacturing competitiveness.

By providing an international perspective, we seek to encourage an understanding of the motivations and strategies of foreign competitors. President Clinton and Vice President Gore affirmed the importance of manufacturing in their February 22, 1993 treatise Technology for America's Economic Growth: A New Direction to Build Economic Strength when they stated: "Manufacturing remains the foundation of the American economy. Although the United States was the unchallenged world leader in manufacturing for many years, our performance has slipped badly in recent decades. American firms still excel at making breakthroughs...but foreign firms are often better at follow through: namely, turning technology into new products and processes both quickly and cheaply." This perception has encouraged interest in promoting domestic industries by many Federal agencies.

"Advanced manufacturing" is used as a catch-all term for evolving improvements in manufacturing technology. The term has been used to describe automation of production steps and, more recently, integration of processes. We use the term in its broadest sense, defining the evolving component technologies in Part 3. The following document was contracted to the International Materials and Technologies Group at Lawrence Livermore National Laboratory by the Department of Energy. The IM\&T Group consists of research engineers who have experience in assessing foreign technology developments. It is our intent to provide a balanced examination of international advanced manufacturing from a technologist's perspective. 


\section{Advanced Manufacturing: Technology and International Competitiveness}

Part 1. Human Capital

February 1995
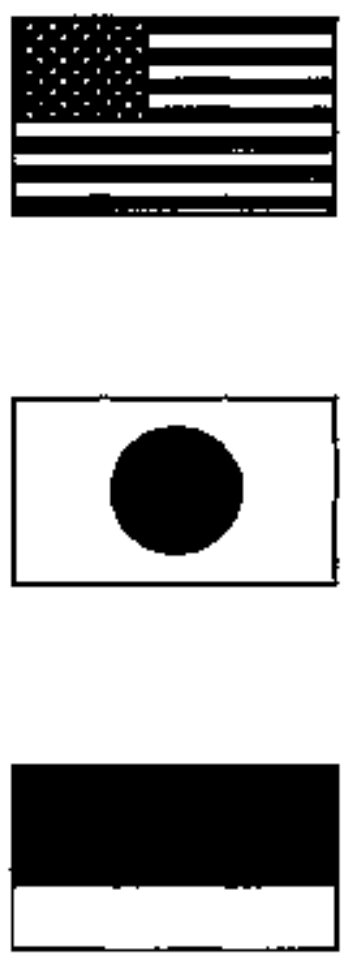


\section{Contents}

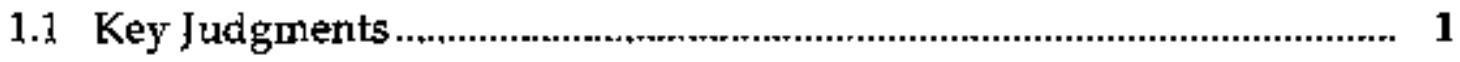

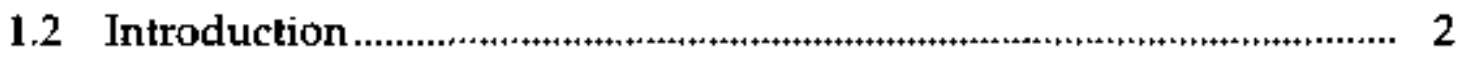

1.3 Comparison of Human Capital for German, Japanese, and U.S. Manufacturing.

1.3.1 What is a working metric of economic manufacturing competitiveness?

1.3.2 How do the manufacturing productivities of Germany, Japan, and the United States compare? .

1.3.3 What are the trends in manufacturing employment?

1.3.4 Why is the difference between wages for unskilled workers in the U.S. larger than in Germany and Japan?

1.3.5 Is the negative growth in U.S. manufacturing due to competition from Germany and Japan?

1.3.6 Does advanced technology destroy jobs? 16

1.3.7 Does application of advanced technologies generate job opportunities?

1.3.8 Is the disparity in productivity between small and large manufacturers due to advanced manufacturing technologies

1.3.9 How well do companies adjust to technological changes in manufacturing

1.3.10 How is the requirement for flexibility in advanced manufacturing changing employment?

1.3.11 How does the general education level of the workforces in Germany, Japan, and the United States compare?

1.3.12 Are there well-defined differences in engineering education between German, Japanese, and U.S. universities which are significant to manufacturing competitiveness?

1.3.13 How do manufacturing companies keep up with rapidly advancing technology?

1.4 References 


\section{List of Tables}

1.1 Capital and labor expenditures as a faction of manufacturing production for 1986 and 1991 .

1.2 Labor productivity and productivity growth ................................................. 7

1.3 Scientists and engineers in manufacturing: most current years ......................2.27

1.4 Scientists and engineers employed in manufacturing: percentage of total in workforce.

\section{List of Figures}

1.1 Hourly compensation costs in U.S. dollars for production workers in manufacturing (exchange rates were used for the comparison................... 5

1.2 Manufacturing labor costs: 1993.................................................................. 6

1.3 Labor productivity (using exchange rates to compare value-added ........................................................................................ 8

1.4 Labor productivity (using purchasing power parity to compare

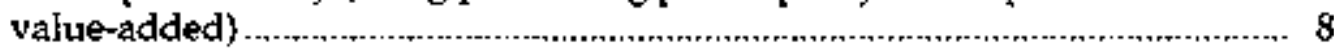

1.5 Economic competitiveness metric (see section 1.3.1) ....................................... 9

1.6 Civilian employment ......................................................................... 10

1.7 Percentage of civilian employment in manufacturing ............................. 11

1.8 Percentage of civilian employment in services ............................................. 11

1.9 Manufacturing production in each country compared withpurchasing power parity ............................................................................. 12

1.10 Male wage differentials calculated as the upper limit of ninthdecile divided by the upper limit of first decile ....................................................... 13

1.11 Unemployment rates. (Note: The unofficial Japanese unemployment rate for 1993 was estimated between $6.2 \%$ and $8.4 \%$ ) ................................... 15

1.12 Internationalization of "other' manufactures: the flow of manufacturing to low wage countries (average manufacturing labor costs for 1992) ............ 16

1.13 Percentage of unemployed who are jobless one year or more: 1991 ............... 19

1.14 The changing structure of manpower and tasks in automobile assembly

1.15 Percentage of the population (ages 25 to 64 ) who have attained various levels of education: 1988

1.16 Number of Natural Science and Engineering degrees per number of 22-year-old citizents 28

1.17 Scientists and engineers engaged in R\&D per 1,000 laborforce ........................30 


\section{Part 1: Human Capital}

\subsection{Key Judgments}

Dramatic changes in the competitiveness of German and Japanese manufacturing have been most evident since 1988. All three countries are now facing similar challenges, and these challenges are clearly observed in human capital issues. Our comparison of human capital issues in German, Japanese, and U.S. manufacturing leads us to the following key judgments:

- Manufacturing workforces are undergoing significant changes due to advanced manufacturing technologies. As companies are forced to develop and apply these technologies, the constituency of the masufacturing workforce (especially educational requirements, contingent labor, job content, and continuing knowledge development) is being dramatically and irreversibly altered. The new workforce requirements which result due to advanced manufachuring require a higher level of worker sophistication and responsibility.

- Increasing responsibility will be placed on manufacturing employees to keep up with rapidly advancing technology of all the human capital issues in manufacturing, this pacing of technology by employees will demand the most change in the next decade. Through training, communication opportunities, and involvement in $R \& D$, manufacturers in these three countries who wish to remain competitive will promote continuing excellence by their employees.

- Undergraduate engineering education in Germary, Japan, and the U.S. has converged to stress the same three components: fundamental knowledge frameworks, laboratory experience, and an engineering project. The differences between German, Japanese, and U.S. engineering education are usually in response to certain industrial product sectors which ane stressed domestically.

- German, Japanese, and U.S. manufacturing companies face the same two major competitive challenges: low-wage, laborintensive manufacturing and rapid technological progress. These challenges are being met by raising productivity and by rapid product irnovation, i.e., producing value-added products which are either high quality for the price and/or technically advanced.

- Advanced manufacturing technologies erhance competitiveness by reducing the amount of labor required for a given operation (that is, increasing productivity). Reducing the amount of labor 
can balance the high cost of labor in these three countries.

Therefore, a direct link between productivity and advanced manufacturing technologies is made. Implementation of advanced technologies is recognized as critical to manufacturing in all three countries.

- Competition between German, Japanese, and U.S. companies has a minor effect on employment. The majority of manufacturing job loss is caused by the implementation of advanced manufacturing as companies in these high wage countries ane facing increasing competition from companies in low wage countries (particularly with products that are not considered high tech). Domestic manufacturing production in Germany, Japan, and the U.S. continued to increase over the last decade even as the numbers of manufacturing employees dwindled.

- U.S. manufacturing is shown to be more competitive than German or Japanese manufacturing since 1992, due to a combination of higher productivity and low labor cost. This is a recent change, dramatized by high labor costs in Germany and Japan. Japanese manufacturers no longer have the advantage of significantly lower labor costs. U.S. manufacturing is likely to maintain this lead for several years until labor rates once again become similar.

- Advanced manufacturing technologies are providing new opportunities for smaller companies in Cermany, Japan, and the U.S. The productivity gap between small companies and large companies is expected to narrow due to increased technology investment by small companies, easing their ability to compete in the global marketplace.

\subsection{Introduction}

The interest of the governments of Germany, Japan, and the United States in manufacturing stems from societal pressures to enhance the quality of life. For example, "quality-of-life" can be linked to competitiveness as in the following definition:

"Interest in the competitiveness of the U.S. economy has grown steadily over the past 20 years, as the preeminent economic position of the United States has been eroded and as particular industries have come uncler intense competitive pressure from foreign firms. At the national level, the term 'competitiveness' refers to the ability of a nation to achieve overall levels of productivity that can sustain a rising standard of living in a complex world economy. At the industry or company level, it reflects the ability of particular firms to produce product that can meet the tests of international markets while providing an adequate retum to the resources they employ." [1.1] 
Human capital issues are at the heart of justifying costly R\&D, education programs, special legislation, tariffs, tax incentives, etc. Competent human capital is critical to manufacturing competitiveness in all three countries. Because of fast and easy access to technical information and with global markets in techrical equipment $(i, e$, the same equipment is available for purchase internationally), a country's manufacturers depend strongly on the available human capital to compete. A more prepared, skilled, flexible, and efficient workforce may give a company an edge when labor costs do not.

It is generally accepted that there are currently fewer impediments to manufacturing innovation in the U.S. than in Germany and Japan. Low regulatory burdens, free market competition, the availability of capital, flexible labor, well established infrastructure, and an entrepreneurial tradition are all very important elements to providing an environment which fosters successful industry. Innovation in advanced manufacturing technologies is just one factor. It is this factor and its effect on the workforce which is examined in Part 1: Human Capital.

\subsection{Comparison Of Human Capital For German, Japanese, and U.S. Manufacturing}

Requirements for labor, skill types and levels, and utilization of technology are changing due (in part) to advances in manufacturing technologies. This section addresses current issues comparing the manufacturing workforce for the three countries. Thene is often confusion regarding these issues in the manner in which information is presented. It is our intent here to provide the comparisons as briefly and clearly as possible, rather than in detail. The approach is to answer a number of questions which demonstrate the impact of advanced technologies on German, Japanese, and U.S. manufacturing.

\subsubsection{What is a working metric of economic mantufacturing competitiveness?}

The following equation is offered to provide a working metric for economic manufacturing competitiveness:

$\begin{aligned} & \text { Economic } \\ & \text { Manufacturing } \\ & \text { Competitiveness }\end{aligned}=\frac{\text { Productivity }}{\text { Unit Cost of Output }}=\frac{\text { Value Added (\$) } / \text { Labor Input }}{\text { Labor Cost }}$


This equation is an intentional over-simplification of what can become an incredibly complex, multifaceted description of economic factors which influence competitiveness. The simplification is necessary to illustrate the strong relationship between Economic Manufacturing Competitiveness and Labor Input and Labor Cost.

Labor Input is strongly influenced by advanced manufacturing technologies. Labor Cost is strongly influenced by cost of living and government taxes. ${ }^{1}$ Figures $1.1 \& 1.2$ indicate that very recently the U.S. has gained a competitive advantage in labor cost with respect to both Japan and Germany. Because the take-home pay of the average japanese production worker has risen rapidly, reflecting cost-of-living increases, the average labor cost is now higher than that of the average U.S. production worker. This removes a certain competitive advantage Japanese manufacturing companies have previously enjoyed. The German average labor cost has dramatically increased since 1985 due to a very high tax burden, as indicated in Figure 1.2. Minimizing the tax burden on industry is an important ingredient to realizing an economic manufacturing advantage. Another ingredient is the effjcient application of advanced marufacturing technologies. As will be discussed in the following sections, advanced manufacturing technologies influence the labor input necessary for value-added activities. Advanced marufacturing technologies provide German, Japanese, and U.S. manufacturers with an opportunity to compete by reducing labor requirements.

The economic manufachuring competitiveness metric presented above reflects the effects of an increasingly open global market and the rapidly accelerating exchange of large amounts of information. The metric's simplification is also warranted on the basis of three separate arguments. First, basic science research and new product technologies are quickly absorbed by international competitors. Recent history has demonstrated that it is extremely difficult to protect against reverse engineering, intellectual property rights violations, and clones which continue to complicate global markets. There is a distinct economic advantage to a competitor in knowing that an end-product is achevable. The reduced risk associated with pursuing a defined product technology gives a cost advantage. Thus, the first company to manufacture a given product may not realize a large competitive advartage simply by being first, and if the product is highly successful, any advantage will be quickly challenged. Secondly, capital investment and the availability of capital is important, but again it is not necessarily a competitiveness issue. Competition will develop for a commercial product which is viable and generating profit. Essential capiral for purchasing equipment and raw materials is sirmilar for different companies and in different countries. For example, a Japanese glass company and a L.S. glass company will pay similar prices for a

\footnotetext{
1 Labor cest is also intluenced by the level of education and training. This will be addressed in section 1.3.4.
} 


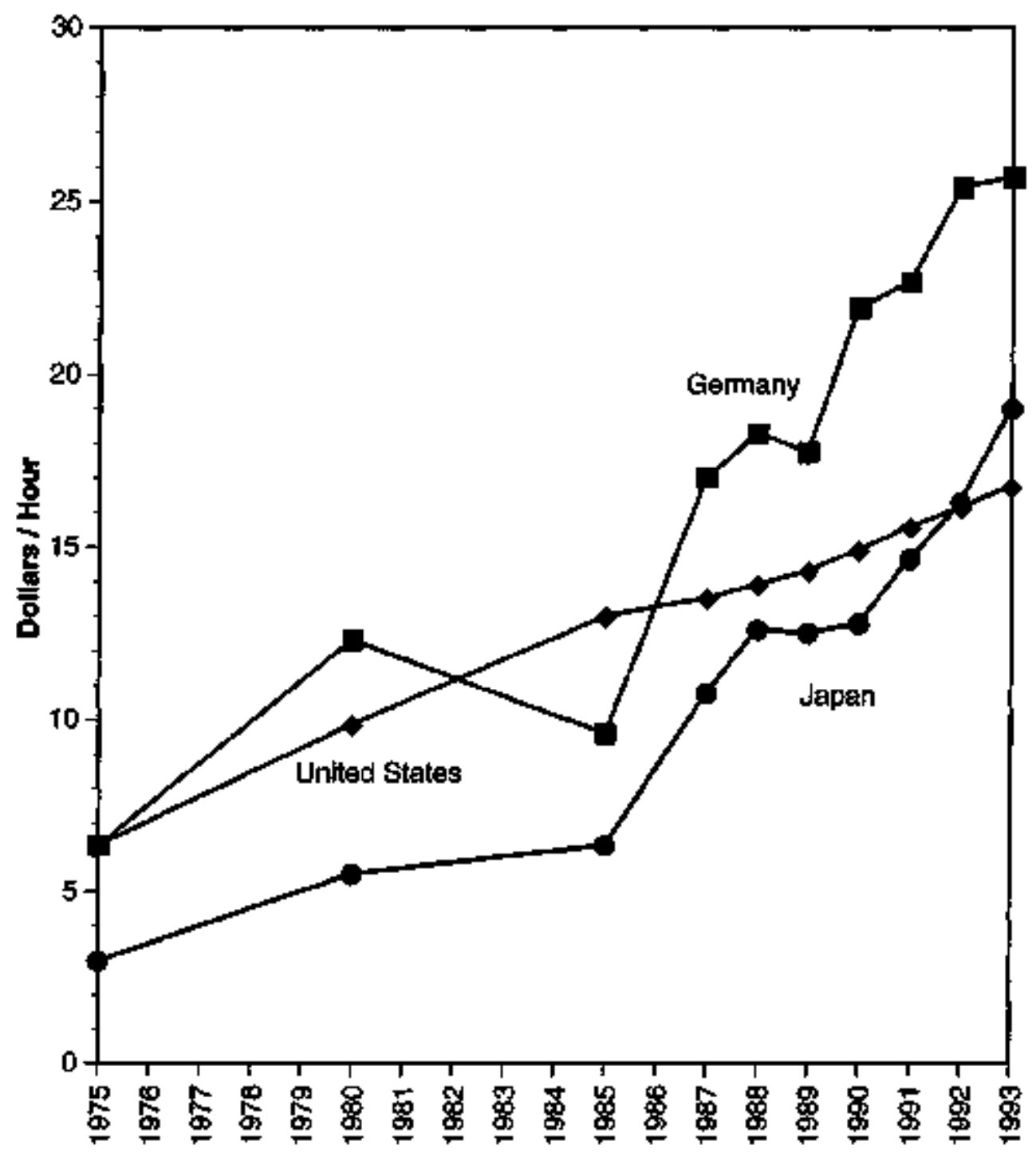

Figure 1.1. Hourly compensation costs in U.S. dollars for production workers in manufacturing (exchange rates were used for the comparison). [1.2]

Siemens float glass manufacturing equipment lire. There is minimal competitive advantage to be realized when buying capital goods in a readily accessible international market. Third, capital expenses ${ }^{2}$ account for $-\$ 0.04$ per $\$ 1$ of production while labor experises ${ }^{3}$ are $-\$ 0.2$ per $\$ 1$ of

2 Capital expenses are defined as grose flxed capltal formation. The methods used to recond capital expenses varles by coustity. For example, Germany records investrment in companies of >19 exrployeses, while Japan records imvestment in companies of >29 employees. Therefore only gross comparisons can be made. [1.4]

${ }^{3}$ Labor expenses are defined as gross wages, salaries, and certain contributions to pensions and temnination allowances. Each couniry defines this slightly differently. For example, the stalistics for Japan do not include taxes and social securty costs. The numbers should only be usedd for grose comparisons. $[1,4]$ 


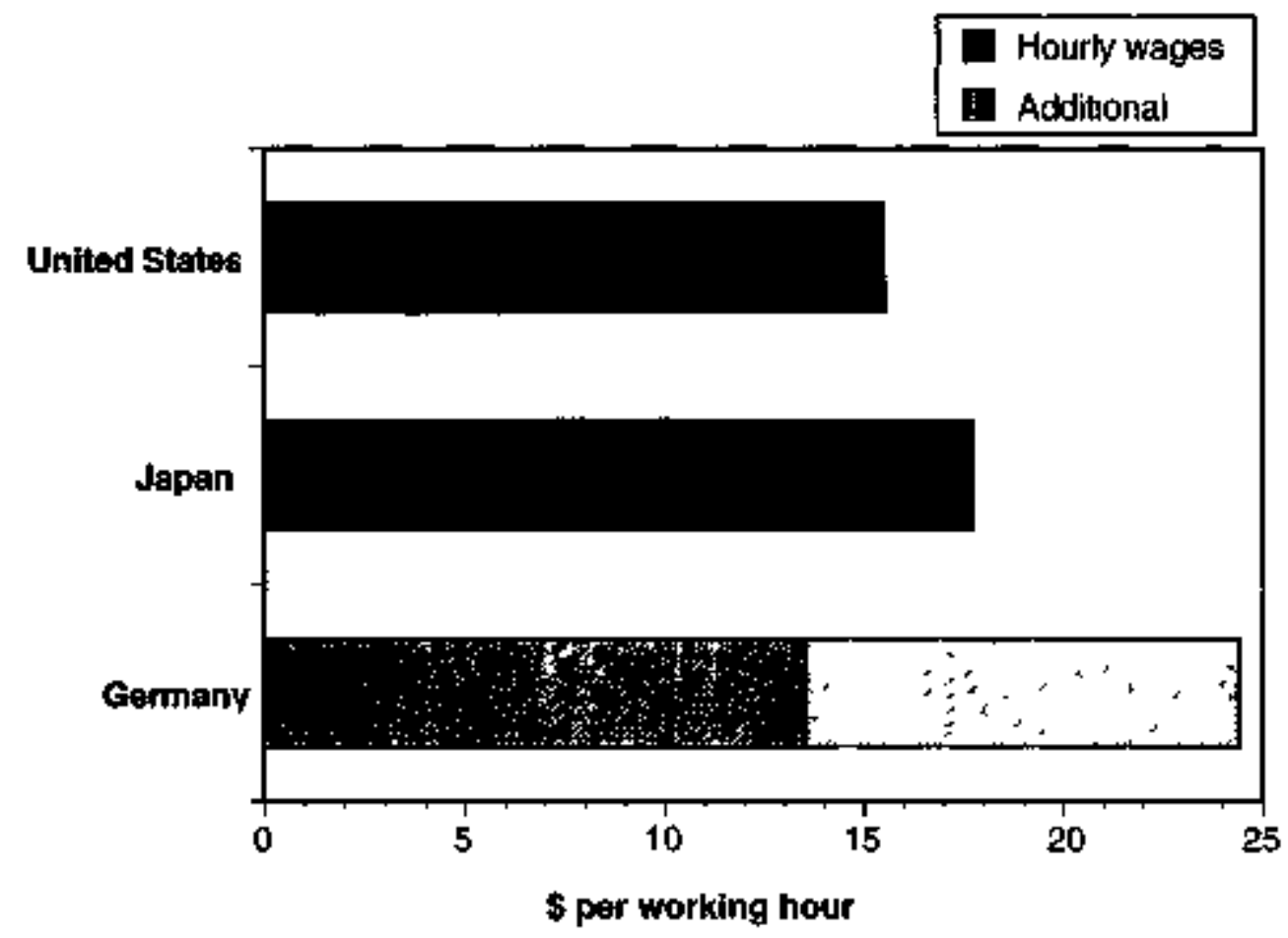

Figure 1.2. Manufacturing labor costs: 1993. [1.3]

production (see Table 1.1). The factor of five difference between capital and labor indicates that labor is the critical expense $n$ manufacturing for these three countries.

1.3.2. How do the manufacturing productioities of Gemany, Japan, and the United States compare?

The total 1991 manufacturing productivity of U.S. industry greatly exceeded that of both German and Japanese industry. German, Japanese, and U.S. manufacturing companies face the same two major competitive

Table 1.1. Capital and labor expenditures as a fraction of manufacturing production for 1986 and 1991. [1.4]

\begin{tabular}{|lcccc|}
\hline & $\begin{array}{c}\text { Average Capital Expense } \\
\text { per } \$ \text { of Production } \\
1986\end{array}$ & 1991 & \multicolumn{2}{c|}{$\begin{array}{c}\text { Average Labor Expense } \\
\text { per } \$ \text { of Production }\end{array}$} \\
\hline Getmany & 0.05 & 0.05 & 1986 & 1991 \\
Japan & 0.04 & 0.05 & 0.21 & 0.20 \\
United States & 0.03 & 0.04 & 0.14 & 0.13 \\
\hline
\end{tabular}


challenges: low-wage, labor-intensive manufacturing, and rapid technological progress. These challenges are being met by raising productivity and by rapid product innovation, i.e., producing valueadded products which are either high quality for the price and/or technically advanced. An indication of the effective application of advanced manufacturing techniques (coupled with sound management practices) is reflected in total productivity. Table 1.2 lists both the 1991 manufacturing productivity and the labor productivity growth from 1980-1988. Although the overall Japanese labor productivity growth over those years surpaseed that of the U.S., the U.S. has maintained a stggrificantly higher absolute manufacturing productivity than Germany or Japan. The rate of growth in productivity for U.S. mantufacturing in the 1990s has improved. [1.7] Productivity statistics from various sources are rarely comparable, but these general trends are usually observed.

A useful definition of labor productivity is the ratio of value-added 4 during the manufacturing process to the hours of labor consumed in that process. One comparison of labor productivity ${ }^{5}$ over the last decade is presented in Figures 1.3 and 1.4 using exchange rates and purchasing power parity, respectively. Due to these monetary comparisons, there is an interesting difference between the trends of German and U.S. manufacturing. In both figures, the average productivity of Japanese manufacturing lags that of German and U.S. manufacturing. Although the labor productivity growth varies for each country in each year, there is a continuing trend towards increasing productivity. The differences due to monetary comparisons are negated when calculating the economic manufacturing competitiveness metric. By taking into ascount both labor

4 Value-added can be thought of as the product sales (production) minus the cost to produce those products (usually including equipment, other capital, raw materiats, and labor).

5 The manufactaring value-added and manufacturing labor values used in this cakulation were tabulated in Feference [1,4].

Table 1.2. Labor productivity and productivity growth.

\begin{tabular}{|c|c|c|c|}
\hline \multirow[b]{2}{*}{ Country } & \multirow[b]{2}{*}{$\begin{array}{l}\text { Productivity [1.5] } \\
\text { (index US 1991 }=100 \text { ) }\end{array}$} & \multicolumn{2}{|c|}{$\begin{array}{l}\text { Productivily Growth: 1980-1988 [1.6] } \\
\text { (index US 1980 = 100) }\end{array}$} \\
\hline & & $\begin{array}{c}\text { Total } \\
\text { Manufacturing }\end{array}$ & $\begin{array}{l}\text { Metal Working } \\
\text { \& Machinery }\end{array}$ \\
\hline Gemmany & 86 & 126 & 113 \\
\hline Japarn & 72 & 142 & 149 \\
\hline United States & 100 & 129 & 155 \\
\hline
\end{tabular}




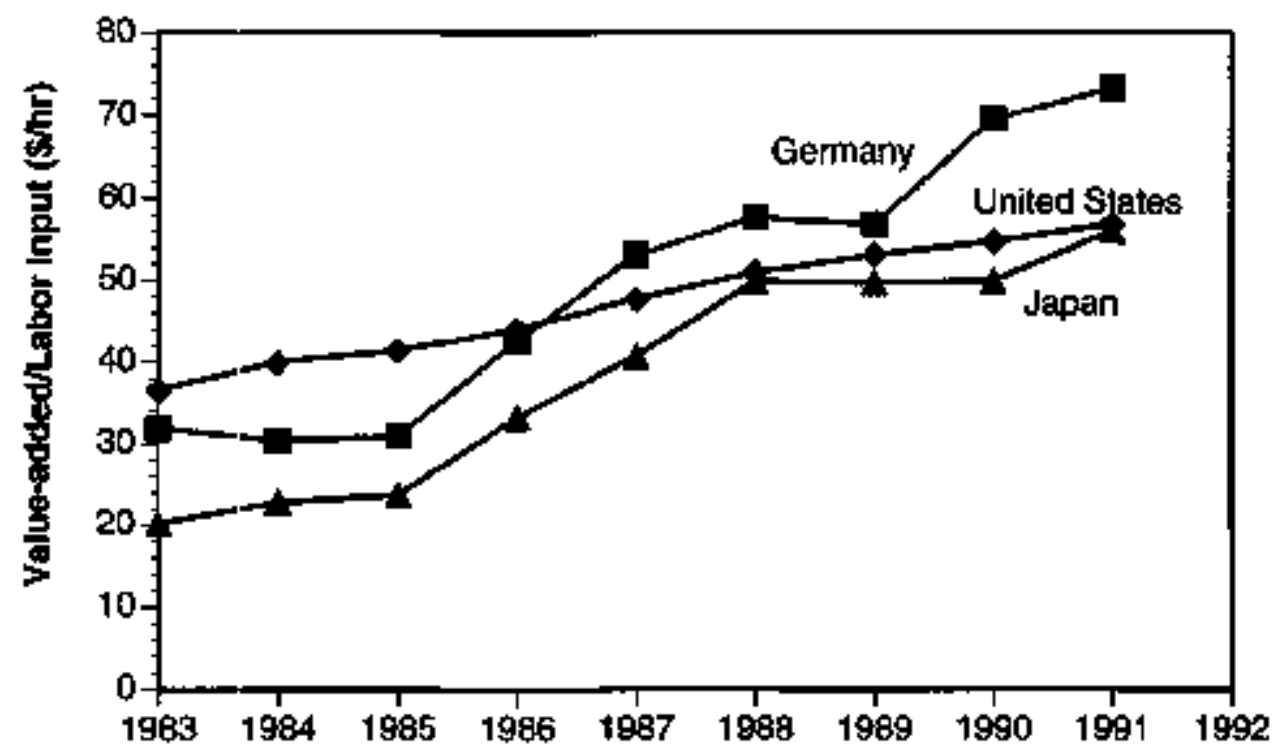

Figure 1.3. Labor productivity (using exchange rates to compare value-added). [1.4]

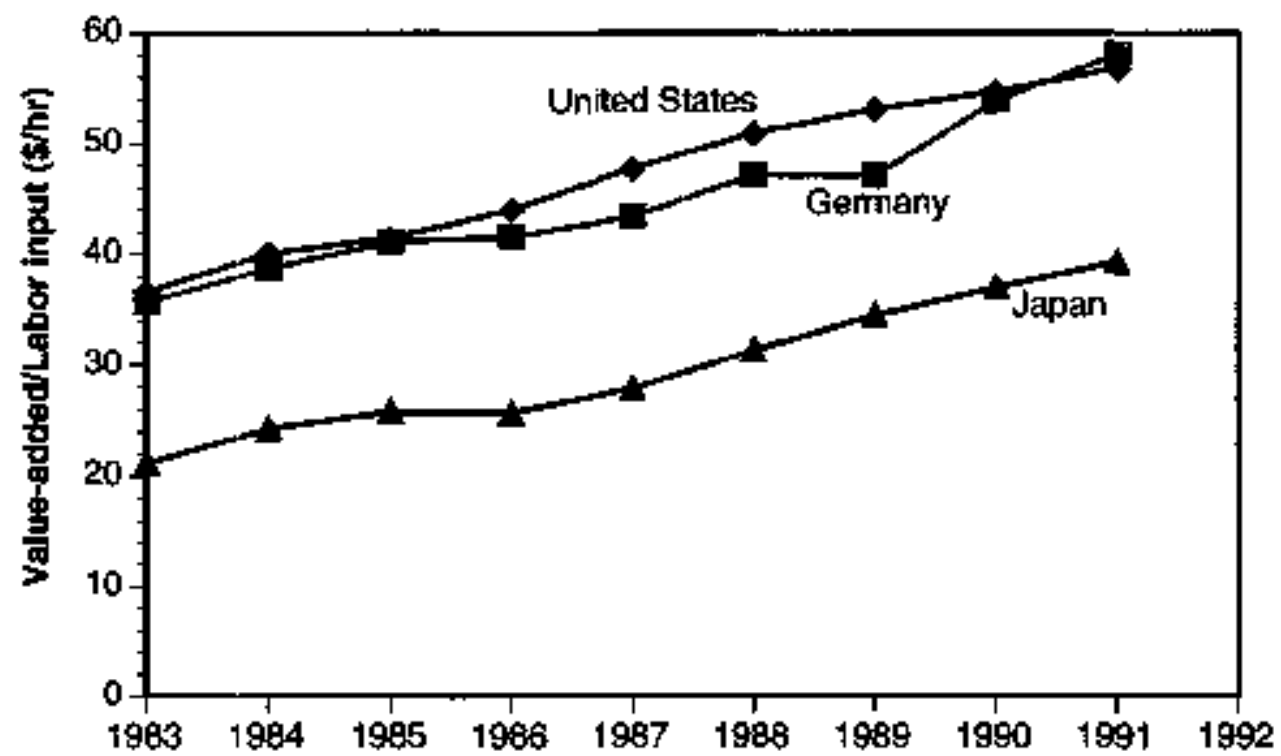

Figure 1.4. Labor productivity (using purchasing power parity to compare value-added). [1,4] 
productivity (i.e., value-added and labor input) and labor cost, competitiveness trends are presented in Figure 1.5. It is interesting that U.S. manufacturing is shown to be more competitive than German or Japanese manufacturing in 1992. This is because the U.S. maintained a compebitive position on labor costs while the economic drivers have precipitated a downturn in both German and Japanese manufacturing.

\subsubsection{What are the trends in manufacturing employment?}

Education and training can enhance manufacturing employment opportunities and raise productivity if useful skills and understanding have been developed to manipulate manufacturing technologies. There are no clear trends which can be shown between education, productivity, and employment, partly because of the changes which have occurred in our labor markets and consuner markets within the last decade. However, thene are important indications. For example, Figure 1.6 shows

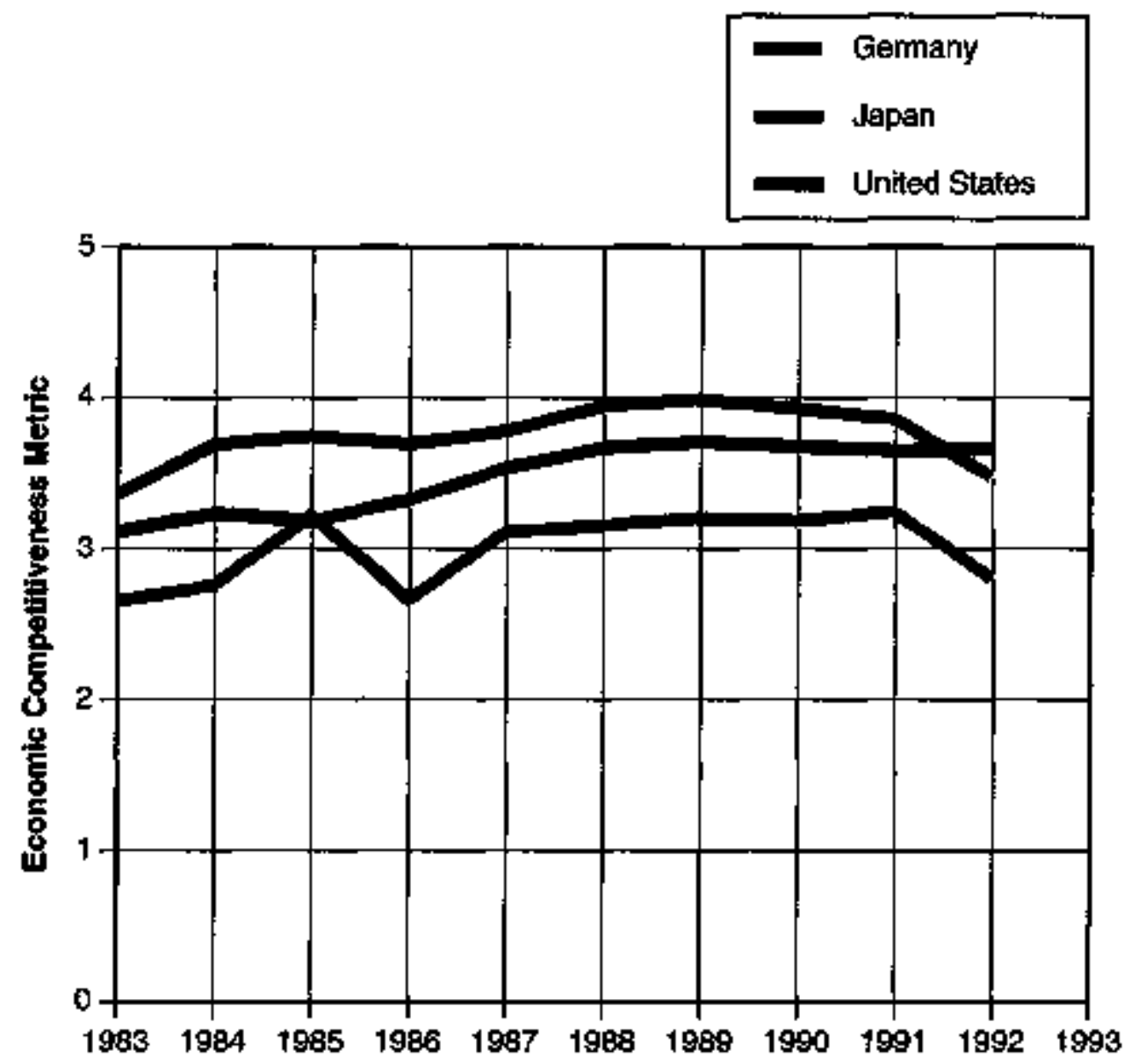

Figure 1.5. Economic competitiveness metric (see section 1.3.1.) 


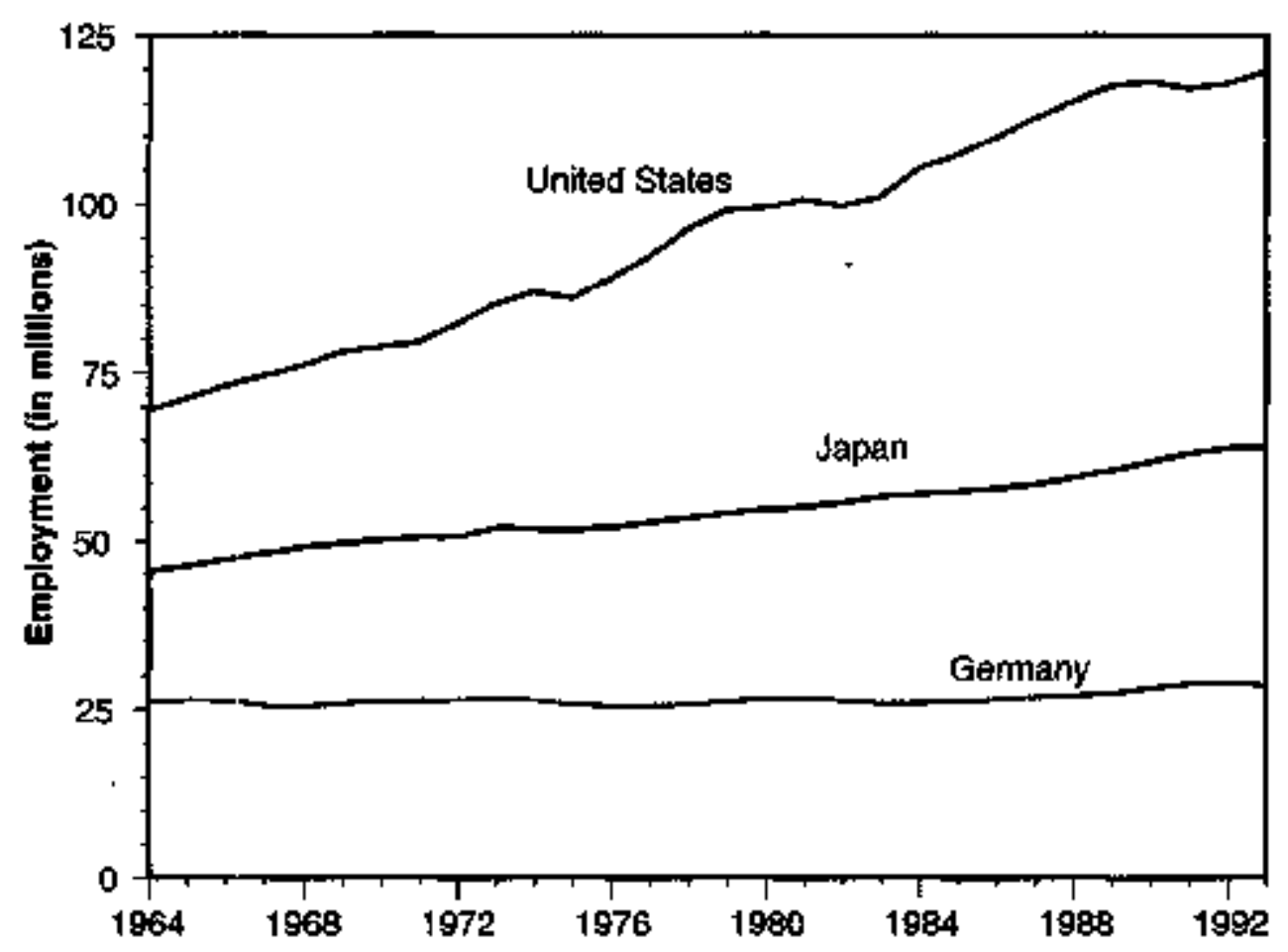

Figute 1.6. Civilian employment. [1.2]

that overall employment in the U.S. has increased more than in Japart and Germany. The U.S. economy leads in producing jobs. Figures 1.7 and 1.8 demonstrate the changing proportions of manufacturing sector jobs and service sector jobs for all three countries. Although U.S. manufacturing has had a greater rate of job loss, the U.S. leads in the creation of service sector jobs. It is well established that service sector jobs (loosely termed valuedispersing jobs) depend on manufacturing jobs (loosely termed valueadded jobs). [1.1,1.8] Because U.S. manufacturing productivity is currently higher than in Japan and Germany, it is supporting a larger service industry with fewer manufacturing workers. Even with the diminished growth in manufacturing employment, other employment which depends on manufacturing has increased.'

Manufacturing output continued to increase over the last decade (as shown in Figure 1.9) even as the numbers of manufacturing employees leveled off. The increased output was largely due to company-bycompany emphasis on enhanced efficiercy: partly through the downsizing of megacorporations which became too expensive to compete [1.91, partly through applying new technologies and developing product innovations, and partly through hiring fewer, more highly educated workers and utilizing them more effectively. The trends based on technology are also not clear because the ability to innovate given an understanding of how to 


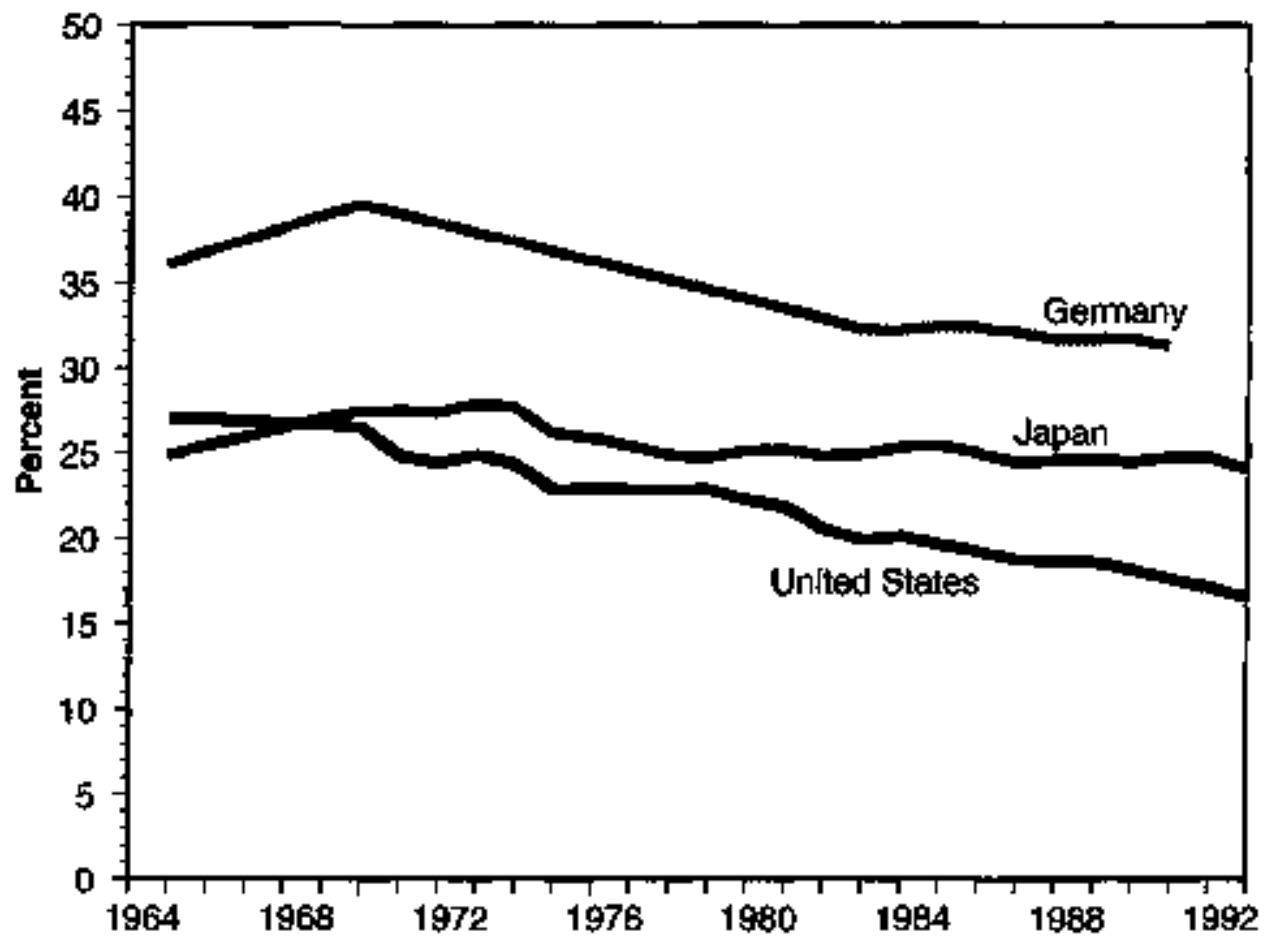

Figure 1.7. Percentage of civilian employment in manufacturing. [1.2]

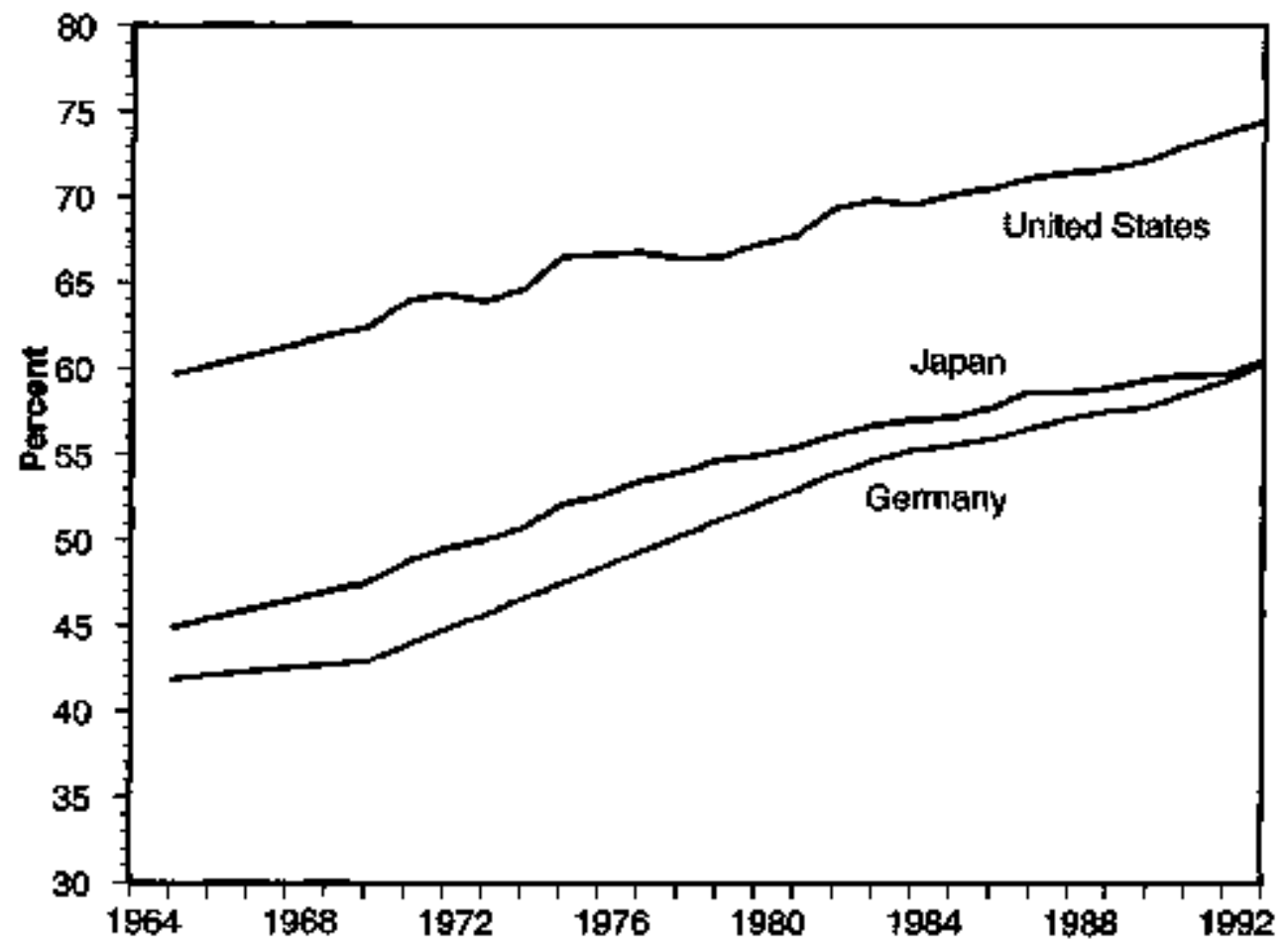

Figure 1.8. Percentage of civilian employment in services. [1.2] 


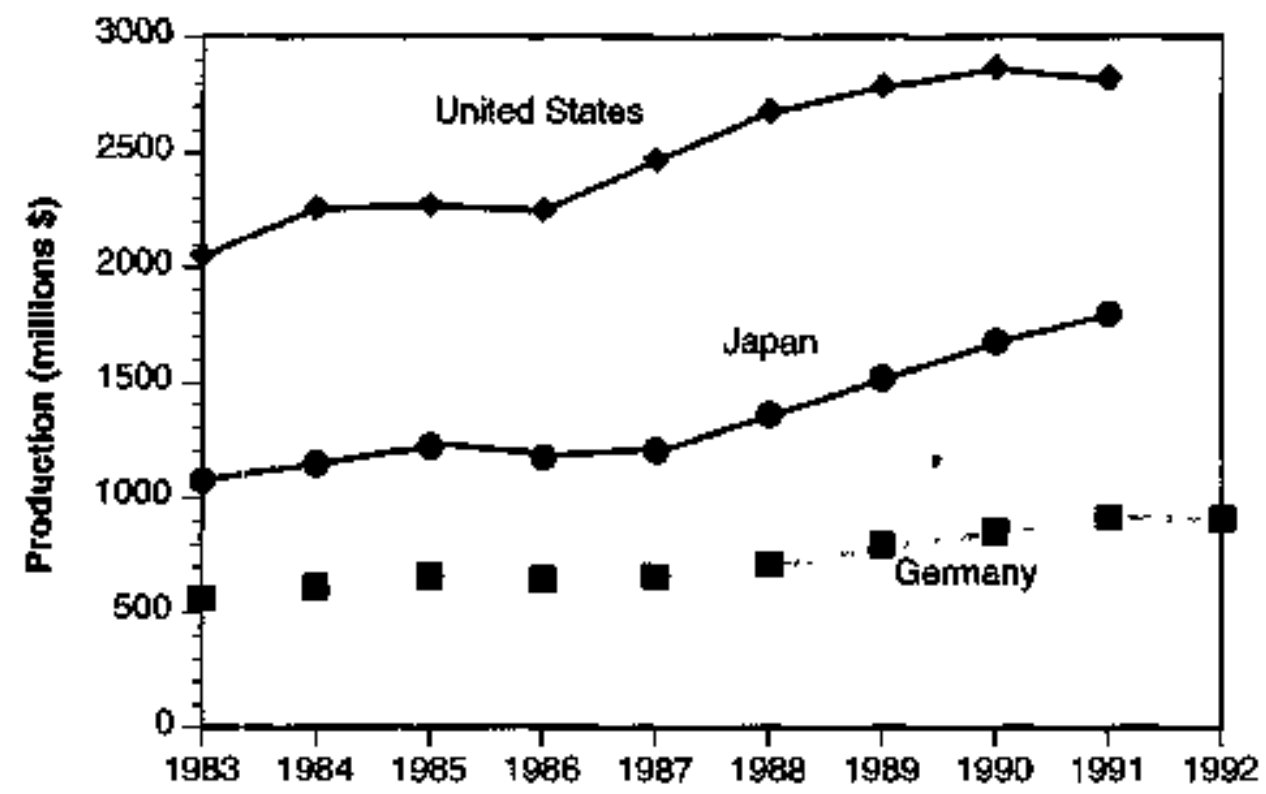

Figure 1.9. Manufacturing production in each country compared using purchasing power parity. [1.4]

apply manufacturing technologies is difficult to quantify except as part of a productivity parameter. The recent U.S. growth in productivity is improving. [1.7] Japan and Germany are having more difficulty achieving a sumilarly enhanced efficiency for different reasons. Downsizing of megacorporations (releasing workers) to improve flexibility and redirect efforts is counter-culture in Japan. In Germany, the workforce is not generally motivated to apply new technologies, and the long history of rigid union structure in worker utilization is difficult to overcome. Changes in the ubilization of the manutacturing workforce will require time, giving the U.S. a period to build a strong lead in improving efficiency and productivity.

\subsubsection{Why is the difference between wages for unskilled workers and} well-educated workers in the U.S. Iarger than in Germany and Japan?

Wage differentials have been calculated to be much greater in the US. than in Germany and Japan. Statistics which compare only the manufacturing workforce wage differentials were not found. It should be noted that the wage differential statistics shown in Figure 1.10 do not account for the lucrative and widespread perquisites for engineers and management in Japan (which would push their upper $10 \%$ much higher); nor all of the lower wages of apprentices and foreign laborers in Germany 


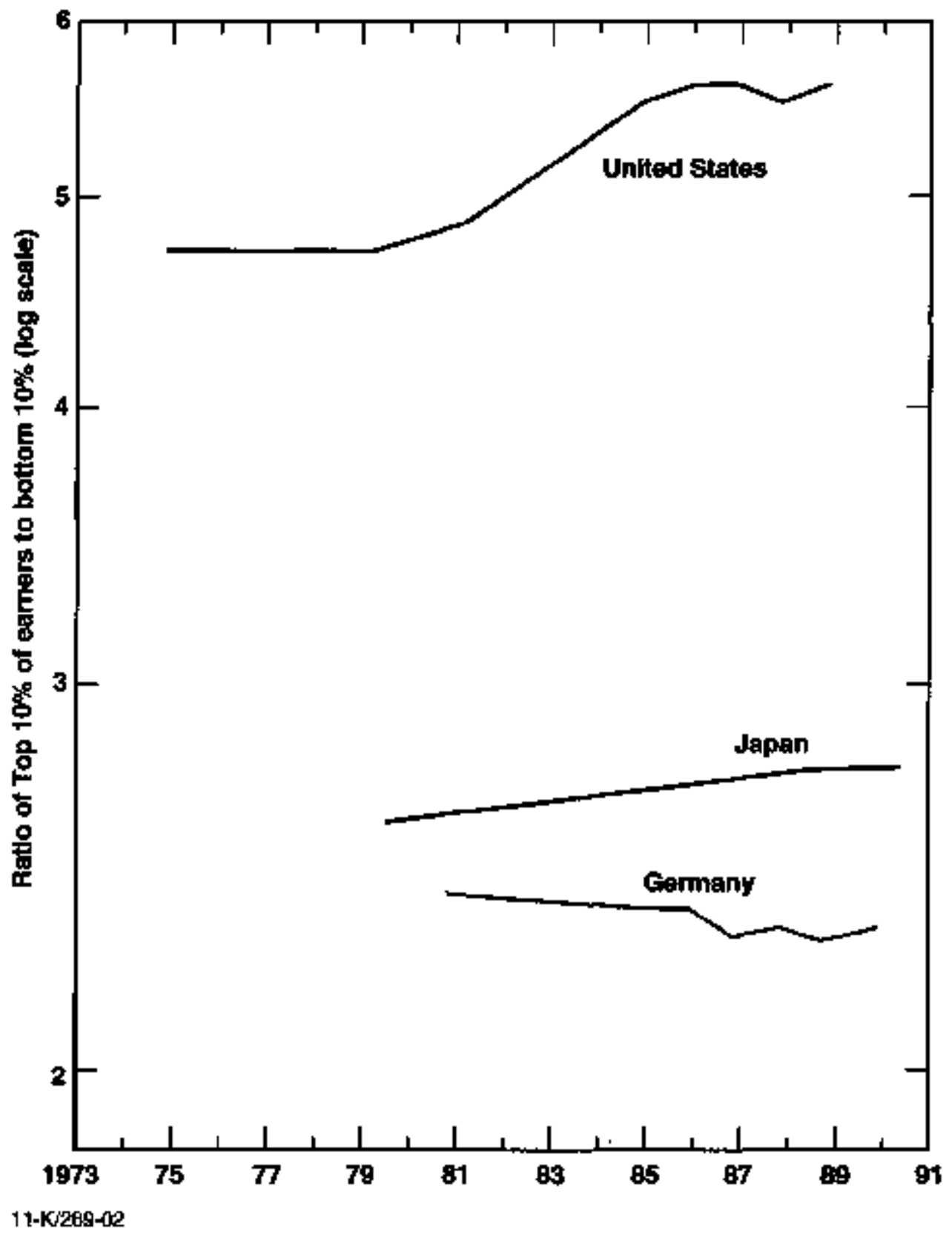

Figure 1.10. Male wage differentials calculated as the upper linit of ninth decile divided by the upper limit of first decile. [1.10] 
(which would push their lower $10 \%$ much lower). Education, however, can have a dramatic effect on wages when employers can establish wages based on the value of the employee to the company. The value of education to employers was emphasized by the $\mathrm{OECD}^{6}$ as the key issue in wage differentials between college-educated and high school-educated workers. In the U.S., the wage differential for these two groups increased from $37 \%$ in the 1970 s to $53 \%$ in 1989 . [1.10] A recent analysis clearly indicated that education and work experience are increasingly valued because of the expanding demands of technical change, and that technical change is the major cause of wage differentials. [1.11] Minor contributions to wage differentials included (i) declining manufacturing employment (i.e., blue-collar jobs) with increasing numbers of service jobs having higher pay; (ii) declining union power which artificially ensured high wages for blue-collar workers in certain manufacturing industries; and (iii) increasing demand for college-educated workers as the supply stagrated during the 1980s. These minor contributions have begun to emerge in Gexmany and Japan, except for the latter: the availability of college educated workers continued to grow even as the populations in both countries stagnated. Consequently, the large supply of well-educated workers has grown much more rapidly than demand in these two countries.

\subsubsection{Is the negative growth in U.S. manufacturing employment due to competition from Germant and Japan?}

Competition by German and Japanese companies may have a relatively minor effect on U.S. manufacturing employment. The decreasing growth in U.S. manufacturing employment (depicted in Figure 1.7) is not caused solely by competition from Germany and Japan. Furthemore, foreigr competition can be viewed as positive for the U.S. economy when foreign technology and product development spurs domestic innovation and efficiency improvements similarly to competition between several domestic companies. [1.12] Figure 1.11 indicates that Germany and Japan are currently also experiencing high unemployment rates. The unofficial Japarese unemployment rate for 1993 was estimated to be between 6.2$8.5 \%$ as shown on Figure 1.11. As manufacturing remains a latger portion of the labor force in these two countries which are extibiting high unemployment, manufacturing jobs are not simply moving to Germany and Japarn from the U.S. In the late 1980 s, with Japanese and German wages rising rapidly, a low dollar, and recognized high productivity, U.S.manufacturing enterprises received considerable foreign investment (especially from Europe and Japan). It is estimated that by 1990, one in ten U.S. manufacturing workets was employed in a foreign controlled firm. [1.14]

\footnotetext{
6 The OECD (Organization for Economic Co-operation and Development) has a multinational membership dedicated to contributing to the development of the world economy.
} 


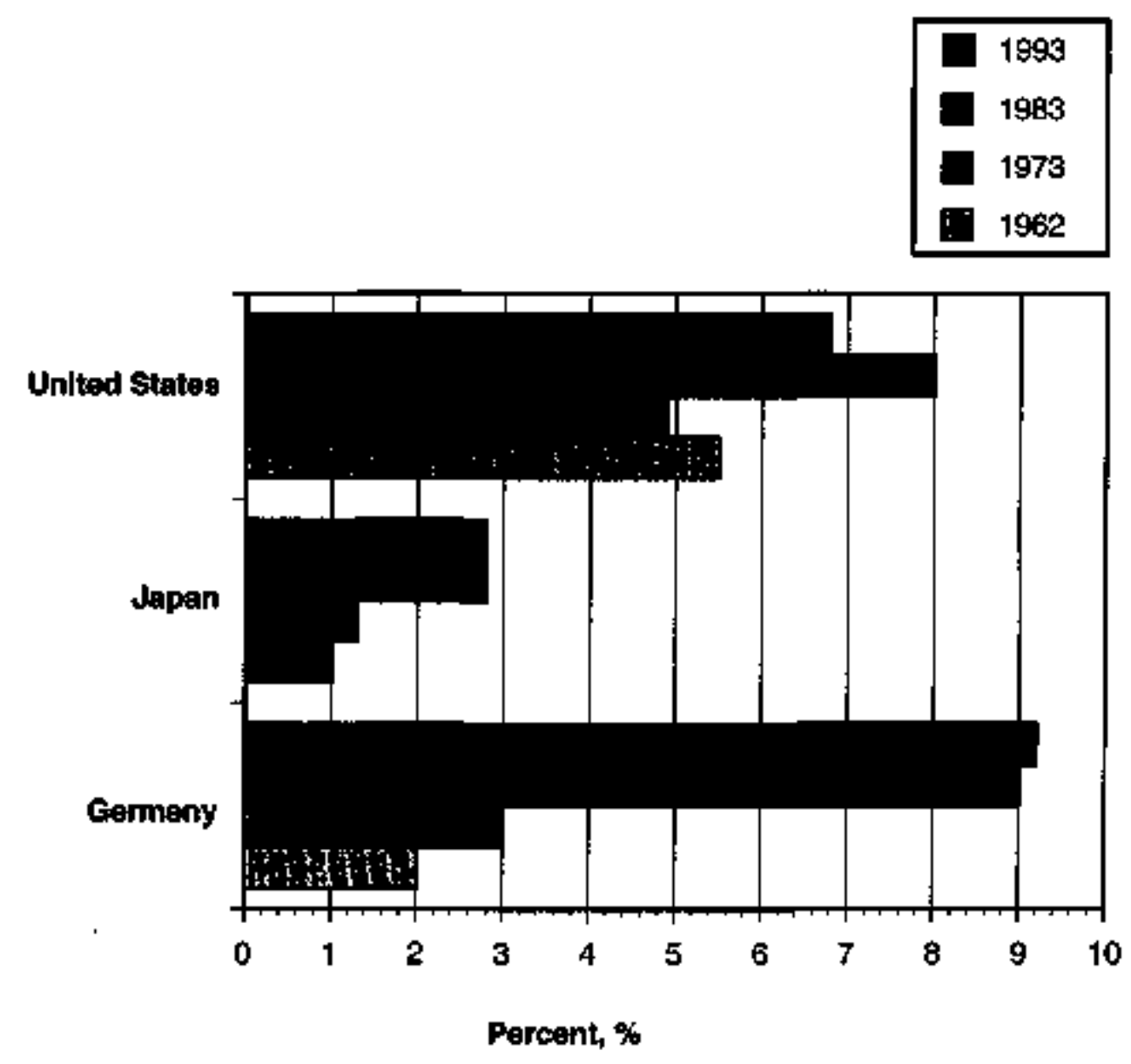

Figure 1.11. Unemployment rates. [1.13] (Note: The unofficial Japanese unemployment rate for 1993 was estimated between $6.2 \%$ and $8.4 \%$ )

The overwhelming loss of manufacturing jobs since the 1970s in the U.S. has been in what is termed by OECD as "other manufactures", or the low-tech product sectors such as textiles, low-grade steel, paper, etc. The related industries have traditionally expended little effort (i.e., R\&D funding) to develop advanced manufacturing techniques perhaps because these industries were assumed to be "mature". Consequently, manufacturing facilities located in low-wage countries were able to use botuntiful labor inefficiently and still produce goods at lower cost. It is critical to realize that Germany and Japan have this same competition problem. The schematic drawn in Figure 1.12 simplifies the current situation. Martufacturing of low tech products in newly industrializing economies with low wages is being encouraged by multinational corporations based in Germany, Japan, and the United States. U.S. domestic manufacturers of such "other manufactures" are on the offensive and are gaining market shares by introducing state-of-the-art process lines with process equipment which is purposely designed to 


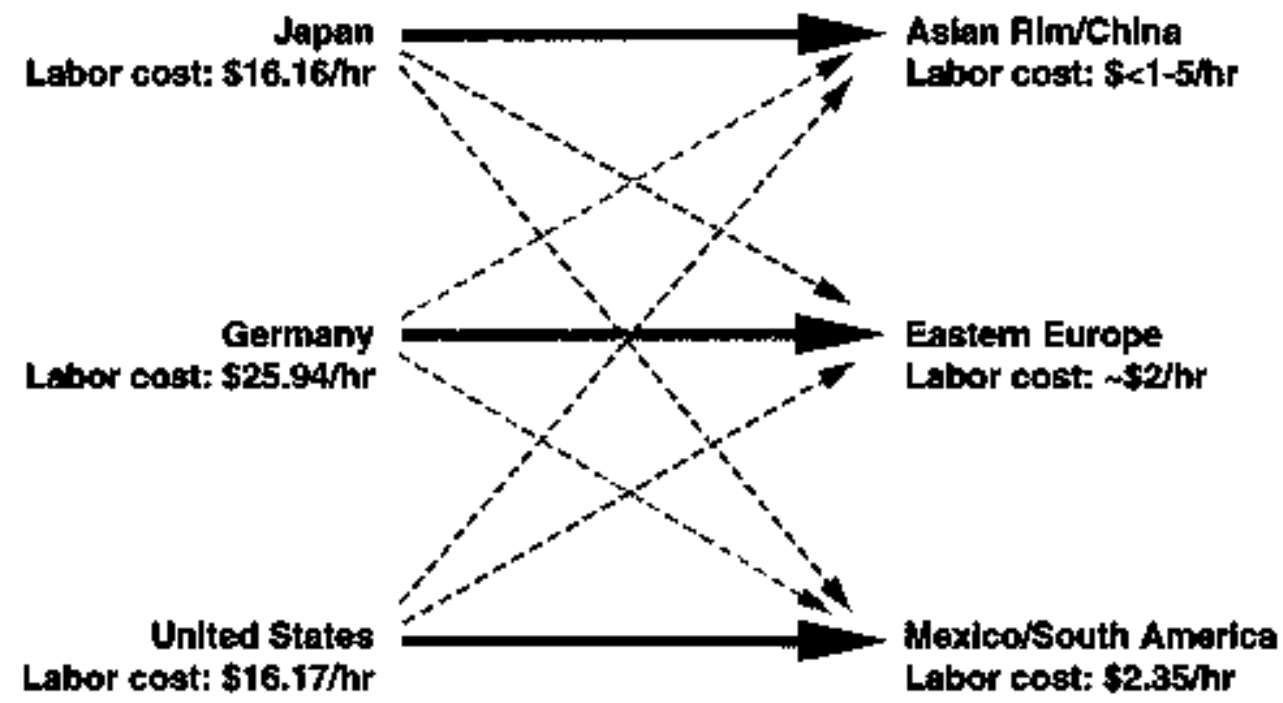

Figure 1.12. Internationalization of "other" manufactures: the flow of manufacturing to low wage countries (average manufacturing labor costs for 1992). [1.2]

require fewer workers. The number of domestic jobs in such manufacturing sectors may increase with projected facility demand (i.e., product demand), but not in relation to the numbers or job types held in the 1960s and 1970s. These industries have dramatically changed due to advanced manufacturing technologies.

\subsubsection{Does advanced technology destroy jobs?}

Application of advanced technology can destroy jobs as certain functions no longer are most efficiently performed by workers. The obsolescence of manufacturing jobs by advancing technological sophistication only occurs when there is an economic or quality advantage. A historical example of an advanced technology which destroyed jobs is sewing machines, which quickly replaced hand tailors. Although many tailors lost jobs, the result was clothing of higher quality which could be provided to a growing population at a smaller proportion of a family's income.

Manufacturing companies located in Genmany, Japan, and the United States must continue to sell products at competitive prices or else a greater number of manufacturing jobs will be lost and products will not be produced domestically. Production is rising (see Figure 1.9) even as the number of manufacturing jobs in Germany, Japan, and the United States is decreasing. The decrease in the real number of manufacturing jobs in 
the United States has accelerated during the early 1990s. The ratio of manufacturing jobs to all jobs is changing more dramatically as the service sector grows (see Figures 1.7 and 1.8).

The governunents of all three countries feel the need to "maintain a productive life for less skilled workers in an era when demand for their services is falling". [1.15] The major job loss issue which was addressed at the $1993 \mathrm{G}-7$ Summit Meeting is that some advanced technologies are being applied in manufacturing companies located in countries with inexpensive labor. Germany, Japan, and the United States face similar situations on this issue. The difference is that the manufacturing workforce in the United States has been adjusting to the problem since the early 1970s. The shock to the sheltered German workforce and Japanese workforce is currently much more devastating, and is expected to continue to be more devastating for several years. The basis for this last statement are as follows. Manufacturing wealth as a percentage of the total economy is much higher in Germany and Japan than in the United States. The percentage of manufacturing contribution to GDP in 1988 was $44 \%, 29 \%$, and $22 \%$, respectively. The respective sizes of the workforces supported by manufacturing correspond to the proportions of GDP. In Gexmany, there is adamant opposition to lowering the wages and official hours of less skilled workers to encourage their employment (a widespread practice in Japan). In Japan, companies are strongly discouraged from laying-off some employees to save the majority of jobs ("downsizing" has recently become widespread in Germany). In the United States both of these measures have been utilized.

There continues to be copious popular discussion regarding downsizing and the loss of manufacturing jobs. The textile industry is a prime example of an industrial sector which has been through downsizing. As a recent study indicated, $20 \%$ of the decline in U.S. manutacturing employment between 1972 and 1991 occurred in the textile and apparel industry. [1.16] During this period, textile and apparel imports from lower-wage countries rose dramatically in volume. This competition forced the implementation of advanced manufacturing processes and equipment in domestic U.S. companies in order to dramatically increase productivity. The study concluded that almost all of the pob loss in the U.S. textile industry was due to enhanced productivity. Another study attempted to separate the effect of foreign competition on job loss from the effect of advancing technological sophistication on job loss. [1.17] The conclusion stated that the major factor in reduced manufacturing employment is the implementation of advanced manufacturing technologies. Foreign competition, in the form of imports, had a minor effect on domestic job loss. The bottom line is that competition, whether foreign or domestic, forces companies to invest in new manufacturing technologies which increase efficiency and which can cause job obsolescence. 


\subsubsection{Does application of advanced technologies generate job opportunities?}

Application of advanced technologies to manufacturing generates job opportumities in several ways. First, application of advanced technologies can improve productivity. When a manufactured product is produced which is less expensive or of higher quality than others on the market, market share may increase. Total market consumption may increase as well. In both cases, production volume would expand and it follows that the number of manufacturing jobs would increase. Second, advanced manufacturing tecthologies permit production of radically new products which open new industries and related jobs. Third, manufacturing activities affect the economy in other job sectors. A recent report points out that "marufacturing induces more output from all components of the economy then is stimulated by virtually any of the other broadly defined economic sectors." [1.18] This is consistent with the argument that manufacturing promotes jobs in other sectors. The number of jobs supported depends on the type of manufacturing activity. Irt economic terms, the supported jobs are referred to as an employment multiplier. The steel industry is one example where enhanced efficiency due to advanced manufacturing technologies may have reduced the multiplier in recent years. In 1983, the multiplier was 2,35 other jobs for 1 steel manufacturing job. By 1988, the multiplier was estimated as 1.35 other full-time jobs for 1 steel manufacturing job. [1.8] Less total labor is needed per unit of output in 1988 than was needed in 1983 due to enhanced efficiency. [1.8] The reason those extra 1.35 jobs exist now, however, is because the more efficient steel industry is able to compete. This multiplier does not include labor in the various support industries which provide capital equipment and supplies.

The new jobs being generated in advanced manufacturing are demanding a higher level of skill and education. Unskilled workers are in less demand. This is especially noticeable not only in production but also in the supporting industries. Furthermore, the added complexity and flexibility of production methods utilizing advanced technologies means that, in general, white-collar and technical workers are becoming increasingly in demand relative to general labor and blue-collar workers. [1.19-1.21]

The question as to how the German, Japanese, and U.S. workforces compare in adjusting to this situation is difficult to address. There are distinct indications that the U.S. workforce is more readily adapting to changing job demands and that more new jobs are available in the United States from which to choose. One such indicator is shown graphically in Figure 1.13. The percentage of the U.S. workforce which becomes unemployed and is not able to find new jobs within a year is many times lower than the percentages in Japan or Europe. 


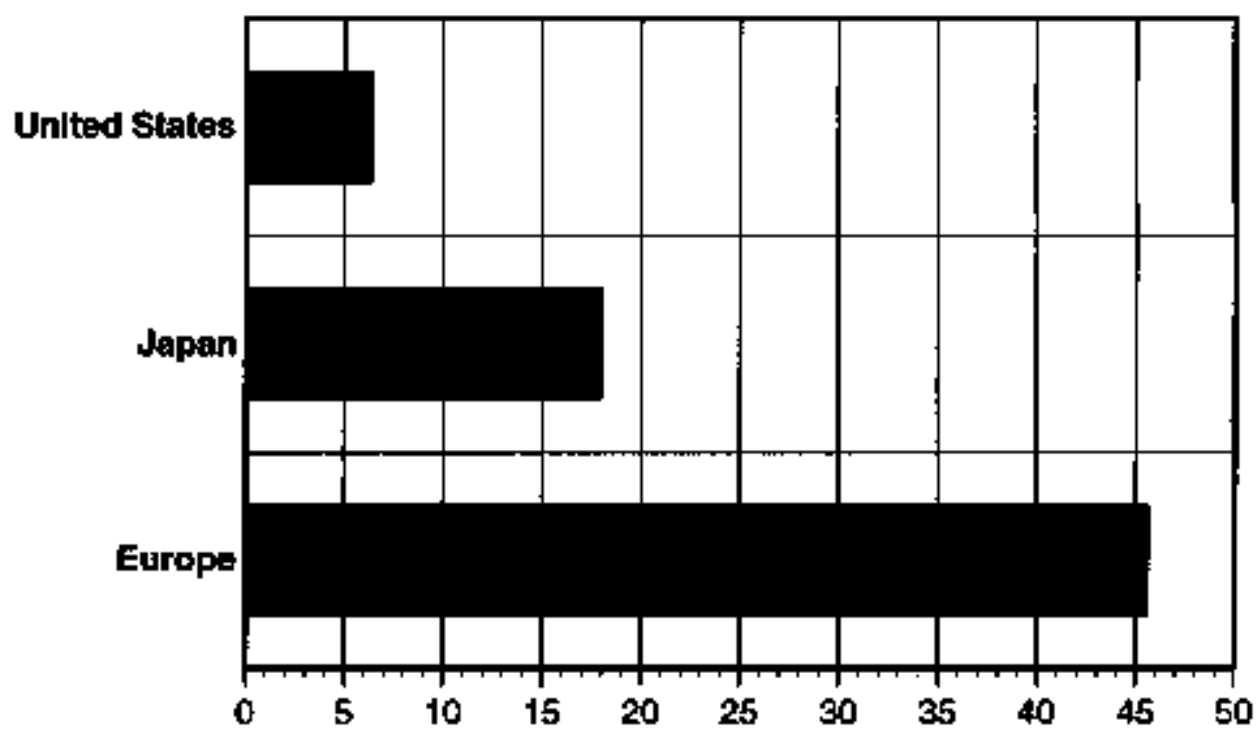

Percent

Figure 1.13. Percentage of unemployed who are jobless one year or more: 1991. [1.19]

\subsubsection{Is the disparity in productioity between small and lange manufacturers due to adoanced manufacturing technologies?}

Circumstantial evidence suggests that the higher productivity of large manufacturers (as compared to small and medium sized enterprises ${ }^{7}$ ) is rela ted to a greater tradition of investment in advanced manufacturing technologies. In order to accommodate these techrologies, the average employee of larger companies are of a caliber which demands higher wages. It logically follows to further suggest that the investment in advanced marufacturing technologies requires a higher degree of training and responsibility on the part of the workers. 8 Manufacturing enterprises which are large and utilize advanced manufacturing technologies also tend to export more products. These statements can be uniformly applied to enterprises in Gernany, Japan, and the U.S.

The statistics in reference to the size of manufacturing enterprises are significant. The percentage of Japanese SMEs at $99.5 \%$ of mantufacturing enterprises is significantly higher than the U.S. at $98 \% .{ }^{9}$ It is informative to recogrize that the other $0.5 \%$ of Japanese companies, which are large, produced almost half of the products. [1.22] In 1985, the average

\footnotetext{
7 Small- and mediurn-sized enterprises are referred 10 as SMEs. In this discussion SMEs are llmited to manutacturning enterprises in particular. A large company is usually defined by $>500$ employees in the U.S. and $>300$ employees in Japan.

- This will be discussed firther in section 1.3.12.
} 
Japanese $\$ \mathrm{ME}$ worker was $-50 \%$ as productive and $78 \%$ as expensive as a worker in a large enterpise. J1.23J In 1987, the average U.S. SME worker was $-70 \%$ as productive and $72 \%$ as expensive. [1.24] More than a quarter of all U.S. midsized enterprises do not invest in any form of research and cevelopment. [1.25]

The traditional picture of large manufacturers and small manufacturers as presented above will change over the next decade, spexifically because of advanced manufacturing. SMEs are exporting in increasing volume. [1.26] Although their average productivity still lags that of large companies, some small manufacturers are becoming competitive precisely because of the opportunities which advanced manufacturing technologies provide, especially redundancy of operations or "flexibility". Automation and information processing is becoming less expensive and easier to assimilate into the manufacturing system (i.e., PCs vs. mainframe computers, numerically controlled machtines vs. fixed automation, light tools replacing heavy tools, etc.). Pehr Gyllenhammar ${ }^{10}$ states that it is now possible for a manufacturer to go from a 5000-employee plant (large enterprise) to a 500-employee plant and still compete. [1.27] He continues: "Today we have evidence that such a plant can compete and in many ways is more efficient...As a result of various technological developments, the automotive industry, which in the 1970 s was labeled a mature industry, is now called high tech. It is very technology intensive." Although there may be some truth in the statement that "Until the early 1980 s, the dominant response of American industry...was an unselfconscious determination to survive by past practices ${ }^{t t}[1.28]$, what was also occurring was an "explosion of small firms using the latest technologies." [1.28] The theory that large companies are less flexible and more resistant to technology change, and that this is causing the downsizing and staff reductions now epidemic in Germany, Japan, and the U.S., is not an accurate picture. Advanced manufacturing technologies are changing manufacturing.

\subsubsection{How well do companies adjust to technological changes in Manufacturing?}

There are indications that Japanese manufacturing companies adjust more rapidly to changes in manufacturing than U.S. and German companies. A recent survey 11 of 600 companies reported that development of a new product takes an average of 19.1 months in Japanese companies, 22.6 months in U.S. comparies, and 23.4 months in German companies. [1.29] In this context, development of a new product must indude the design, construction, and testing of a new manufacturing system. Another

9 Detailed iniormation on German SWEs or Mittelstand was not lound.

10 Pehr Gyllenhammar is the Chalman and CEO of ABVolvo. 
category of adjustments which occurs is the "rapid development cycle" which represents rapid incremental improvements in the product or manufacturing efficiency. However poorly defined it may be at this point, the speed at which a company can adjust to changes by setting up and improving a manufacturing system is a factor in competition. The workers are the innovation factor. As Mark Myers stated: "Future engineers will work in an environment that includes continuous technological improvements as well as radical technological discontinuities. The competitive paradigm will shift back and forth many times during their careers, and they must be able to adjust." [1.30]

The radical adjustments to job content which manufacturing employees will continue to face are a result of advanced technologies used in manufacturing, not a result of product development. Figure 1.14 shows an example of changing tasks in automobile assembly. Note that the depiction is independent of the design of the particular car (i.e., product development). In moving from the Traditional System, to Substituting New Technology, to Integrated Production, the manpower requirements dropped and the allotment of manpower tasks changed dramatically. Fabrication represented over $75 \%$ of the manpower time in the Traditional System. This was superseded by computer integrated services and retooling/function changes in the Integrated Production mode.

Perhaps the most significant point is that the new manpower requirements which result from advanced martufacturing technologies require a higher level of worker sophistication. The futuristic scenario from the Jetsons comic where George's job consists of pushing a button and a product pops out is unrealistic. No competitive company would pay for that operation. Advanced manufacturing technologies do not trivialize the workers; on the contrary the responsibility is increased. Worker involvement in heavy, dangerous, and monotonous tasks can be minimized. With new, light, and flexible technologies "a manufacturer can organize people so that they are in command of the technology-a very dramatic change." [1.27] Manufacturing now requites fewer routine and repetitive tasks by factory employees. One description of new demands is given in the following: "Because of the use of flexible automated manufacturing 5ystems and electronically controlled equipment, they must process information symbolically. Instead of manipulating parts of a (purely mechanical) machine, for example, workers must now interact with symbols on a computer. Higher-order language and reasoning skills are often required. Because companies reset their assembly lines many times a day, assembly-line workers must deal with quality control. They must use statistical numerical controls

\footnotetext{
11 The survey was limited to large companies with a production of greater then U\$ $\$ 100$ million. We to not know if the definition of "now product" was uniformly applied to improved products as well as radical varialions in product design.
} 
Traditional System

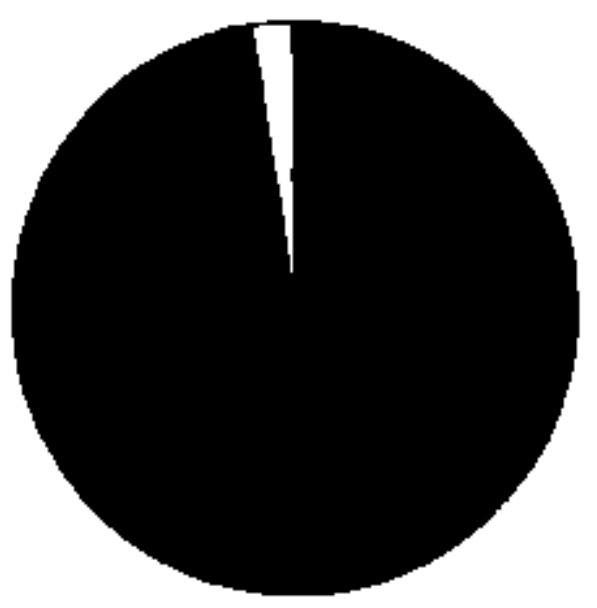

$($ Manpower $=100 \%)$

\section{Substitute New Technology}

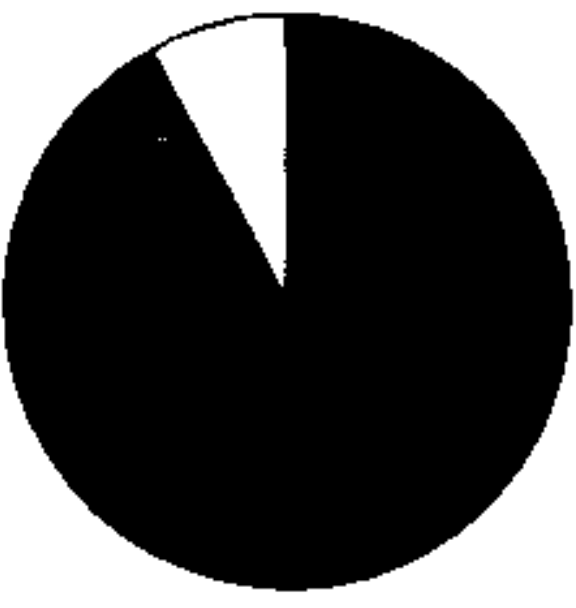

$($ Manpower $=50 \%)$
Integrated Production

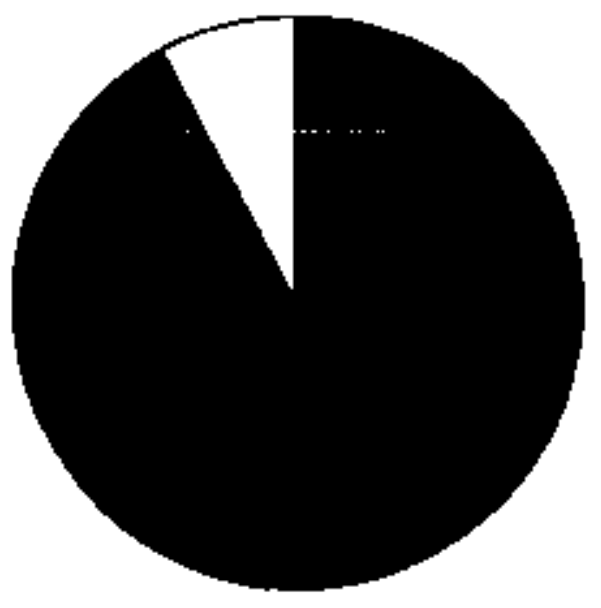

(Manpower $=40 \%)$

Computer integrated services

Fabrication/manual

[. Repair/maintenance

Logistics/planning

Quality control

Retool/funct. change

Fgure 1.14. The changing structure of manpower and taskb in automobile assembly. [1.13] 
and understand other advanced technological applications involving statistics, logic, probability, measurement systems, and applied physics. They must be familiar with wide area network systems and do a great deal of technical reading and writing. " [1.32]

\subsubsection{How is the requirement for flextbility in advanced marufacturing changing employment?}

The employment strategies used by manufacturing companies are evolving towards the use of a core workforce and a growing contingent workforce. A balance is desired between long-term stable capabilities, flexibility, and short-term technical expertise. Industry has for decades used skilled contract employees, temporary employees, consultants, and subcontractors. The increasing trend towards the use of contingent labor is not expected to be reversed in Germany, Japan, and the U.S. Although this trend may be encouraged by tax laws, one of the driving forces is clearly the growing need for short-term, varied expertise in efficiently solving problems associated with implementing advanced manufacturing technologies.

In Germany, part-time labor and subcontracted R\&D is common. In 1993, $15.5 \%$ of all workers in the laborforce were part-time. [1,33] In Japan, there is also a high percentage of part-time work. One distinction is that less R\&D is subcontracted in Japan. Manufacturing work, however, is routtnely subcontracted by large Japanese enterprises to smaller contractors to reduce the requirement for internal resources, and thereby increase the flexibility of the large company. [1.34] In the U.S., a wide variety of options are used. The overat temporary employment market grew 36\% between March 1991 and July 1993.12 This accounted for $28 \%$ of the 1.9 million new jobs created. [1.35] A high percentage of temporary and contract jobs in manufacturing are engineers and scientists.

Pethaps the largest impact is in research and development. Few companies are maintaining comprehensive $R \& D$ facilities. The reason is straight forwand: the bertefit of the investment is not always immediately obvious. "Exploratory R\&D for new business development can be a very uncertain area in which to commit resources. At the same time, it can have special needs and require expertise, especially in emerging technologies." [1.35] Manufacturing companies in all three countries are more dependent on extemal support in managing their technology investment than ever before. The support includes contracts with specialty companies who build, supply, and install equipment; private engineering consultants; university research and development programs; resources at national laboratories and institutes; and industrial research consortium.

12 Information specific to the growth of part-time manutacturing employment was not found. 


\subsubsection{How does the general education level of the workforces in Gemany, Japan, and the United States compare?}

The growing complexity of manufacturing covers the gamut from international enterprise operation to implementation of advanced manufacturing. The availability of diverse human capital capable of these operations is essential. The educational attainment ${ }^{13}$ of a nation's workforce (e.g.t between the ages of 25 and 64) gives an indication of overall skill level. In 1988, the educational attainment of the U.S. workforce clearly surpassed that of Japan and the former West Germany. [1.36] The U.S. had a higher percentage of people (81\%) who had completed at least an upper secondary education. The West German workforce was similar (at $78 \%$ ), whereas of the Japanese workforce, only $70 \%$ had completed upper secondary education. [1.36] The proportions of the U.S., West German, and lapanese workforces which had completed university education were $23 \%, 14 \%$, and $10 \%$, respectively. The percentage of the U.S. workforce with post-secondary, nonuniversity education was also higher. The 1988 comparison of educational attainment is shown graphically in Figure 1.15.

Since 1988, greater proportions then ever before of the populations of these three countries are pursuing university education. In Japan, the percentage of the workforce that has not completed upper secondary education is shrinking. Due to the reunification, the German workforce educational attainment will be diminished compared to that of the former West Germany for a number of years before the new emphasis on university degrees is expected to dramatically change the percentages. The workforces in both Germany and Japan are said to be "aging" as population growth has declined. Predictions of massive labor shortages, however, have not been realized. Advanced manufacturing technologies are one factor which was not considered in these predictions and which can reduce the amount of labor required in manufacturing systems. In these three countries there is no shortage of well-educated labor, and none is projected for 2005. [1.37]

The avatlability of a well-educated workforce is considered to be increasingly desirable as manufacturing becomes more sophisticated. A 1989 German study found that the availability of skilled workers is gaining importance as to where a company will locate operations. [1.38]

Not only is industrial performance thought to be tied to the competence of the manufacturing laborforce, the service sector which supports the manufacturing effor't also effects performance. Companies depend on local services, techrical support, and other infrastructure. These relationships are difficult to quantify and vary considerably not only by

\footnotetext{
13 As referred to here, the educatonal attainment in all three couniries is achieved in schooks. It is considered to be "qualifying training": usually related to qualliying for a given category of entry-lovel jobs.
} 


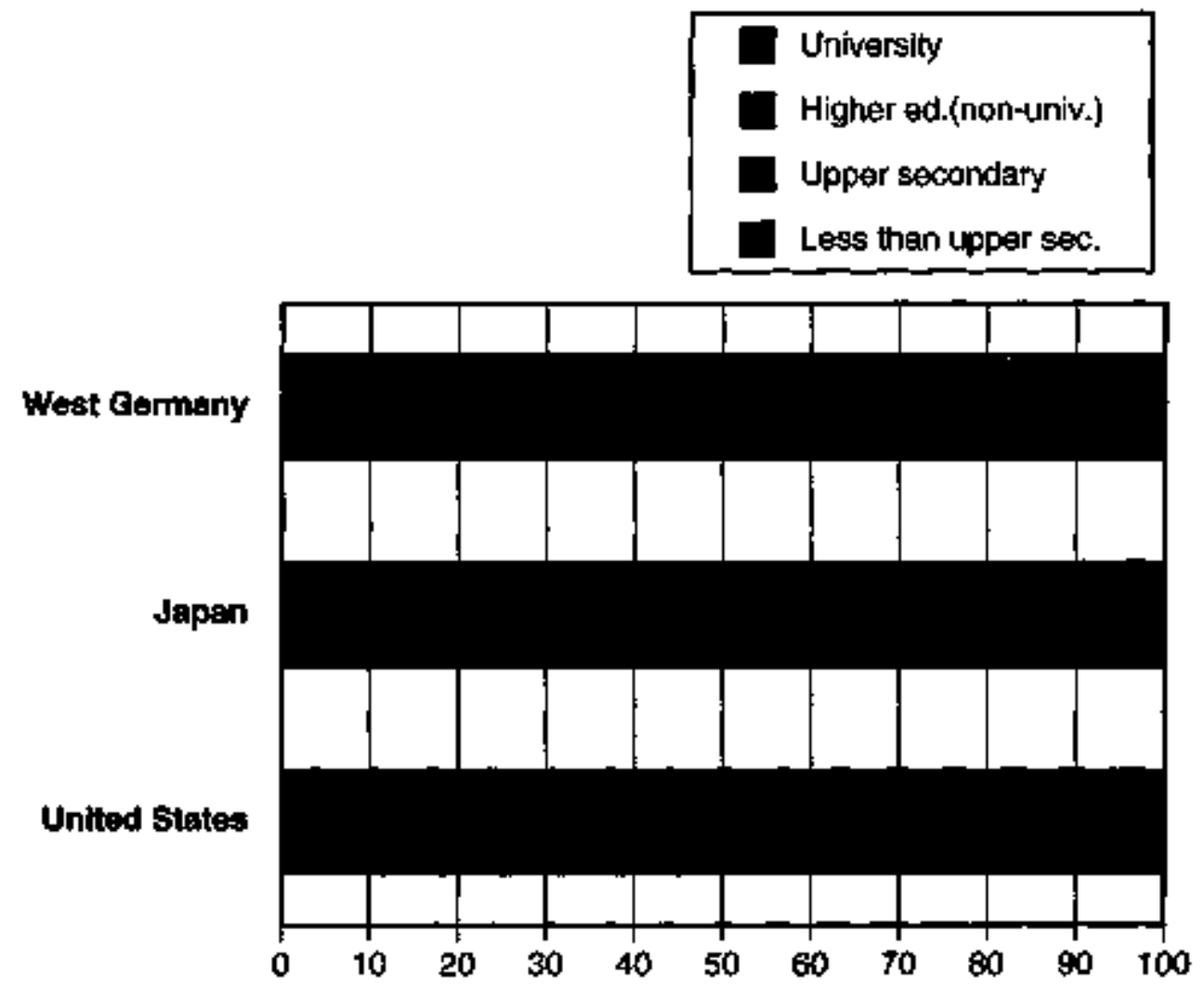

Figure 1.15. Percentage of the population (ages 25 to 64) who have attained various levels of education: 1988. [1.36]

industry, but also from company to company. It is generally accepted that human capital attributes of diverse backgrounds and multidisciplinary education are of growing importance to manufacturers. As one education expert stated: "...the blurring of traditional boundaries implies that more opportunities will be available at the 'fringes' of a discipline, i.e., at the intersections with other disciplines. It also means a greater need for interpersonal skills, for task orientation, and for greater flexibility... [1.39]

\subsubsection{Are there well-defined differences in engineering education between} German, Japanese, and U.S. universities which are significant to manufacturing competitiveness?

Engineers are a critical part of the manufacturing workforce. If available to the company, engineers are usually responsible for identifying and applying technologies including designing processes, evaluating problems, and implementing equipment. The educational preparation of engineers will continue to have a tremendous impact on their ability to deal with complex systems. In the 1990 s, Germany, Japan, and the United States provide many opportunities for qualified students seeking engineering degrees. The choices of quality university curriculum in the 
U.S. are unparalleled. Efforts to correlate industrial requirements with engineering curricula and student preparation has intensified since the early $1980 \mathrm{~s}$ in all three countries. There are differences in curricula and teaching methods. [1.32] The differences in German, Japanese, and U.S. engineering education provide advantages in response to certain industrial product sectors which are stressed (e.g., machine design, electronics, and aerospace, respectively) rather than in manufacturing as a whole.

Undergraduate programs in Germany Japan, and the U.S. have all converged to stress the same three components: fundamental knowledge frameworks, laboratory experience, and an engineering project. [1.32] The emphasis placed on each of these areas varies widely. In the U.S., cooperative education opportunities with industry have greatly increased since the early 1980s. [1.41] This is a significant and positive improvement in engineering education. Cooperative education is uriversally required in German university programs. Manufacturing engineering degree programs are usually associated with mechanical engineering programs. Although several universitles in both the former West Gemany and Japan have traditionally maintained strong prograns in manufacturing engineering, this particular discipline was ignored in the U.S. until the early 1980s. Since then, many outstanding programs have continued to be developed. [1.32]

There is limited inforination available on the proportions of engineers and scientists with various majors working in manufacturing (see Table 1.3). Because of the limited information, an expected increase in the proportions of engineers in the German and Japanese manufacturing workforces can not be confirmed. The available information suggests that the proportions of scientists to engineers is similar for Getmany, Japan, and the U.S. One striking difference is the very low percentage of civil engineers in U.S. manufacturing. Manufacturing industries producing high technology products employ a far greater number of scientists and engineers than the manufacturing average. In the U.S, for example, the instruments, chemicals, transportation equipment, electrical and nonelectrical machinery industries employ $42 \%$ of all manufachuring personnel and $82 \%$ of all scientists and engineers in manufacturing. [1.42]

The trends in Figure 1.16 present a statistic often cited as a major competitiveness problen: the proportion of the Japanese workforce receiving engineering degrees is higher than in the U.S. or Germany. However, these numbers are brought into a different light when the percentages of all engineers who are employed in manufacturing are considered (see Table 1.4). In 1990, only $30.6 \%$ of Japanese engineers were employed in manufacturing. In all three countries, less than $50 \%$ of each workforce's engineers are employed in manufacturing and the percentages are expected to decrease further. This suggests that there are an abundance of engineers in a variety of jobs, and that the large number produced in Japan probably has little effect on manufacturing. The 
Table 1.3. Scientists and engineers in manufacturing: most current years. [1.40]

\begin{tabular}{|lcrrr|}
\hline & West Germany & Japan & \multicolumn{2}{c|}{ United States } \\
Occupation & $(1985)$ & $(1985)$ & $(1988)$ & $1992)$ \\
\hline Total scientists \& engineers & 100.0 & 100.0 & 100.0 & 100.0 \\
Scientists & 18.4 & 25.7 & 20.5 & 21.2 \\
Natural & 10.9 & 4.4 & 10.0 & 9.3 \\
Computer & na & 21.2 & 10.4 & 11.9 \\
Social/other & 7.4 & 0.1 & 0.1 & 0.0 \\
Engineers & 81.6 & 74.3 & 79.5 & 78.8 \\
Civil & 25.9 & 32.1 & 0.8 & 0.7 \\
Electrical/electronic & 13.0 & 15.4 & $\mathbf{2 5 . 0}$ & $\mathbf{2 5 . 3}$ \\
Industrial/mechanical/other & 42.8 & 26.8 & 53.7 & $\mathbf{5 2 . 8}$ \\
\hline
\end{tabular}

Notes: Figures for Japan and West Germany are estimates prepared by the U.S. Bureau of the Census based on published and unpublished census and survey data for the years shown. For West German statistics, systems analysts are included with natural scientists, computer engineers are induded with electrical/electrontic engineers.

numbers of engineering degrees granted in each country may be less important than the educational quality, degree content, and variety of curricula available in preparing a capable workforce.

\subsubsection{How do manufacturing companies keep up with rapidly advancing technology?}

Manufacturing enterprises depend on their employees to identify, pursue, acquire, and implement beneficial technical advances. Employees must continue to gain knowledge to avoid obsolescence. In Germany, Japan, and the U.S, the company is responsible for and benefits from supporting employees in continuing education. Of all the advanced manufacturing technology issues, this is the one that stands out for the most positive growth in the future. The practice of hiring a new employee with specific knowledge training to match a specific task and then ignoring the obsolescence of that employee's knowledge base is being phased out. Manufacturer's who wish to stay competitive are realizing the benefits of continuing to groom their core employees.

The three main methods for enhancing employee technical knowledge are training, communication opporturities, and involvement in R\&D. Training occurs informally within the company or through formal training programs chosen to meet identified education goals and skill requirements. It was recently noted that "the best training programs anticipate changes in technology and equip their workers to cope with 


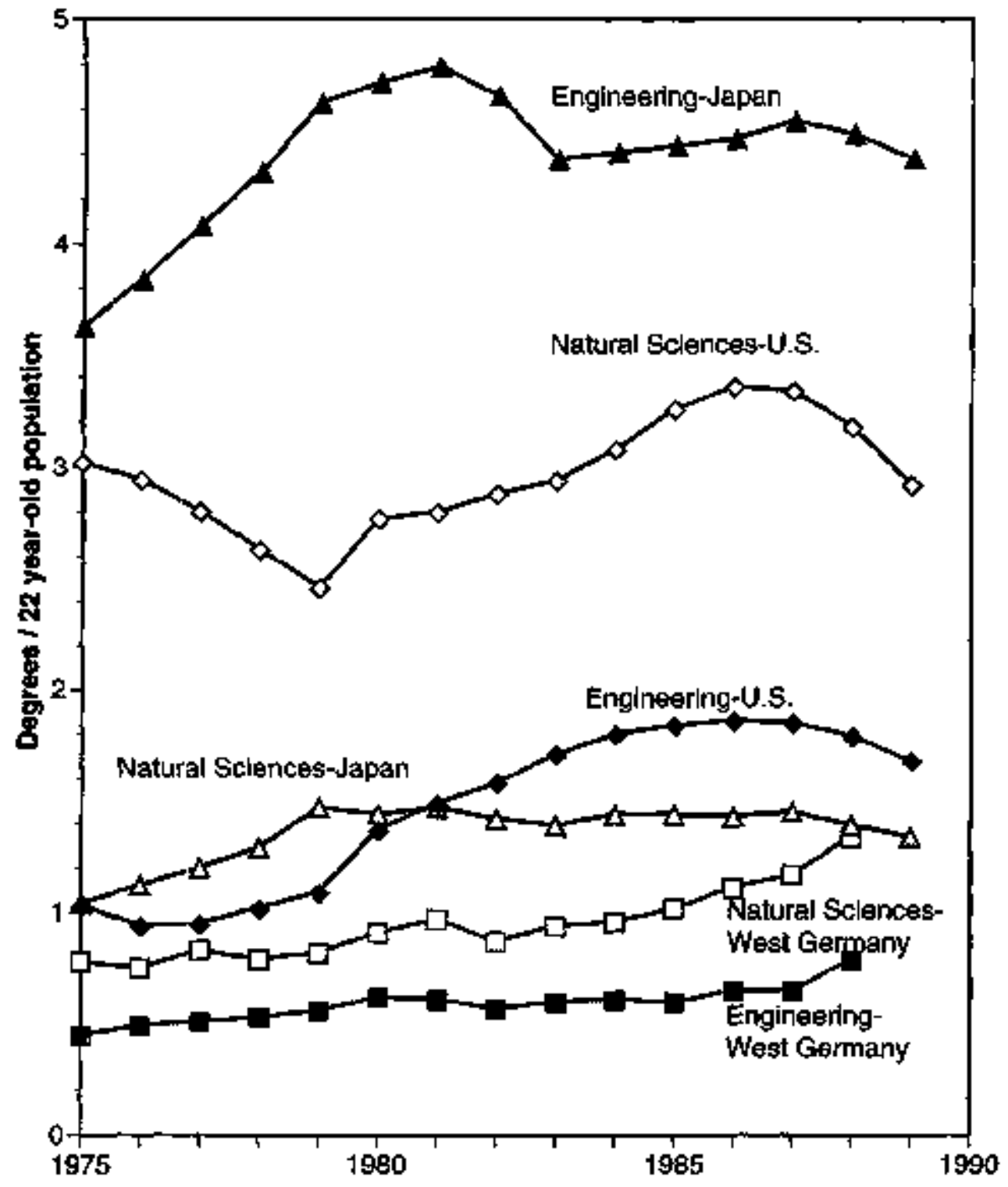

Figure 1.16. Number of Natural Science and Engineering degrees per number of 22 year-old citizens. [1.40] 
Table 1.4. Scientists and engineers employed in manufacturing: percentage of total in workforce. [1.40]

\begin{tabular}{|lccc|}
\hline & $\begin{array}{c}\text { West Germany } \\
(1985)\end{array}$ & $\begin{array}{c}\text { Japan } \\
(1990)\end{array}$ & $\begin{array}{c}\text { United States } \\
(1992)\end{array}$ \\
\hline Scientists & $43.0 \%$ & $23.0 \%$ & $22.2 \%$ \\
Engineers & $43.9 \%$ & $30.6 \%$ & $48.4 \%$ \\
\hline
\end{tabular}

Notes: Figures for Japan and West Germany are estimates prepared by the U.S. Bureau of the Census based on published and unpublished census and survey data for the year shown

them ahead of the competition". [1.43] An explosion of technical short course and refresher course offerings is occurring in all three countries. German and U.S. companies ate continuing to provide limited opportunities for employees to pursue advanced university degrees in areas of strategic importance. Japanese companies are increasing their use of this option. As Janet Hansen pointed out, the major problem with training is " $\mathrm{it}$ is confusingly diverse. The exact training opportunities available to individuals vary significantly from place to place, and there is no uniform way to describe these opportunities to either would-be traines or to employers." [1.44] Part of the increasing responsibility of employees is to monitor technology and predict their training requirements to best meet future company requirements.

Communications oulside of the company ("networking") are perhaps the most pervasive method for pacing tectuology and gaining new knowledge. Information flow through publications, intemet channels and databases, professional association meetings, and personnel interactions with other techrical professionals (especially equipment suppliers and customers) will continue to gain importance.

Involvement in R\&D develops depth of knowledge in employees. In the former West Germany and Japan, the number of scientists and engineers engaged in R\&D has grown significantly (see Figure 1.17). During the 1980 , U.S. scientists and engineers once again increased their involvement in R\&D. Because $R \& D$ involvement in a manutacturing environment is expensive, cotnpanies in all three countries are expanding their access to research environments at national laboratories, institutes, and university research centers. Hands-on participation, extended visits, and personnel exchange are valued opportunities for gaining technical knowledge. 


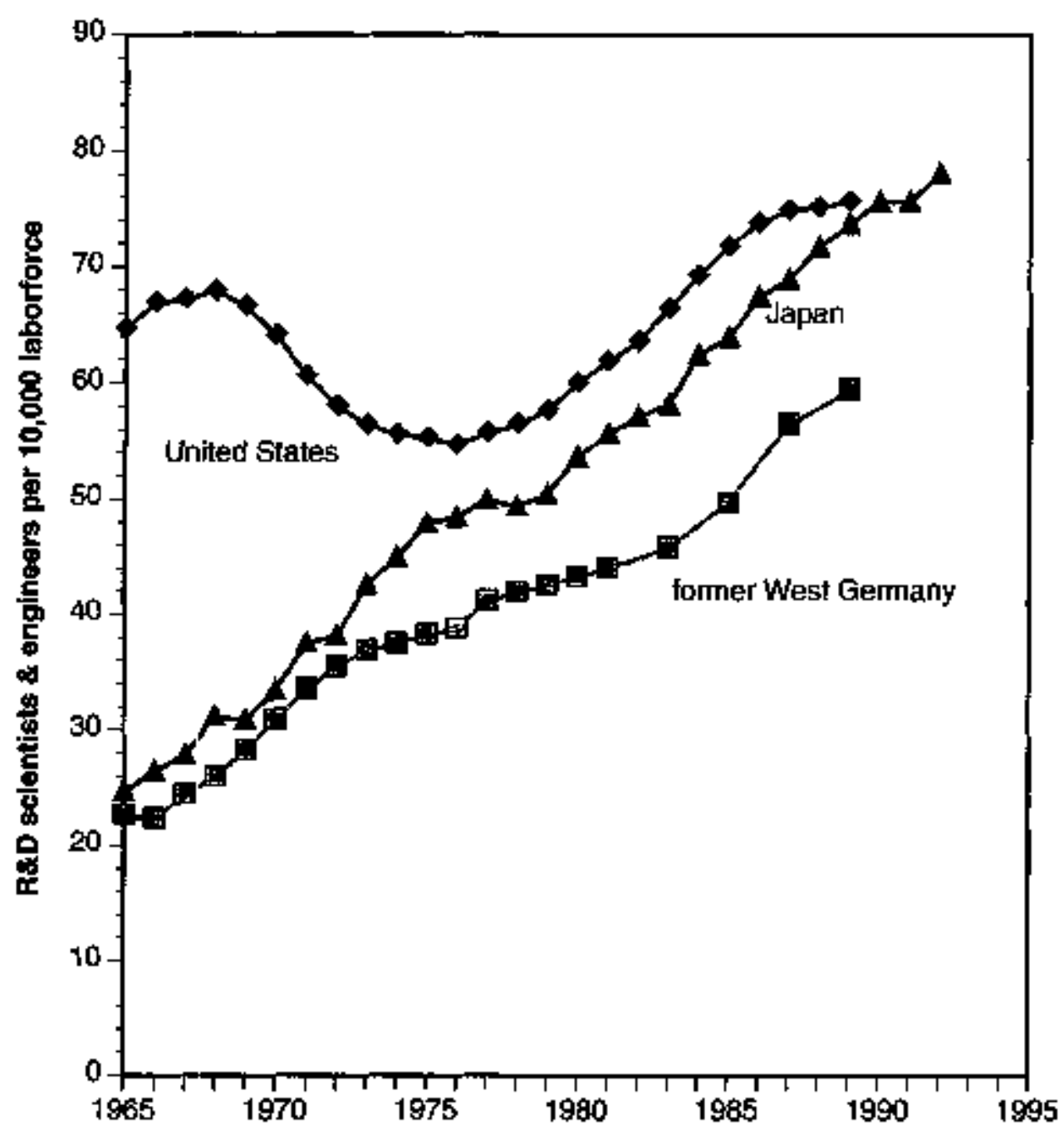

Figure 1.17. Scientists and engineers engaged in R\&D per 1,000 laborforce. [1.40] 


\subsection{References}

[1.1] High-lechnology competitiveness: Trends in U.S. and foreign performance. GAO Report, NSIAD-92-236, United States General Accounting Office, Washington, DC: September 1992.

[1.2] Comparative labor force statistics. Office of Productivity and Technology, Bureau of Labor Statistics, Washington, DC: May 1994.

[1.3] Training for jobs. The Economist, March 12, 1994: p.20.

[1.4] Industrial Structure Statistics: 1992. Organization for Economic Cooperation and Development, Paris.

[1.5] Kenichi Ohmae, Shukan Daiyamondo, June 2, 1991; Economic Trends, Japan, Vol.2, no.22, EBPSP 93-022, FBIS, Washington, DC:

November 4, 1993.

[1.6] Indicators of Industrial Activity: 1989. Organization for Economic Cooperation and Development, Paris.

[1.7] Christopher Farrel and Michael Mandel, Why are we so afraid of growth? Business Week, May 16, 1994: p.62-72.

[1.8] David J. Cantor, The steel industry's impact on the economy in 1988. Congressional Research Service Report 88-664E, Library of Congress. Washingtor, DC: October 20, 1988.

[1.9] Debra Phillips, The new service boom: Corporate America is downsizing. Entrepreneur, August 1994: p.134-138.

[1.10] Rich man, poor man. The Economist, July 24, 1993: p.71.

[1.11] John Bound \& George Johnson, Changes in the structure of wages in the 1980's: Ant ezuluation of alternatioe explanations. Amer. Econ. Rev, 82, 1992: p.371-392.

[1.12] James K. Jackson, Effects of Erade on U.S. jobs and wroges.

Congressional Research Service Report 9469 E, Library of Congress, Washington, DC: January 28, 1994.

[1.13) Dale Stein, Myths in jobs and earnings. The Bridge 23 (1), Spring 1993: p.20-21.

[1.14] Robert F. Black \& David Hage, Danger and the dollar. U.S. News and World Report, September 28, 1992* p. 62.

[1.15! Richard B. Freeman, Dealing withunemployment, the U.S. Way, The New Economy, 1. 1994: p. 1-7.

[1.16] Industries and world markets: a sampling of the US experience in the 1980s. Congressional Research Service Report 92-302E, Library of Congress, Washington, DC: March 23, 1992. 
[1.17] Paul R. Krugman and Robert Z. Lawrence, Trade, Jobs, and Wages.

Scientific American, April 1994: p.44-49.

[1.18] David J. Cantor, Manufacturing indusiry: Its impact on the economy. Congressional Research Service Report 93-370E, Library of Congress, Washington, DC: March 29, 1993.

[1.19] Jerome Mark, Technological change in employment: Some results from BLS research. Monthly Labor Review, 110, 1987: p.26-29.

[1.20\}] Joseph P. Gannon, Scientists, engineers, and technicians in manufacturing are highly concentrated in high technology indtstries. National Science Foundation, Division of Science Resources Studies, Washington, DC: November 29, 1991.

[1.21] Michael J. Mandel, The tew world of work. Business Week, October 17, 1994: p.78-90.

[1.22] Ken Inoue, The education and training of industrial manpower in Japan, World Bank Staff Working Papers No. 729, Washington, DC: 1985.

[1.23] White paper on small and medium entetprises in Japan 1988. Ministry of International Trade and Industry, B]-67, Tokyo: 1988.

[1.24] Modernization metrics; A call for knowing where we stand on fechnolosy, productivity, and agility. Foundation for Industrial Modernization, Washington, DC: December 1993.

[1.25] U.S. RED may need a shot in the arm. Manuf. Eng., April 1993: p. 26-30.

11.26] Therese Eiben, U.S. exporters keep on rolling. Fortune, june 14, 1993: p.130-131.

[1.27] Pehr Gyllenhammar, Fifteen years of major struciural changes in manufacturing. Globalization of Technology: International Perspectives, Janet H. Muroyama \& H. Guyford Stevens, eds, Natl. Acad. Press, Washington ${ }_{t}$ DC: 1988.

[1.28] Michafl J. Piore and Clarles F. Sabel, The Second Industrial Ditide. Basic Books, Inc., NY: 1984.

[1.29] Stride: science and technology news in Germany EZ05: October 1993.

[1.30] Mark B. Myers, Issues în S\&T, Winter 1992-93: p.19.

[1.31] Grahan Vickery and Duncan Campbell, Advanced manufacturing technology and the organization of work. STI Review: No. 6r, OECD, December 1989: p.105-146. 
[1.32] Komell F. Ehmann \& Philip C. Jones, Training for manufacturing: Master's programs and more. IEEE Spectrum, September 1993: p.76-81.

[1.33] Part-time employment attracting attention. FBIS- Western Europe Vol. III \#10. March 10, 1994: p,12.

[1.34] A firm of their own. The Economist, June 11, 1994: p.59-61.

[1.35] Temporary employees fill wiches in chemical $R \& D$ work force. C\&EN, February 28, 1994: p.25-30.

[1.36] Laura Hersh Salganik et al., Education in States and Nations:

Indicators companing U.S. States with the OECD countries in 1988. National Center for Education Statistics, Washington, DC 1992.

[1.37] D. J. Braddock, Scientific and technical employment: 1990 - 2005.

Monthly Labor Review. Bureau of Labor Statistics, Washington, DC:

Nowember 1991 and February 1992.

[1.38] Kolner Wirschafts - und Arbeitsmarkbericht, 1990: p.65-72.

[1.39] Marion B. Brernan, Rebecca L. Rawls, and Pamela S. Zurer, New graduates face tight job prospects. Chem. Eng. News, 70, October 19, 1992: P. 3640 .

[1.40] Science and Engineering Indichtors: 1993, National Science Foundation, Washington, DC.

[1.41] Unpublished communications with university administrations at U.C., U.W., U.T., U.M., U.N.C., and Purdue.

[1.42] Joseph P. Gannon, Scientists, engineers, and technicians in mantufacturing are highly concentrated in hight technology industries. Science Resources Studies Data Brief, National Science Foundation, Washington, DC: November 29, 1991.

[1.43] How to train workers for the 21st century. U.S. News \& World Report September 21, 1992: p.72-78.

[1.44] Janet S. Hansen, Making sense of worker training. Hssues in Science \& Technology, Winter 1993-94: p.21-25. 


\section{Advanced Manufacturing: \\ Technology and International Competitiveness}

Part 2. Manufacturing Initiatives

February 1995
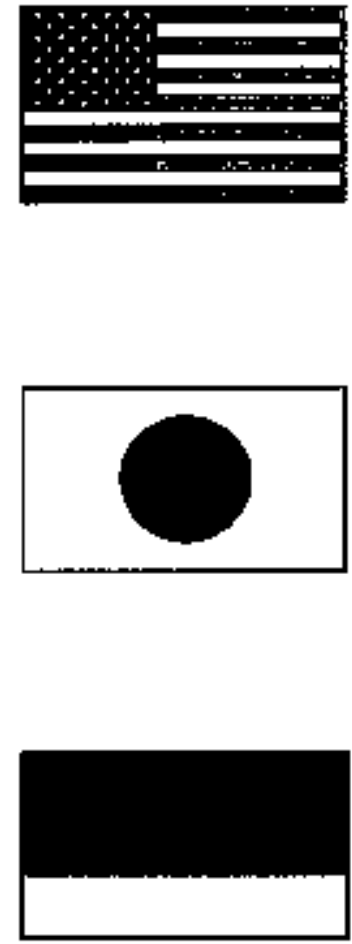


\section{Contents}

2.1 Key Judgments ................................................................................. 1

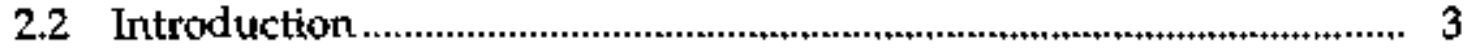

2.3 Comparison of Manufacturing Performance ........................................ 4

2.3.1 How Do the Manufacturing Industries Compare by Product Sectors? ....................................................................... 5

2.3.2 What Does International Trade Tell Us About Manufacturing Competitiveness?............................................. 10

2.3.3 How Do the Levels and Disbursement of R\&D Funding Compare?

2.4 Governments' Role in Major R\&D Initiatives and Advanced Manufacturing …................................................................ 18

2.4.1 GERMANY ….................................................................. 20

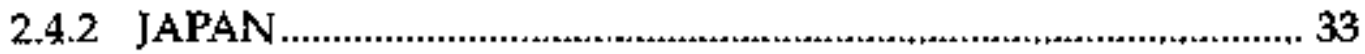

2.5 References ...........................................................................................44 


\section{List of Tables}

2.0 Goals of Policy Development in Govemment Programs for the 1990s

2.1 1991 Manufacturing Production by Product Sector ........................................... 6

2.21991 Manufacturing Value-Added By Product Sector ....................................... 7

2.31991 Manufacturing Production by Product Sector .......................................... 8

2.41991 Manufacturing Value-Added By Product Sector.................................... 9

2.5 Ten Largest Industrial Enterprise R\&D Performers in 1990 ........................... 14

2.6 Comparison of 1991 Gross Domestic Expenditure on

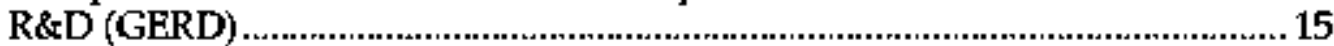

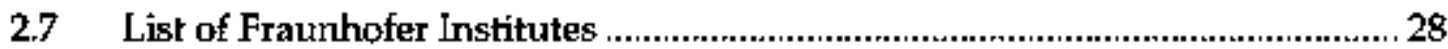

2.8 List of IMS Technical Themes and Test Studies .............................................42

\section{List of Figures}

2.1.1 Trade balance in manufactured products: Urited States ................................. 11

2.1.2 Trade balance in manufactured products: Japan ........................................... 12

2.1.3 Trade balance in manufactured products: Germany ....................................... 13

2.2 Performers and sources of 1991 domestic expenditures on R\&D: 1991 .......... 26

2.3 Distribution of national $R \& D$ budget appropriations, by sociceconomic objective: 1992 ....................................................................... 17

2.4 Industrial development as a percentage of national R\&D budget appropriations

2.5 Industrial development as a percentage of national $R \& D$ budget appropriations

2.6 Percentage of companies with high reliance on external sources for technology.

2.7 Technology-related cooperation among Japan, the U.S. and Europe in the automotive industry 


\section{Part 2: Manufacturing Initiatives}

\subsection{Key Judgments}

Our examituation of German and Japanese initiatives aimed at developing advanced manufacturing technologies leads us to the following key judgments:

- Advanced technology development in itself is not a uniquely effective competitiveness goal. Efficient implementation of advanced technologies is also necessary to achieve an advantage in competing in the global marketplace. As manufacturers become more interdependent, international techuical exchanges are increasingly beneficial to gauge the capabilities and interests of suppliers, customers, and competitors. Germany and Japan are adopting technology strategies which reflect all three aspects (development, implementation, and international perspective).

- Improvement in manufacturing competitiveness in low- and medium-technology products is where the most economic gain can be made in the economies of Gemmany, Japan, and the U.S. Effective application of advanced manufacturing technologies can provide competitive advantages to manufacturers for all three countries in these areas.

- The major emphasis of technology development in publicsupported Marufacturing Initiatives does not reflect support in promoting competitiveness in low- and medium-tech industrial sectors.

- A balance in government R\&D programs between product technologies and manufacturing technologies is lacking. Both Germany and Japan have shifted towards precompetitive product technologies, specifically to promote high-tech product sectors in competition with the U.S.

- The goals of government R\&D programs regarding manufacturing competitiveness in Germany, Japan, and the U.S. are similar, although the particular policy emphasis is changing (see Table 2.0).

- The industrial policies of Germany and Japan have not prevented changes in trade balances and the movement of manufacturing production to other countries. The industrial product sectors gairing the most government R\&D support through indwstrial policies have not become the most competitive. 
Table 2.0 Goals of Policy Development in Government Programs for the 1990s.

1.) Emphasis on engineering tor competitlveness in manufacturing (englneering vs. science)

2.) Strengthening the nation's civll technology base

3.) Strateglc technologles at the precompettitive stage for next generation Industry ("help industry to tocus on promising new fields")

4.) Maintaining a high level of basic research ("domestic S\&T capabillty Is esential')

5.) Cooperative research belween institutes, universities, and industry

6.) Internationalization (sharing) of research

7.) Support of SME's to engender innovation (technology extension centers)

8.) Promoto beneficial legal framework and businecs environment ("attractlveness as a location for Industry")

9.) Support for long-term projects ("blg acience")

10.) Upgrading ressearch facilities

11.) Campaigns to promote soclal acceptance of technology

12.) Autonomy from govemment tifiluence in S\&T research

13.) Building-up R\&D In certain regions of nation

\begin{tabular}{|c|c|c|}
\hline Germany & Japan & United States \\
\hline 1 & $\downarrow$ & $\star$ \\
\hline$\uparrow$ & $\uparrow$ & * \\
\hline$\uparrow$ & $\uparrow$ & * \\
\hline$\uparrow$ & $\star$ & $\uparrow$ \\
\hline$\uparrow$ & $\uparrow$ & $\uparrow$ \\
\hline$\uparrow$ & $\star$ & $\uparrow$ \\
\hline$\uparrow$ & $\uparrow$ & $\uparrow$ \\
\hline$\star$ & * & $\downarrow$ \\
\hline$\downarrow$ & * & $\downarrow$ \\
\hline$\downarrow$ & $\uparrow$ & $\downarrow$ \\
\hline$T$ & $\uparrow$ & $\downarrow$ \\
\hline$\uparrow$ & $\downarrow$ & $\downarrow$ \\
\hline * & $\downarrow$ & $\downarrow$ \\
\hline
\end{tabular}

NOTE: * new emphesis, $\uparrow=$ incressing emphesis, $\downarrow=$ decreasing emphasis. 
- The importance of the export-driven industrial policies of Germany and Japan is decreasing as domestic technology issues (e.g., related to health, the environment, and energy supplies) become more dominant.

- Germany and Japan each have one significant program for advanced manufacturing. In Gexmany, manufacturing technologies are implemented and transferred by the Fraunhofer Institutes for a fee. In Japan, promotion of advanced manufacturing technologies is sought through regulated international exchanges, particularly in the Intelligent Manufacturing Systems project (IMS). Both programs require substantial company investment to receive benefits.

- The Intelligent Manufacturing Systems Project (IMS), initiated by the Japanese government, is one case of what could become a significant advanced manufacturing technologies R\&D program. The IMS is designed to promote open, international exchange of manufacturing technology innovations. This design is for a specific purpose: Japanese manufacturing comparúes excel at rapid implementation of R\&D inuovation in manufacturing.

- A balanced national advanced manufacturing technology R\&D progxam does not currently exist in Germany. However, the programs at the National Laboratories and Fraunhofer Institutes, in particulas, provide advanced manufacturing technology application.

- A continuing trend can be expected towards multinational corporations, internationtal technical exchange, "cross fertilization," and joint R\&D. This trend is dramatizing the difficulty in protecting technologies that are publicly funded.

\subsection{Introduction}

Common wisdom connects technology innovation with economic growth. This perception has often been extended to link strategic key technologies with new industries and markets. Strategic key technologies that impact manufacturing competitiveness can be sorted (with admitted overlap) into two categories: product technologies and manufacturing technologies. It is important to recognize that advanced manufacturing technologies are used in mature industries (for example, the paper industry) as well as in new industries. Part 2 compares the status of the manufachuring industry in Germany, Japan, and the U.S. and major R\&D initiatives related to advanced manufacturing in Germany and Japan. Part 2 follows an assessment of human capital issues in Part 1. Assessments of manufacturing technologies are pregented in Part 3. 
Discussions of manufacturing competitiveness tend to center on performance of industrial sectors and especially high technology product sectors. R\&D is often focused to improve market share in a specific product sector where a limited number of compantes are involved. Precompetitive technolog $y^{1}$, promoted as a basis for developing new products, has recently become the clear favorite for R\&D funding by the governments of Germany and Japan because this area is clear of subsidies and industrial policy implications. The governments of all three countries are keenly sensitive to the negative view of unfair competition which other nations take of their industrial subsidies and efforts at market protection. To avoid the appearance of supporting product oriented R\&D which benefits only a few companies, precompetitive R\&D is shared, and if it is shared domestically, it generally becomes shared internationally. If the precompetitive technology is too basic, the R\&D cannot be easily transferred and assimilated when manufacturing technologies are not available to produce the product. This situation eventually shifts the competitiveness race towards that of who can first put effective manufacturing in place and away from competition in innovative product research. In otherwords, cost effective manufacturing becones more important in competition than who developed the basic science. If the product carnot be made cheaply enough to be sold to a customer, the patents are not worth very much.

\subsection{Comparison of Manufacturing Performance}

In this section a few key issues are raised to guide a general comparison of R\&D for Germany, Japan, and the U.S. Private and public R\&D investment levels are discussed. It is shown that although low- and medium-tech product sectors are more important, in terms of total production value, than high-tech prochuct sectors, the lown and mediumtech sectors do not receive commensurate $R \& D$ investment. Although the trade balance for all three countries in these latter sector's is declining much more rapidly than for high-tech sectors, the published data reflects that the majority of public R\&D funding is devoted to seeking new hightech product technologies rather than maintairing competitiveness in mature industries through development of advanced manufacturing technologies. This problem is accentuated by the increasing interest by companies to utilize technologies developed elsewhere.

\footnotetext{
1 The term precumpetilfye technology is used to categorize technologies that will require so much develogment to reach the marketplace th any prochuct that thene is no immediale competitive interesi. R\&D ith these "technologles" is assoclated with a high level of basic science.
} 


\subsubsection{How Do the Manufacturing Industries Compare by Product Sectors?}

An examination of ISIC (International Standard Industrial Classification) data on manufachuring performance in Germany, Japan, and the U.S. indicates that medium- and low-technology products are far more important than high technology products in terms of both total market price and value-added ${ }^{2}$. It is critical to understand the difference between the manufacture of high-tech products and advanced manufacturing. Advanced manufacturing is not limited to "adding value" in producing high-tech products such as semiconductors and computers. Low-tech products ("other manufactures") can be made using either advanced manufacturing technologies or traditional inefficient manufacturing. Lowtech products can be affordably produced inefficiently in countries where labor is inexpensive (low grade steel is one farniliar example). Companies in countries with high labor rates, on the other hand, require high productivity to compete, and can do so by judiciously investing in manufacturing technology development and implementation. Companies in Germany Japan, and the United States are well awate of this leverage. Successful advanced manufacturing technology strategies must provide either the ability to make new and improved products or economical advantage.

In Tables 2.1 and 2.2, product groups are categorized by technology level. In Tables 2.3 and 2.4, the same product groups are categorized by what is considered the primary characteristic of the industries that manufacture those products. These categories are as designated by $\mathrm{OECD}^{3}$. [2.1] Such categorization may suddenly become outdated as advanced manufacturing technologies change the way the products are produced. Differences in the manner that the statistics are compiled by each country makes specific comparisons difficult. [2.2] Even so, the categories are still useful in illustrating a few key generalizations. The statistics in Tables 2.1 show that in 1991, Japan excelled in production of high technology products. However, with respect to the value-added data presented in Table 2.2, the U.S. had a higher percentage of wealth generated in this category, mostly in strong market shares of aerospace and scientific instruments. In low-tech products, the U.S. had higher percentages than Japan in both production and value-added. Further examination of the statistics in Table 2.2 shows that each of the three countries becomes wealthier due to manufacturing value-added of between $75 \%$ to $80 \%$ in

\footnotetext{
2 Value-added can be thought of as the product sales (production) minus the cost to produce those products (ustuahy including equipment, raw materials, and labor). The numbers are as deflned by OECD unless otherwise noted.

${ }^{3}$ OECD, the Organlzation lor Economic Co-operation and Development, has a multinational membersip dedicated to contributing to the development of the world economy. The offices publish uselul infommation and statistics supplied by the member nations. Yen and deutche marks were converted to dollars using exchange rates.
} 
Table 2.t. 1991 Manufacturing Production by Product Sector.

\begin{tabular}{|c|c|c|c|c|c|c|}
\hline \multirow{3}{*}{ High Technology Products } & \multicolumn{2}{|c|}{ Germany } & \multicolumn{2}{|c|}{ Japan } & \multicolumn{2}{|c|}{ Uniled States } \\
\hline & MS & \multirow{2}{*}{$\%$} & $M \$$ & \multirow[t]{2}{*}{$\%$} & $M \$$ & \multirow{2}{*}{$\%$} \\
\hline & & & & & & \\
\hline Aerospace & 10696 & & 6072 & & 131345 & \\
\hline Computers & 15553 & & 96417 & & 59453 & \\
\hline Electronics & 53532 & $17 \%$ & 225815 & $22 \%$ & 121758 & $21 \%$ \\
\hline Phamaceuticals & 17865 & & 39772 & & 60836 & \\
\hline Scientific Instruments & 14979 & & 35133 & & 118405 & \\
\hline __Electrical Machinery & 73052 & & 166387 & & 84783 & \\
\hline \multicolumn{7}{|l|}{ Medium Technofogy Products } \\
\hline Motor vehicles \& other iransport & 162849 & & 336752 & & 233747 & \\
\hline Chemicals & 107927 & & 141312 & & 237049 & \\
\hline Non-electrical machinery & 131094 & $42 \%$ & 248478 & $36 \%$ & 207662 & $30 \%$ \\
\hline Rubber and Plastics & 48410 & & 114841 & & 102841 & \\
\hline Non-ferrous metals & 19089 & & 40166 & & 52855 & \\
\hline Other manufacturing & 5081 & & 36610 & & 34519 & \\
\hline \multicolumn{7}{|l|}{ Low Technology Products } \\
\hline Inorganic, mineral-based products & $328+9$ & & 82165 & & 62522 & \\
\hline Food, drink, and tobacco & 135536 & & 257051 & & 419632 & \\
\hline Shipbutiding & 4707 & & 18357 & & 14524 & \\
\hline Petroleum refining & 63796 & & 65827 & & 158077 & \\
\hline Ferrous Matals & 37074 & $41 \%$ & 138999 & $42 \%$ & 68862 & $49 \%$ \\
\hline Other metal products & 79662 & & 163499 & & 139716 & \\
\hline Printing & 22006 & & 103313 & & 156685 & \\
\hline Wood and paper producls & 14223 & & $10 \nmid 242$ & & 175974 & \\
\hline Textlles and aposare fumiture & 66136 & & 168376 & & 173336 & \\
\hline$M \$ 1$ & 116,086 & & 586,484 & & 814779 & \\
\hline
\end{tabular}


Table 2.2. 1991 Manufacturing Value-Added By Product Sector.

\begin{tabular}{|c|c|c|c|c|c|c|}
\hline \multirow{3}{*}{ High Technology Products } & \multicolumn{2}{|c|}{ Gormany } & \multicolumn{2}{|c|}{ Japan } & \multicolumn{2}{|c|}{ United Statos } \\
\hline & $M \$$ & $\%$ & \multirow{3}{*}{$\begin{array}{l}M \$ \\
2405\end{array}$} & \multirow{2}{*}{$\%$} & \multirow{3}{*}{$\frac{M \$}{66149}$} & \multirow[t]{2}{*}{$\%$} \\
\hline & & & & & & \\
\hline Aerospace & 5549 & & & & & \\
\hline Computers & 12355 & & 35140 & & 27741 & \\
\hline Electronics & 37892 & $19 \%$ & 86834 & $23 \%$ & 68703 & $25 \%$ \\
\hline Pharmacesticals & 11891 & & 27250 & & 43245 & \\
\hline Scientfic Instruments & 8424 & & 14371 & & 77139 & \\
\hline Electrical Machinery & 36233 & & Esho7 & & 43065 & \\
\hline \multicolumn{7}{|l|}{ Miedfum Technology Products } \\
\hline Motor vehlcles \& other transport & 65157 & & 95861 & & 84153 & \\
\hline Chemicals & 51929 & & 67000 & & 114029 & \\
\hline Non-electrical machinery & 72700 & $39 \%$ & 110321 & $35 \%$ & 109164 & $30 \%$ \\
\hline Rubber and Plastics & 25195 & & 49630 & & 50994 & \\
\hline Non-ferrous matals & 7574 & & 12760 & & 15541 & \\
\hline Other manufacturing & 2944 & & 15900 & & 18558 & \\
\hline \multicolumn{7}{|l|}{ Low Technology Products } \\
\hline Inorganic, mineral-based products & 19132 & & 42541 & & 33505 & \\
\hline Food, drink, and tobacco & 76644 & & 90679 & & 169820 & \\
\hline Shipbuilding & 1974 & & 6681 & & 7959 & \\
\hline Peiroleusn refining & 22564 & & 9999 & & 19796 & \\
\hline Ferrous Metals & 18174 & $42 \%$ & $\$ 4745$ & $42 \%$ & 27084 & $45 \%$ \\
\hline Other metal products & 42229 & & 74995 & & 67686 & \\
\hline Printing & 10981 & & 54492 & & 103771 & \\
\hline Wood and paper products & 20972 & & 39594 & & 75798 & \\
\hline Textilos and apparei, humiture & 26636 & & 57602 & & 81586 & \\
\hline \multicolumn{3}{|c|}{$M \$ 579,149$} & ME1,017,47g & & 305.506 & \\
\hline
\end{tabular}


Table 2.3. 1991 Manufacturing Productlon By Product Sector. (U)

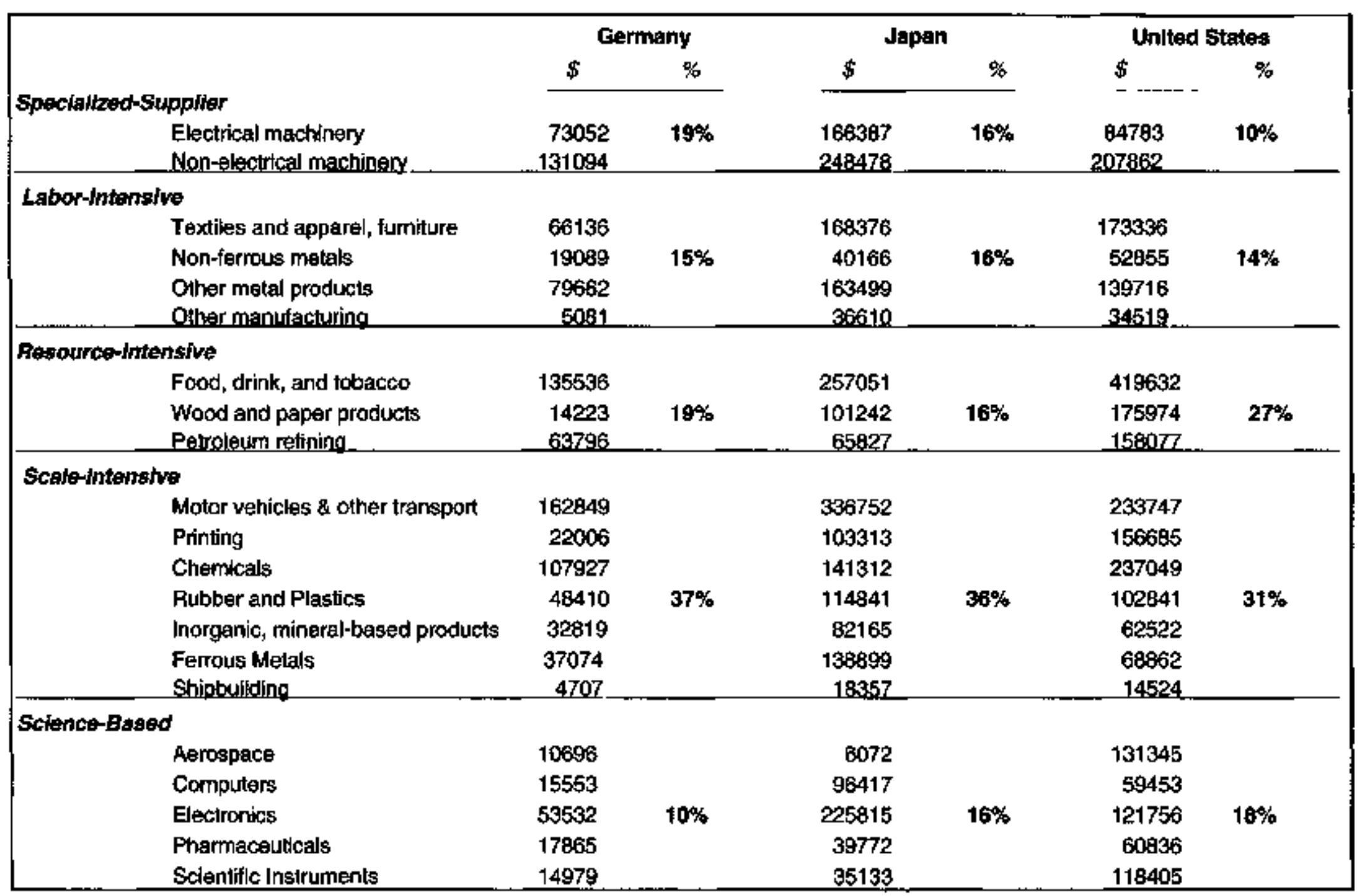


Table 2.4. 1991 Manufacturing Value-Added By Product Sector.

\begin{tabular}{|c|c|c|c|c|c|c|}
\hline \multirow[b]{3}{*}{ Specialked-Suppller } & \multicolumn{2}{|c|}{ Germany } & \multicolumn{2}{|c|}{ Japan } & \multicolumn{2}{|c|}{ Unlted States } \\
\hline & $\$$ & $\%$ & \multirow{4}{*}{$\begin{array}{r}\$ \\
68678 \\
110921\end{array}$} & \multirow{4}{*}{$\frac{\%}{18 \%}$} & \multirow{4}{*}{ 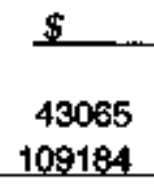 } & \multirow{4}{*}{$\begin{array}{l}\% \\
12 \%\end{array}$} \\
\hline & & & & & & \\
\hline Electrical machinery & 36233 & $19 \%$ & & & & \\
\hline __. ____. Non-electrical machinery & 72700. & & & & & \\
\hline \multicolumn{7}{|l|}{ Labor-Intensive } \\
\hline Textiles and apparel, furniture & 28636 & & 57602 & & 81586 & \\
\hline Non-ferrous metals & 7574 & $14 \%$ & 12760 & $16 \%$ & 15541 & $14 \%$ \\
\hline Other metal products & 42229 & & 74995 & & 67686 & \\
\hline Other manufacturing & 2944 & & 15900 & & 18558 & \\
\hline \multicolumn{7}{|l|}{ Resounce-intensive } \\
\hline Food, drink, and tobacco & 76644 & & 90679 & & 169820 & \\
\hline $\begin{array}{l}\text { Wood and paper products } \\
\text { Petroleum refining } \\
\end{array}$ & $\begin{array}{l}20972 \\
22564\end{array}$ & $\mathbf{2 1} \%$ & $\begin{array}{r}39594 \\
9999\end{array}$ & $14 \%$ & $\begin{array}{l}75798 \\
19796\end{array}$ & $20 \%$ \\
\hline \multicolumn{7}{|l|}{ Scale-intensive } \\
\hline Motor veticles \& other transport & 65157 & & 95861 & & 84153 & \\
\hline Printing & 10981 & & 54492 & & 103771 & \\
\hline Chemicals & 51929 & & 67000 & & 114029 & \\
\hline Rubber and Plastics & 25195 & $33 \%$ & 49630 & $36 \%$ & 50994 & $\mathbf{3 2} \%$ \\
\hline Inorganic, mineratbased products & 19132 & & 42541 & & 33505 & \\
\hline Ferrous Metals & 18174 & & 54745 & & 27084 & \\
\hline Shipbuilding & 1974 & & 6681 & & 7959 & \\
\hline \multicolumn{7}{|l|}{ Sctence-Based } \\
\hline Aerospace & 5549 & & 2405 & & 66149 & \\
\hline Computers & 12355 & & 35140 & & 27741 & \\
\hline Electronles & 37892 & $13 \%$ & 86834 & $16 \%$ & 68703 & $22 \%$ \\
\hline Phannacetuticais & 11691 & & 27250 & & 43245 & . \\
\hline Scientific Instruments & 8424 & & 14371 & & 77139 & \\
\hline
\end{tabular}


medium- and low-tech products. Only $20 \%$ to $25 \%$ of the wealth generated by manufacturing in these three countries is due to high tech products! In facing global market competition, advanced manufacturing technologies for medium- to low-tech products may be more important than for high-tech products.

The statistics in Fables 2.3 and 2.4 indicate trends in the primary characteristics of industries in each country. Because of abundant natural resources, it is predistable that the U.S. percentage of production in resource-intensive industries is higher than for Germany or Japan. In 1991, the U.S. had a much lower percentage of production in specializedsupplier manufacturing (i.e, machinery: the equipment used to manufacture other goods). German industry has excelled in this area. Although Japan and the U.S. had similar percentages of production in science-based industries, the U.S. manufacturers excelled in creating value-added in this category. Science-based category products are currently of lesser value to German manufacturing. Japanese manufacturers do not have a significant lead in any of the five categories. The percentages of production for all three countries were surprisingly similar for labor-intensive and for scale-intensive categories.

\subsubsection{What Does International Trade Tell Us About Manufacturing Competitiveness?}

The difference in customer base for manufacturing industries (export versus domestic) has profoundly influenced marketing, trade balances, and govemment R\&D policy directions for Germany, lapan, and the U.S. It is clear from a historical perspective that economic restructuring, industrial rebuldding, and reparations after World War II obliged German and Japanese industries to emphasize export markets for manufactured products [2.3|. This emphasis began to shift in 1985 to domestic markets in Japan, with diminishing reliance on the U.S. as the major customer [2.4]. In Germany, export of manufactured goods is still the dominant concern [2.5], although the European continent has become a more important customer base than the U.S. [2.6]. In contrast, the domestic market is the primary customer of U.S. industry [2.7].

The very strong concern regarding national trade imbalances in manufactured products between the U.S. and competitor nations is based on the tangible flow of currency out of the country with a relatively intangible improvement in the "quality-of-life" domestically. Recent analyses examining whether international competition is pivotal to a nation's economic problems are still being debated $] 2.8,2.9,2.10,2.11$ ]. We will not explore these arguments here. A trade imbalance clearly shows that a country is in general either better at importing or exporting. To export, manufacturing industries must find benefit in acting aggressively to enter a global market. In 1992 the U.S. exported $\$ 448.2$ billion in 
merchandise, exceeding Germany by only $\$ 18$ billion and Japan by over $\$ 100$ billion [2.12]. It has been stated that "with the U.S. market at $22 \%$ of the world market, a truly global U.S. manufacturer should be exporting $78 \%$ of its products" [2.13]. A comparison of import share (percent of product imported) in $\mathbf{4 2}$ separate manufacturing categories indicated that the average U.S. import share rose from $9.4 \%$ in 1975 to $22.2 \%$ in 1989 [2.14]. International corporations and consortia are prominent in export. It is noteworthy that $-25 \%$ of exports are intercompany transfers from U.S. companies to foreign affiliates. Another $20 \%$ is exported from U.S. affiliates of foreign companies [2.12].

Figures 2.1.1, 2.1.2, and 2.1 .3 present global trade balances in manufactured products over twelve years for Germany, Japan, and the U.S., respectively. All three countries have lost trade to some degree from a peak year. The largest decline occurred in U.S. trade during the early 1980 's, while the most dramatic decline is observed in German trade since

\section{....... High-tech products \\ - All products \\ -.. Medium \& low-tech products}

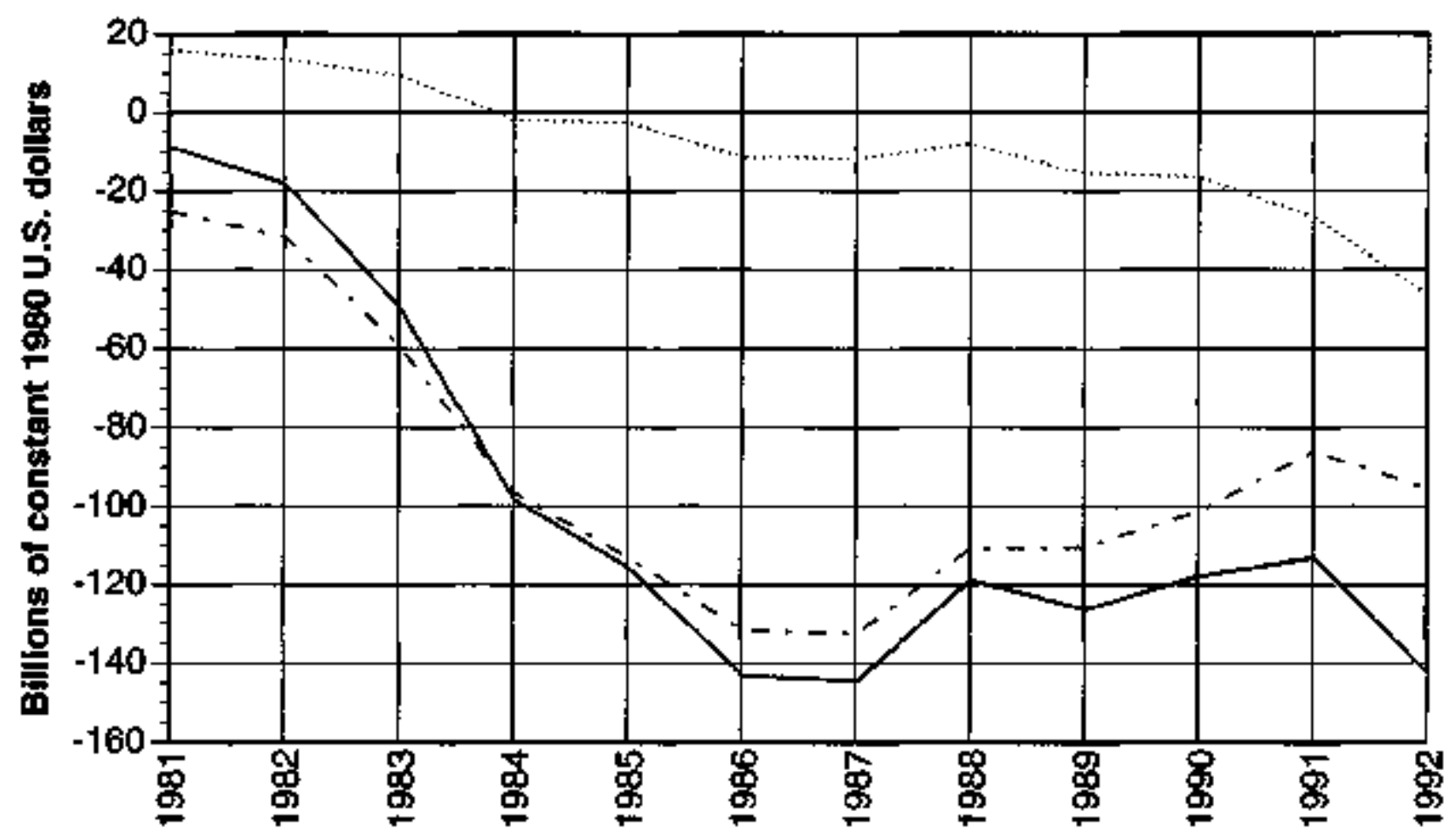

Figure 2.1.1. Trade balance in manufactured products: United States. [2.5] 


\section{High-tech products}

\section{- All products}

\section{- - Medium \& low-tech products}

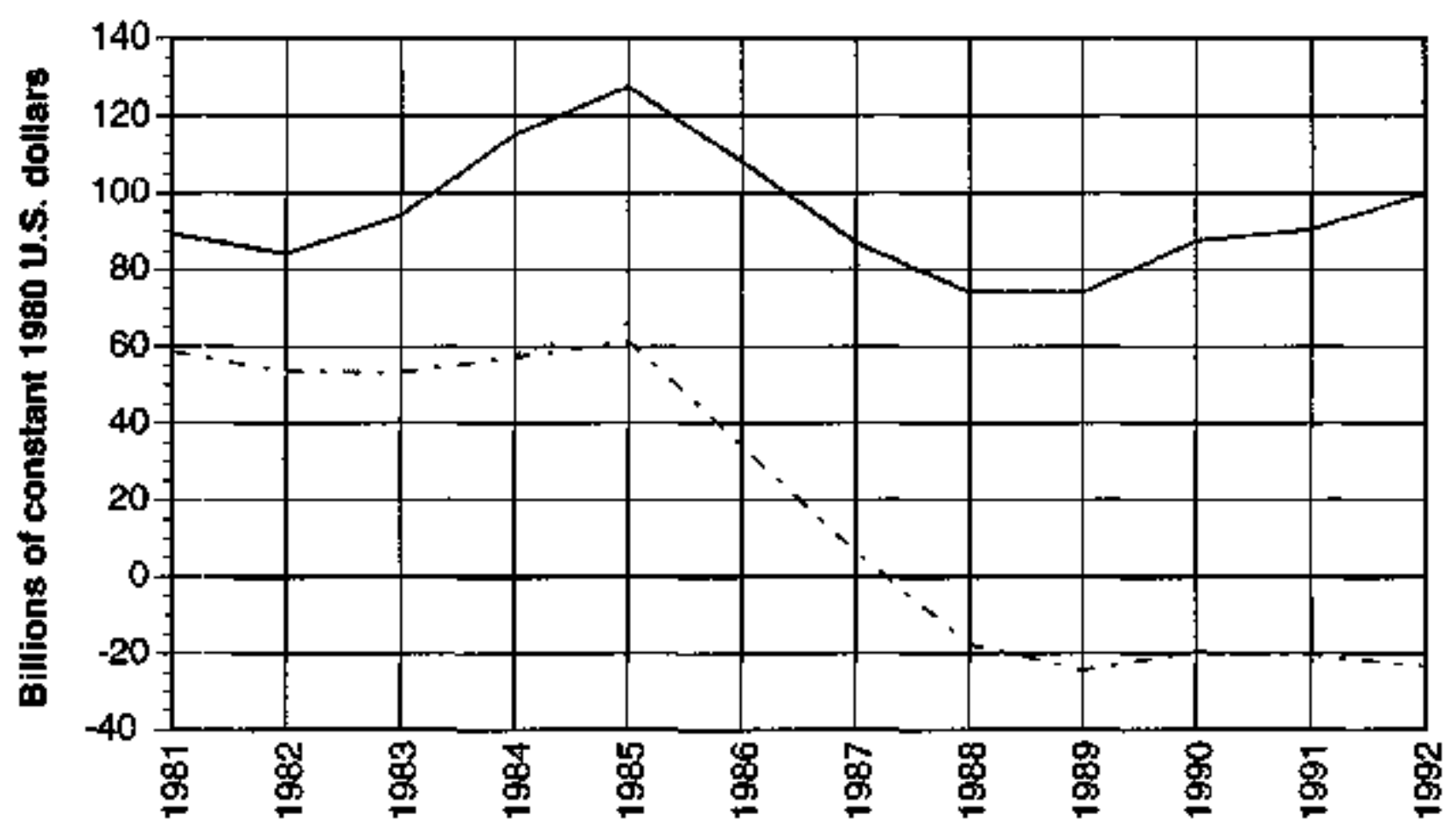

Figure 21.2 . Trade balance in manufactured productei Japan. [25]

1989. By examining the trend of high-tech products with respect to medium- and low-tech products, distinct differences in trade positions car be observed. Germany has depended ovenwhelmingly on medium- and low-tech prcducts for a positive trade balance. In 1989, exports in all categonies began dropping precipitously. The negative trade bakance is unlikely to be reversed in the next decade without significant Government changes regarding free trade practices and deregulation. The Japanese trade balance is positive due to a large export in high-tech products which has grown steadily over these years. The Japanese government is anxious to promote continuation of this trend. The Japanese trade balance in medium- and low-tech products has decreased dramatically since 1985. The U.S. trade balances in both high-tech products and medium- and lowtech products have declined over these years. While the trade balance in high-tech products declined gradually, the balance in medium- and lowtech products decreased dramatically in the early 1980's. There has been a recent resurgence in the latter category, which is attributed to the 
High-tech products

All products

- - Medium \& low-tech products

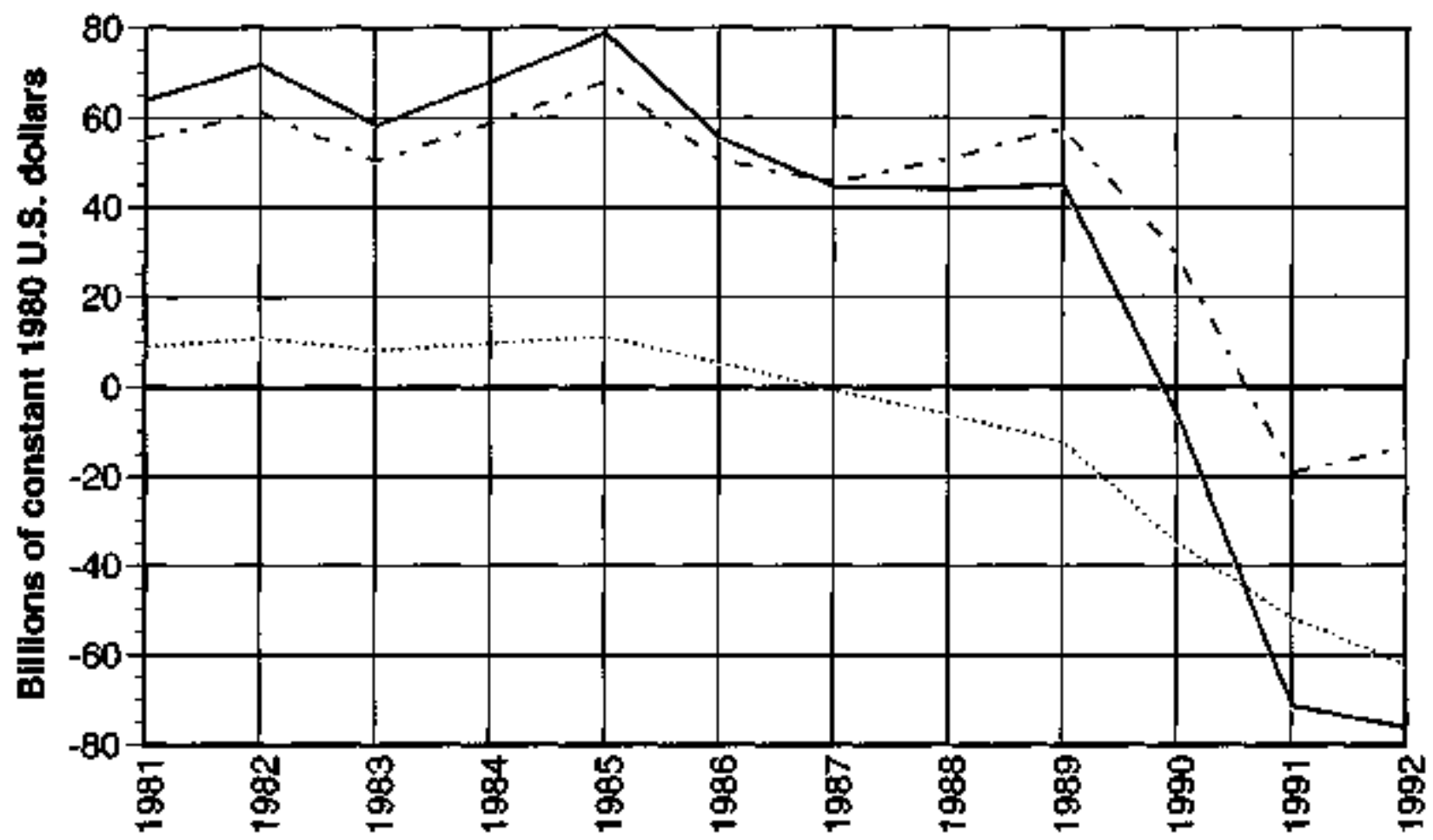

Figure 2.1.3. Trade balance in manufactured products: Germany. [2.5]

application of advanced manufacturing technologies in the related industries (e.g., in textiles).

\subsubsection{How Do the Levels and Disbursement of R\&D Funding Compare?}

A comparison of the amounts and dispersal of $\mathrm{R} \& \mathrm{D}$ funding is often used as a basis to predict the future competitiveness of industry. There are a multitude of other factors between funding and any related application in a manufactured product that affect the value of $R \& D$. The wise choice of R\&D goals can be more important than budget size when resources are limited. Table 2.5 presents a listing of the ten product sectors receiving the most R\&D funding in 1990 from each nation's industry. The amounts 
Table 2.5. Ten Largest Industrial Enterprise R\&D Performers in 1990. [2.1]

\begin{tabular}{|c|c|c|c|c|c|}
\hline \multicolumn{2}{|l|}{ Cermany } & \multicolumn{2}{|l|}{ Japan } & \multicolumn{2}{|c|}{ United States } \\
\hline Electronics & 18.0 & Electronics & 15.5 & Alerospace & 24.4 \\
\hline Motor vehicless & 16.4 & Motor vohlclos & 13.7 & Electronice & 15.2 \\
\hline Chemlcals & 15.7 & Computers & 11.1 & Computers & 11.7 \\
\hline Machinery (nec) & 10.8 & Electrleal machinery & 10.7 & Motor vehicles & 110 \\
\hline Adrospace & 85 & Chemicals & 9.7 & Pharmaceuticals & 6.3 \\
\hline Electrleal machinery & 7.9 & Machlnery (nec) & 7.7 & Instruments & 5.8 \\
\hline Pharmaceuticals & 5.6 & Pharmaceuticals & 5.3 & Chemicals & 5.3 \\
\hline Comptiters & 3.5 & Instruments & 3.6 & Machinery (nec) & 2.7 \\
\hline Fabriceted motals & 24 & Ferrous motals & 3.3 & Potroleum refining & 2.0 \\
\hline Inedruments & 1.6 & Food/drink/obaceo & 2.5 & Electrleat machinery & 1,3 \\
\hline Other Industries & 14.0 & Othor Industries & 16.7 & Other Industries & 14.0 \\
\hline Total BERD & 100.0 & Totel BERD & 100.0 & Total EERD & 100.0 \\
\hline
\end{tabular}

spent in each country do not correlate with total production or gross value-added of the product sector. For instance, the food $/ \mathrm{drink} /$ tobacco product sector is the largest category for the U.S., and does not rank in the top ten for R\&D funding. Electronics receives the most Japanese industrial $R \& D$ funding, yet was fourth in terms of production and value-added. Similarly, electronics ranked ninth in German production and first in terms of R\&D funding.

Industrial R\&D spending is pressured by market competition. There are benefits to companies investing their own funds into $R \& D$; the $R \& D$ will be necessary and related to immediate problems, and the company can appropriately value the resulting advantage as to whether to shate or sell the results internationally. R\&D tax incentives have become popular encouragements (i.e., subsidies) in Japan and the U.S. which are not reflected in comparing national statistics. Along with the benefit of R\&D funding by industry, there is benefit to industry in performing the R\&D: the process of performing R\&D requires concentration on problem solving and integration of solutions through which learning occurs. Therefore, both industrial R\&D funding and industrial R\&D performance are important. In $1991_{t}$ Japanese industry was the source of $72.6 \%$ of national R\&D funds and performed $70.7 \%$ of the R\&D. The sum of the percentages 
of industrial R\&D funding and R\&D performance by industry is 143 . This sum gives an indication of the very high level of Japanese industrial involvement in R\&D. U.S. industry performed $69.2 \%$ of all R\&D yet funded only $50.7 \%$, with a sum of 120 . German industry funded a higher percentage of R\&D at $59.9 \%$ and performed $68.4 \%$, with a sum of 128 . These sums symbolize that R\&D funding in Japan may be more effective in promoting industrial competitiveness.

A comparison of the total amount of R\&D funding in Germany, Japan, and the U.S. indicates that the U.S. invests the most in R\&D. In 1991, the U.S. Gross Domestic Expenditure on R\&D (GERD) was over twice as large as that of Japan and four times as large as the German GERD. As presented in Table 2.6, the R\&D expenditure per capita is also higher for the U.S. Japan appeared to invest more in R\&D only as a percentage of Gross Domestic Product (GDP). The percentages of R\&D funded and performed by public and private sectors are shown graphically in Figure 2.2.4 In 1991 public funding as a percentage of national R\&D was $47 \%$ in the United States, $37 \%$ in Germany, and only $18 \%$ in Japan. From this public funding, R\&D in higher education was funded at similar levels of $16 \%, 17 \%$, and $16 \%$, respectively. These figures demonstrate that the U.S. government has become responsible for the disbursement of a much larger percentage of national $R \& D$ funding than the Japanese or Gernan govemuments.

The distribution of R\&D funds by "socioeconomic objective" indicates profound differences between R\&D activities in Germany, Japan, and the U.S. Figure 2.3 gives a graphical representation of ten funding areas.

Primary emphasis in R\&D spending by the U.S. is defense and health, by Japan is energy, and by Germany is industrial development and advancement of science and technology research. A historical examination of R\&D funding for industrial development is presented in

\footnotetext{
4 There are some minor differences in the way each country clefines these statistics; e.g.t Ihe U.S. government R\&D performance is slightly underestimeted becautse state and local R\&D pertormance is nol included. For more information, please see fleference [2.15].
}

Table 2.6. Comparison of 1991 Gross Domestic Expenditure on R\&D (GERD). [2.15]

\begin{tabular}{|lccc|}
\hline & Mss & $\begin{array}{c}\text { S per capita } \\
\text { population }\end{array}$ & as \% of CDP \\
\hline Germany & 34,813 & 436 & 2.58 \\
Japan & 71,994 & 581 & 3.04 \\
United States & 154,348 & 611 & 2.78 \\
\hline
\end{tabular}



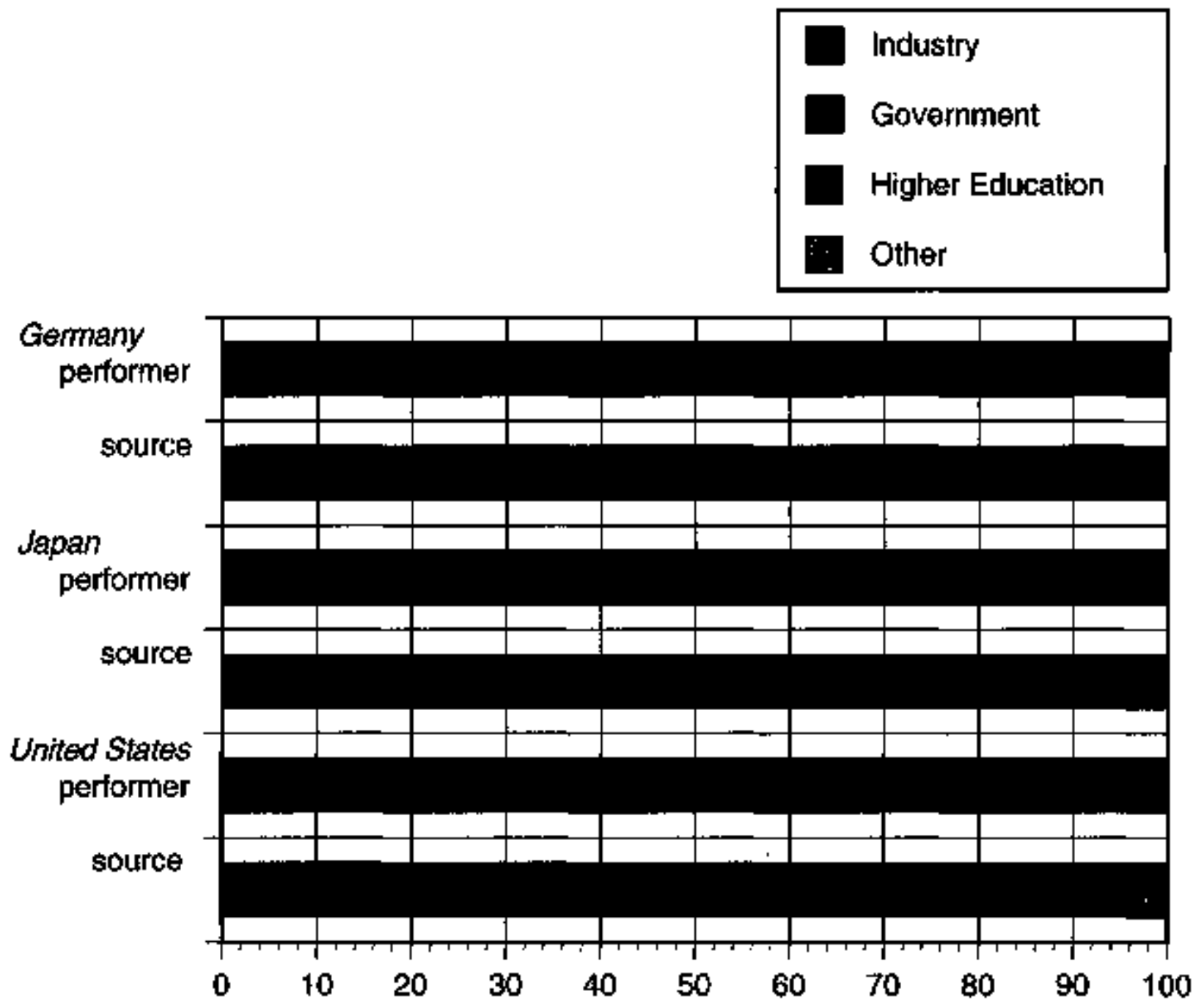

Figure 2.2. Performers and sources of 1991 domestic expenditures on R\&D: 1991. [215]

Figures 2.4 and 2.5. The percentages in Figure 2.4 exclude general university funds from the total R\&D budget, while those in Figure 2.5 additionally exclude defense R\&D funding.

In either case, the U.S. funding of industrial development as a percentage of national R\&D funding is significantly less than German and Japanese funding. Furthermore, the percentage of public R\&D funding for industrial development is decreasing in Japan while on the increase in Gemany.

It is difficult to find comparative statistics regarding basic research. The level of funding for basic research in Germany is unknown. In Japan, corporate basic research is reported to be consistently between $6 \%$ and $7 \%$ of the total R\&D budget. [2.17] Basic research funding in the U.S. has decreased dramatically in the last few years. In 1991, basic research in the U.S. was funded at $4.3 \%$, applied research at $23.6 \%$, and development at 


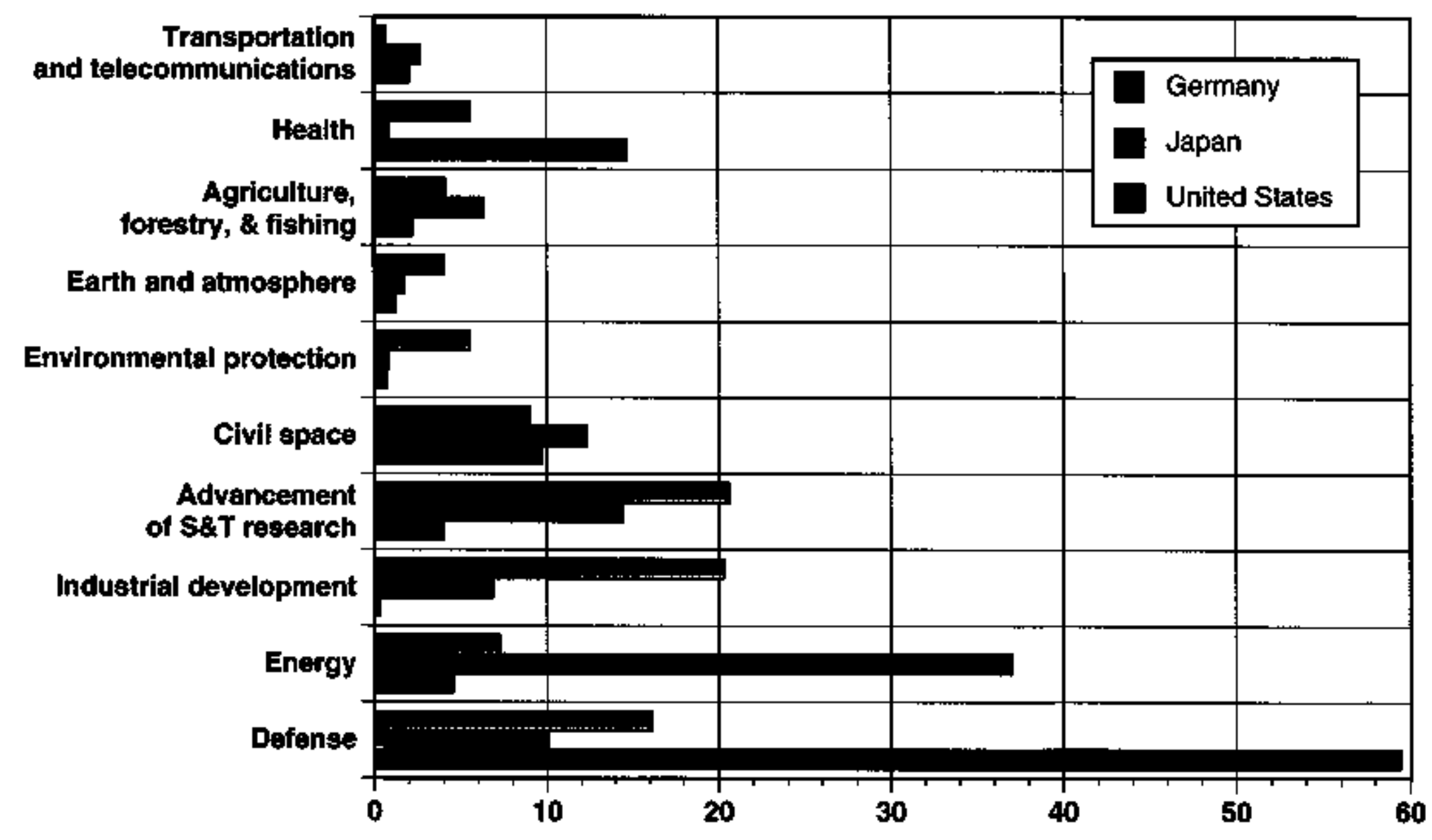

Note: Numbers adjusted to remove the category "General University Funds"

Figure 2.3. Distribution of national R\&D budget appropriations, by socioeconomic objective: 1992. [2.5] 

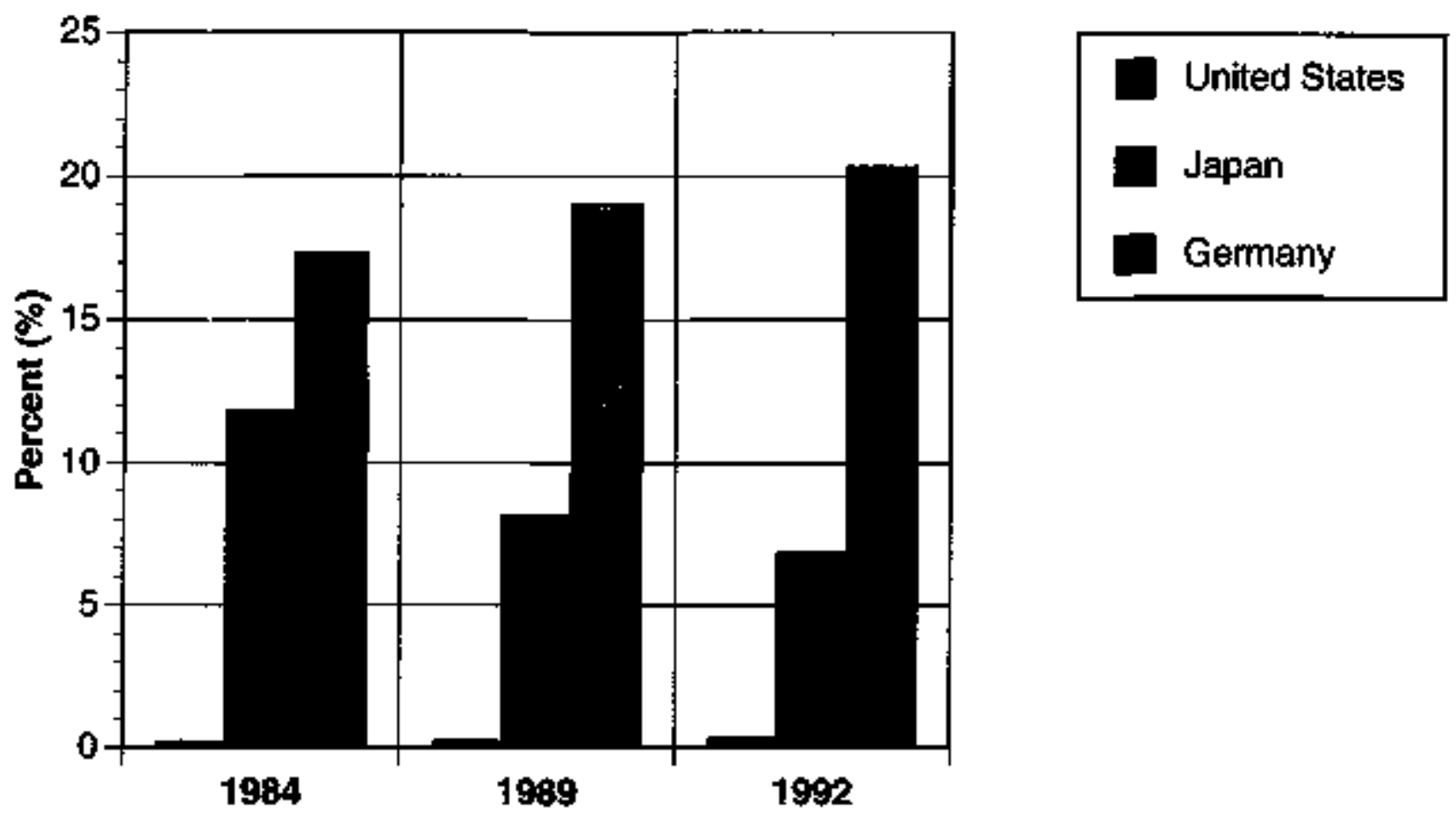

Note: Data were adjusted to exclude general university funds for Japan and Germany, 1984 and 1969 data for western Germany, onty.

Figure 2.4. Industrial development as a percentage of national R\&D budget appropriations. [2.5]

$72.7 \%$ of the total R\&D budget. [2.18] Stagnant or decreasing R\&D funds coupled with rapid changes in technology is forcing comparies in all three countries to become increasingly reliant on technologies developed elsewhere. Figure 2.6 depicts the results of a survey in which companies were asked to predict their dependence on external sources of technology. [2.19] Companies ranked in-house R\&D significantly higher in value than any other source. This is consistent with the previous discussion regarding R\&D performed by ind ustry. Most companies that conduct R\&D emphasize new product development. $[2,20]$ It is likely that industry is not simply becoming more dependent on external sources of $\mathrm{R} \& \mathrm{D}$, but that industry is increasingly utilizing R\&D from external sources to compete.

\subsection{Govemments' Role in Major R\&D Initiatives and Advanced Manufacturing}

This section provides an understanding of German and Japanese R\&D strategies based on the perceived strengths and weaknesses of manufacturers and some historical precedent. Industrial policy tends to 

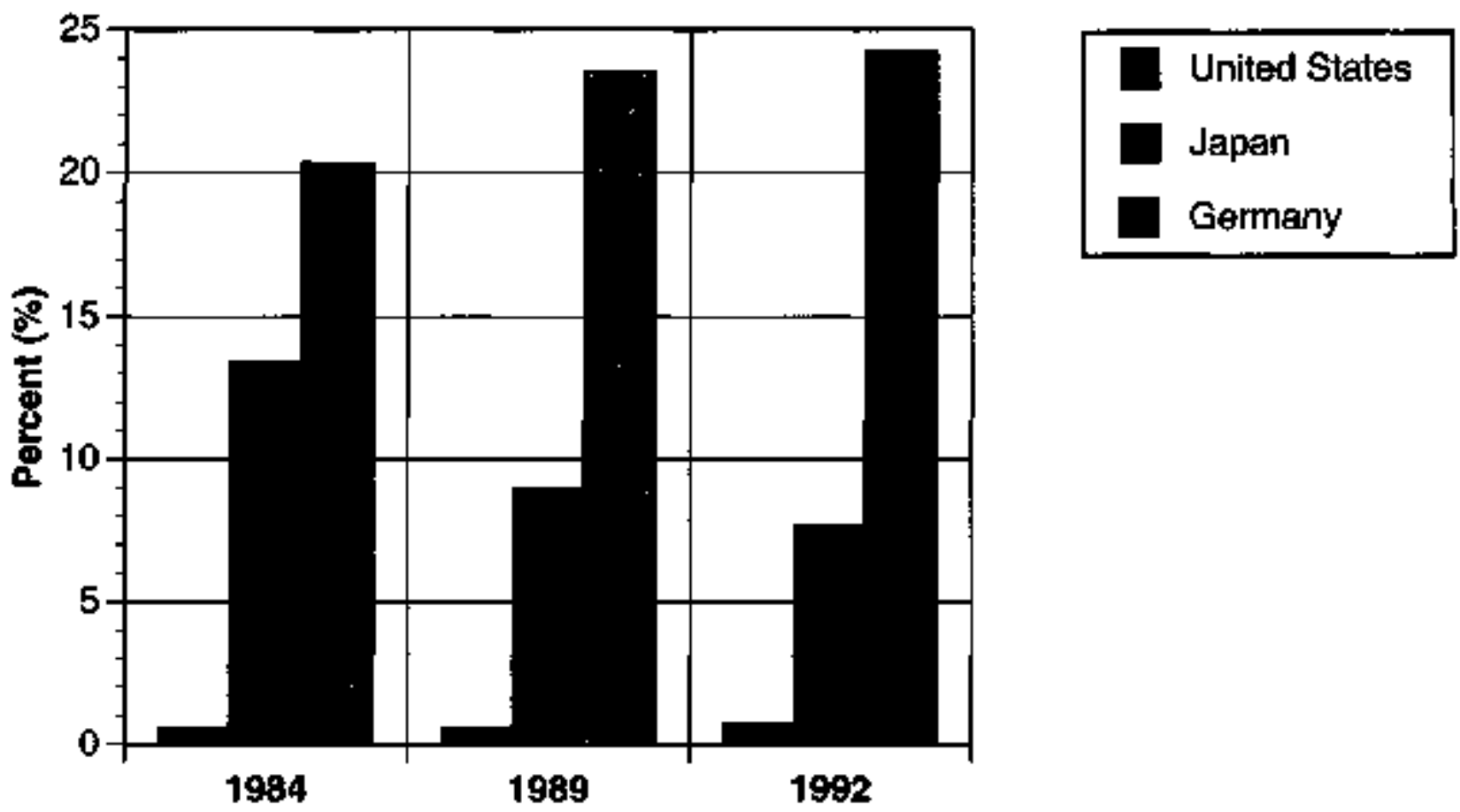

Note: Data were adjusted to exclude general university funds for Japan and Germany, and defense funds for all three nations. 1984 and 1989 data for westem Germany, only.

Figure 2,5. Industrial development as a percentage of national R\&D budget appropriations. [2.5]

encourage government protection based on strategic goals (e.g., to have the best semiconductor industry) and social values, which are distinctly different from competitiveness based on production costs. Gemany and Japan have instituted industrial policies for several decades. The U.S. has not had a formal industrial policy, although some industrial sectors have been "managed" for securtity reasons.

During the late 1980s, the industrial policies in Germany and Japan began to decine in importance and defocused as the challenges to manufacturers changed with increasing global competitiveness, corporate globalization, and international trade agreements, which limited government interference. The governments instituting policies found that the existing policies were not solving problems. Govermment support for R\&D related to commercial markets began to increase. National laboratories in all three countries were given R\&D missions related to manufacturing technologies and commercial products. In the past, German government involvement concentrated on workforce interactions and trade. The government now gutides the direction of basic science $R \& D$ specifically in an effort to open new markets. The Japanese government has had a different role in that industrial policy was primarily to manipulate both markets and industry-led $R \& D$. This role is changing rapidly as international R\&D programs involving long-term and 


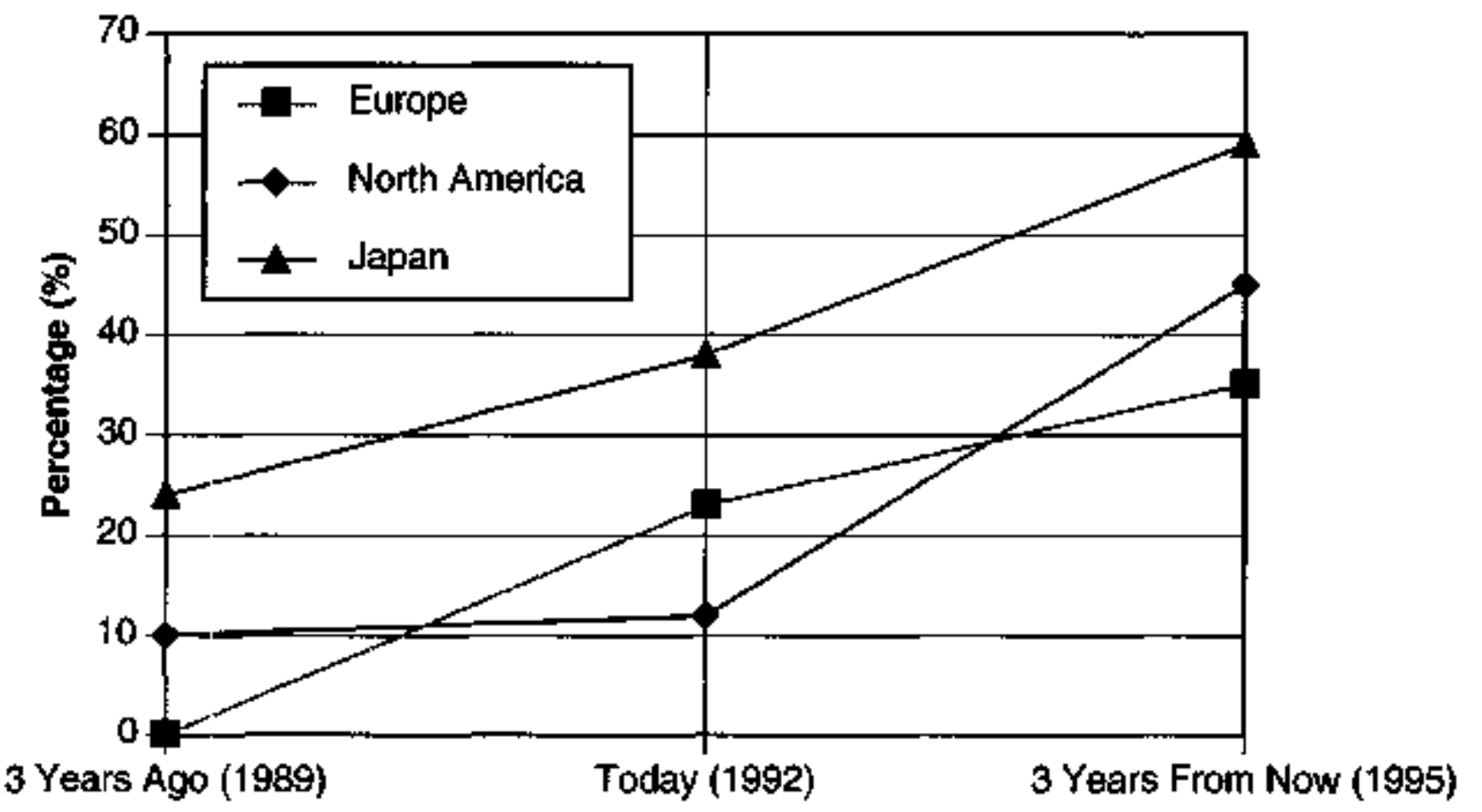

Figure 2.6. Percentage of companies with high reliance on extemal sources for technology+ [2.19]

interdisciplinary efforts are being promoted. Even without a formal industrial policy, the U.S. government has significantly impacted industry for decades by driving innovation as customers for industry through defense, space, and health programs. Related R\&D programs were successful because the government was also the customer of the products.German and Japanese governments have discovered difficulties in promoting large domestic manufacturers because of the increasing dominance of multinational corporations and international corporate agreements. Furthermore, the fact that the overall cost of manufacturing is the overriding competitiveness issue means that at some point a nation's ability to subsidize and protect favored sectors of manufacturing can become untenable. These governments are now emphasizing precompetitive, high technology $R \& D$ for ind ustrial competitiveness.

\subsubsection{GERMANY}

\subsubsection{Goals}

The major goal of German R\&D initiatives is to improve the position of German manufacturers with respect to Japanese and U.S. manutacturers in global markerts for high tech products. Although the world's second 
largest national exporter of manufactured products, the Cerman economy is still recovering from unification, and the manufacturing industries are having difficulties supporting the German society as established today. Some political hetoric indicates that there is a general feeling of failure. [2.21] Since the nineteenth century, the writings of Friedrich List have strongly influenced the German view of the place of mantracturing in the society. As an economist, List drew a direct connection between domestic prosperity and success in world markets. $[2.22,2.23]$ This economic security and the underlying theory is now threatened, not necessarily by Japanese and U.S. competition, but by changes in manufacturing in traditional product sectors.

There is an extremely strong belief that economic security for the German saciety can be gained only by "securing future markets." This means championing new enterprises in high tech products and emerging technologies: a move towards more "intelligent" products involving technologies that are so advanced that other countries cannot duplicate them. [2.22] To gain these specific markets, the Germans must compete directly with Japanese and U.S. manufacturers. As this is seen as their future, there is a tendency to overemphasize these markets as well as technologies in which German companies have typically lagged and will probably continue to lag.

Public subsidies (especially from the Laender (State) governments) are expected to "save" industries that are dying. [2.24] Both the Federation of German Industry (BDD) and the German Chamber of Commerce (DIHT) are calling for more support. [2.25-2.27] It is typical for subsidies and R\&D to be directly linked. One problem is that the general public interest in manufacturing subsidies and $R \& D$ is waning because the programs to date have not shown direct success in capturing key high-tech product markets. [2.28] Government funding of science research relevant to social issues (e.g, health and environment) is increasing while Federal interest in industrial $R \& D$ is diminishing. Laender governments are expected to play an increasingly important role in industrial R\&D.

German R\&D and subsidy programs have traditionally emphasized and continue to emphasize small- and medium-sized enterprises (SMEs). It was estimated that more than one third of the 1992 BMFT $^{5}$ budget for industry specifically subsidized SMEs. [2.29] SMEs are perceived as innovators and conduits for new rechnologies. Flexibility and innovation is thought to emanate from SMEs because of their size. Installing state-ofthe-art technical equipment in SMEs has been an ongoing modemization effort of the German government. [2.29] In 1993, the govemment increased pressure on SMEs to "join forces" and work together on R\&D. [2.30] This newly formulated goal is thought to emerge from increasingly

5 The BMFT is the German Federal Ministry of Research ard Technology and is resporsesble for the majority of R\&D program support. 
limited budgets. The emphasis on SMEs was extended to subsidizing industry and $R \& D$ in eastern Germany since reunification. This accounts for the appearance of an increasing trend in funding for industrial R\&D as shown in Figure 2.4. SMEs in the "new Laender" are perceived to need more aid in order to compete in international markets. Part of the support for eastern German SMEs is to promote technology transfer from newly established eastern German Institutes. Since 1989 government R\&D programs have attempted to boost the productivity of eastern companies to levels comparable to western companies. [2.31] The strong message from the BMFT is that "the new German Laender must not be regarded as an extended workbench of west German industry." [2.32] Although the increased industrial funding by the Federal goverrment is considered a temporary emergency situation, it will be many years before manufacturing in the eastern Laender can rise to the competence level of the western Laender.

The strengths and weaknesses of German manufacturing help to clarify the strategies by which German R\&D is promoted. The German strength is in applied engineering; manufacturing an improved product. [2.33] Germany's manufacturers are strong in conventional product sectors such as electrical machinery, nonelectrical machinery, transportation vehicles, fabricated metal products, and chemicals. In these industries, the fundamental concepts were developed in past decades. German SMEs typically concentrate on manufacturing a few, high quality products. Large enterprises often emphasize complete, integrated systems that incorporate various technologies. A combination of market forces and strength in applied engineering has encouraged flexible manufacturing for customized products. [2.22] Customization and quality service can command high value-added (for example, in making process equipment for mass production of goods). In mass-produced consumex goods markets, however, customization of the goods and service are not primary considerations. The niches defined by this type of specialization (i.e., customization and quality service) appear to be requiring increasing complexity in final products as more manufacturers enter these markets (an example is very high end cars). The increasing complexity of the products eventually becomes too expensive to compete in global markets. [2.34] This is a widespread problem facing German manufacturers. One area where German manufacturers show continued success is customized machinery for manufacturing.

"Innovation" problems are currently the topic of many political debates. A lack of innovation is suggested to cause long product development times, which lengthens the time it takes to place a product in a market. It is more likely that this latter symptom stems from difficulties integrating science and engineering disciplines to prepare a product. it appears that the multidisciplinary efforts required in newly emerging technology areas may not be fostered. As the Research Minister stated the situation: "Germany is one of the leaders, in paxticular in fields of technology, which, like high ^quality chemistry, are related only with very few fields 
of science. The FRG is represented as below average where results from various scientific disciplines must be linked in onder to develop new technologies - e.g, in biomedicine, in processing methods for new materials, or in software . . " [2.35]

The government sees the German companies as "falling behind" Japanese and U.S. manufacturers in several high-tech fields, including nucroelectronics, telecommurucations, biotechrology, consumer electronics, and aerospace. In addition to not competing well in new product markets related to these high-tech fields, it is becoming apparent that the components developed in some of these technology sectors will benefit products in more traditional sectors. An example is sophisticated electronic controls that are now desirable in integrated systems such as cars. [2.25] It appears that there is a fear that as such controls cannot be made domestically, products of large companies are becoming assemblies of components that foreign manufacturers can also purchase and thus some advantage of large systems manufacturing will be lost.

\subsubsection{Interactions}

Cooperation between industry, academia, and research institutes is a growing concern of the German government. Although the "consensus" system that allows labor voice in industrial management has been enforced by stiff regulation for decades, cooperation in research and development is still limited. Public research is carried out at institutes, national laboratoties, and universities. Few programs involve cooperative research in all three. Two notable exceptions include a consortium funded by BMFT to establish applications for porous silicon optoelectronic components, and a second consortium developing light-emitting silicon diodes. [2.36] These consortia, which include industrial participants, are a relatively new trend for Getman establishments. It is the pressure of competition that encourages interactions between consortium members that seek to invent new high-tech products. "Technology trarisfer" is used to disseminate acquired techuology and assocjated information to industry. There are indications that the traditional method of technology transfer from science-oriented research groups to industry has been generally unsuccessful. Studies in the last decade have encouraged more active participation of manufacturers with the institute, laboratory, or university as research is performed. In general, it appears that a clear separation is made between research and manufacturing with little effort to perform both at a manufacturing facility. [2.37,2.38] Industry is expected to pay for and use basic and applied research produced at institutes and universities.

SMEs are considered important recipients of research due to their "lack of resources" whereas large companies "rely heavily on...trained experts and sophisticated equipment:" [2.38] By the end of 1992, there were 102 organizations involved in industrial research funded in combination by 
the Federal Ministry of Economics, the Federal Ministry of Research and Technology (BMFT), the Laender govemments, and industry. [2,38] As public funding for research is being reduced, the Federal government is placing more emphasis on cooperation, especially in asking SMEs to "join forces" and large companies to sponsor institute programs. [2.30, 2.32] Federal programs tend to promote science and technology development. On the other hand, Laender programs are designed to encourage implementation of developed technologies within local industry. [2.39] In 1993, the BMFT and the Laender govemments proposed a national R\&D program specifically to encourage technology transfer with SMEs as the recipients. [2.10] This new program termed "research cooperation" was funded at a level of DM200 million (\$120 million) for three years. [2.32]

The German yovemment is actively encouraging joint $R \& D$ with other nations as a strategy to support German companies. One example is German funding of a joint German-Russian-Japanese aerospace program. [2.41] Pertaps more indicative was a call in 1991 by the presiding Minister of Research \& Technology to strengthen Geman competitiveness by conducting R\&D and manufacturing in Japan. Part of that call suggested patticipation in MITI's industrial projects by German industry. [2.42] Signifisant participation in the MITI-led program in Intelligent Manufacturing Systems appears to be an outgrowth of this encouragement. On a global scale, the German goverrment is setting up industry and trade centers abroad. Each center serves as a "bridgehead" providing administrative and consulting services for German companies in that location. [2.43]

Germany is active in the R\&D efforts of the European Union. As Germany leads the rest of the EU countries in national $R \& D$ funding and activities, such interactions are perceived to be of questionable benefit to Germany unless institutes in eastern Germany receive EU funds and the German government has a strong role in deciding which EU-funded programs are pursued. Both requirements have been net, yet the EU programs have not been acclaimed as large successes. [2.44] The BMFT funds interaction in the EU programs as part of its manufacturing R\&D strategy.

Although the government encourages some international R\&D interactions, there is concern that private $R \& D$ activities are migrating to other countries. Upon moving research activities to the U.S., the head of pharmaceutical research for a major German company stated that research and production "go hand in hand." [2.45] In 1992, thitty-five German "free-standing" R\&D facilities were operating in the U.S. [2.46] The majority of these facilities are involved in biotechnology. The main reasons for locating biotechnology R\&D in the U.S. are to "acquire technology" "keep abreast of technological developments," and "cooperate with other U.S. R\&D laboratories. " For centers involved in applied electronics research, the two main reasons given are to "acquire technology" and to "assist a parent company in meeting U.S. customer needs." [2.46] Foreign R\&D expenditure by German companies tripled between 1980 and 1987. 
[2.47] This "globalization" strategy of private $R \& D$ activities is expected to continue to accelerate.

\subsubsection{Programs}

There is no national advanced manufacturing technology R\&D program in Gerriany. Instead, major funding is being directed towards key or precompetitive product technologies with a strong science component. However, the programs at the National Laboratories and the Fraunhofer Institutes, in particular, provide manufacturing technology application. Manufacturing technology application is continuing to be used to subsidize the modernization of SMEs (especially in eastem Germany) so that they can compete in global markets. Political discussions suggest a clear-cut model where basic technology is developed in public laboratories, institutes, and universities. Government programs are then concerned with helping industry to instail and implement these "public" technologies. The serious problem that has developed is that foreign competition, limited resources, and special interest lobbying is forcing the balance away from basic technology development and to application specific implementation. In the short term, an inexpensive route to existing technology is anticipated by involvement in international programs. This alone does not give Germany an edge on international competitors! In the long term, the trend is progressing to the point that the social aspects of manufacturing (in particular, business management and environmental regulation) are becoming fundamental drivers of German government programs rather than technology for industrial competitiveness.

The BMFT manages centralized R\&D for Germany often in conjunction with Laender support. Federal R\&D is promoted mainly through funding of research institutes, project funding, and contributions to international organizations. Detailed information on the BMFT budgets is avaibable. [2.29] The 1994 BMFT budget is $\sim D M 9.47$ billion ( $\$ 6$ billion). Priority programs for 1995 have a strong science element with industrial potential, and include biotechnology, traffic and transport technology, preventative health research, ecology and environmental technology, climate research, and information technology. Advanced manufachuring is not a priority program. The BMFT and the Federal Ministry of Education receive reports and recommendations regarding reseatch and higher education from the Science Council (similar to the role of the National Academy of Sciences in the U.S.). The Council consists of 54 presidential appointees and government representatives, the majority of whom are from academia. Few members represent industry. The strong science orientation of the council may explain the very strong basic science bias that continues to exist in German research. [2.48] For the last few years, the BMFT has been promoting research in "strategic technologies" at the "precompetitive stage ${ }_{r}$ " especially information technology, biotechnology, materials research, transport (including space), and energy research. [2.32] 
With regard to manufacturing, the official BMFT goal is to "help industry focus on promising new fields of technology." [2.32] However, the emphasis on product development is a shift from the manufacturing production oriented programs of the 1980s. From 1989 to 1994, production engineering was included in the BMFT programs only as a subset of the Information Technology Program. Information technologies are considered key innovation areas for future markets. The program was started in 1989 and in 1992 was slated for DM1.1 billion ( $-\$ 700$ million) from the BMFT. In 1995, the total government funding will be increased to DM1.8 billion. On paper, DM984 will be used for information technology and manufacturing engineering projects, with DM518 reserved for related materials research and physical and chemical technologies. The three major goals for 1993 to 1996 are tirst, to develop high resolution imaging systems (e.g., HDTV and flat panel displays); second, to develop a digital terrestrial radio; and third, to design "safe and environmentally friendly" traffic systems. A 1994 special committee recommendation to the BMFT stated the critical importance of promoting the technologies related to the production engineering projects. [2.49] It is unknown whether the resulting New Manufacturing Technologies initiative (also called "Production 2000") just proposed will include an increase in funding, or just a shift in funding from the Information Techunology Program. The 1988 budget for production engineering was DM500 ( $\$ 284$ million) which may appear to be a serious investment in manufacturing technology deveiopment until one realizes that the majority of the funding was used to subsidize modernization of SMEs (i.e., instaltation of equipment and implementation of technology) rather than technology development per se. More recent funding levels for production engineering activities are not avaitable.

The BMFT has faced on-going budget reductions in 1994 even with continuing requìrements for support of eastem German research activities. [2.50] As a consequence, the BMFT is moving towards smaller projects and shortening long-term programs. [2.51] The wide variety of German institutes plays an important role in not only $R \& D$, but technology transfer and support of SMEs, as well. German institutes consist of:

1. Institutes of higher education with university affiliation that may be supported through the German Research Association (DFG), which is funded 50:50 by the Ministry of Education and Laender goverrments;

2. Laender research institutes;

3. Blue Eist Institutes and Max Planck Institutes funded 50:50 by BMFT and the respective Laender, which concentrate on basic science research;

4. The large National Research Laboratories funded 90:10 by BMFT and the Laender. 
5. The Fraunhofer Institutes funded jointly by BMFT, Laender, and industry, which concentrate on applied research.

All German institutes are facing shrinking budgets and increasing competition between institutes for funding. This is due mairly to the many fledgling eastern German additions, which are using 10\% of the budget. Employment is being reduced in western German institutes. [2.52] The National Research Laboratories and the Fraunhofer Institutes conduct the vast majority of manufacturing related $R \& D$. With funding problems and a continuing need for subsidization of industry, it is difficult to perceive how new initiatives in manufacturing will be adequately supported. German industry has not been forthcoming in increasing funding for R\&D at institutes. This is creating an especially difficult situation in the 1990s for the Fraunhofer programs.

The Fraunhofer Institutes represent the main government effort to provide industry with access to advanced manufacturing technologies. Both the Federal government through BMFT and the local Laender support the Institutes. [2.53] The forty-five research and service institutes are typically contracted to provide applied engineering expertise on nearterm commercial projects, and also operate as field service and demonstration facilities. The resources for basic research at these Institutes are insignificant. Each Institute is tasked with an area of expertise. Table 2.7 lists the current organization of Fraunhofer Institutes under the nine "focal fields." The lack of interdisciplinary engineering reduces flexibility and probably makes such a system more expensive.

The large National Laboratories are directly involved in R\&D for advanced manufacturing technologies. In fact, the BMFT Project Manager for Production Engineering and Quality Assurance is located at the Karlsruhe Nuclear Research Center. Although committees have encouraged the BMFT to increase the orientation of the National Laboratories' programs towards industrial applications [2.54], the BMFT is in large part continuing the trend of bassic research. [2.26] This may change slightly in 1995. A study to redefine the mission of the National Laboratories was presented to BMFT in 1994 by executives of large engineering companies. [2-49] It should not be surprising that the industry based committee strongly urged more industrial interaction in defining and directing programs. A shift from basic research to applied research was recommended. The National Laboratory funding for 1994 ( DM2.3 billion or $\$ 1.5$ billion) is divided into the following ten fields: [2.55]

Solid-state, elementary particle, \& nuclear physics $18.5 \%$

Energy research $17.0 \%$

Environmental research

Space

$11.6 \%$

Health research

$0.4 \%$

Information and communication technology

$8.1 \%$ 
Table 2.7. List of Fraunhofer Institutes.

\begin{tabular}{|c|c|}
\hline $\begin{array}{l}\text { Mleroelectronice } \\
\text { Applied Solid Siate Physics } \\
\text { Solid State Technology } \\
\text { Integrated Circuits } \\
\text { Intiggrated Circuits (Devloe Technology) } \\
\text { Microelectronic Circuits and Systems } \\
\text { Microstructural Techinglogy } \\
\text { Silicon Technology }\end{array}$ & $\begin{array}{l}\text { IAF } \\
\text { IFT } \\
\text { ISS } \\
\text { ALS } \\
\text { MSS } \\
\text { INT } \\
\text { IST }\end{array}$ \\
\hline 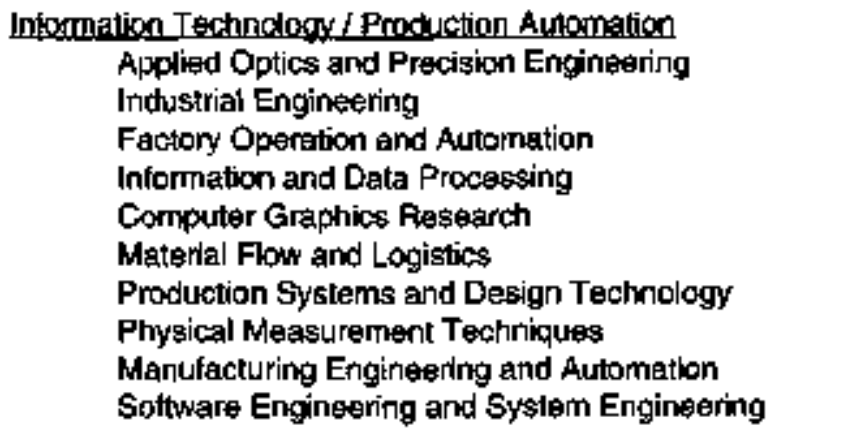 & $\begin{array}{l}\text { IOF } \\
\text { IAO } \\
\text { IFF } \\
\text { IITB } \\
\text { IGD } \\
\text { MUL } \\
\text { IPK } \\
\text { IPM } \\
\text { IPA } \\
\text { ISST }\end{array}$ \\
\hline 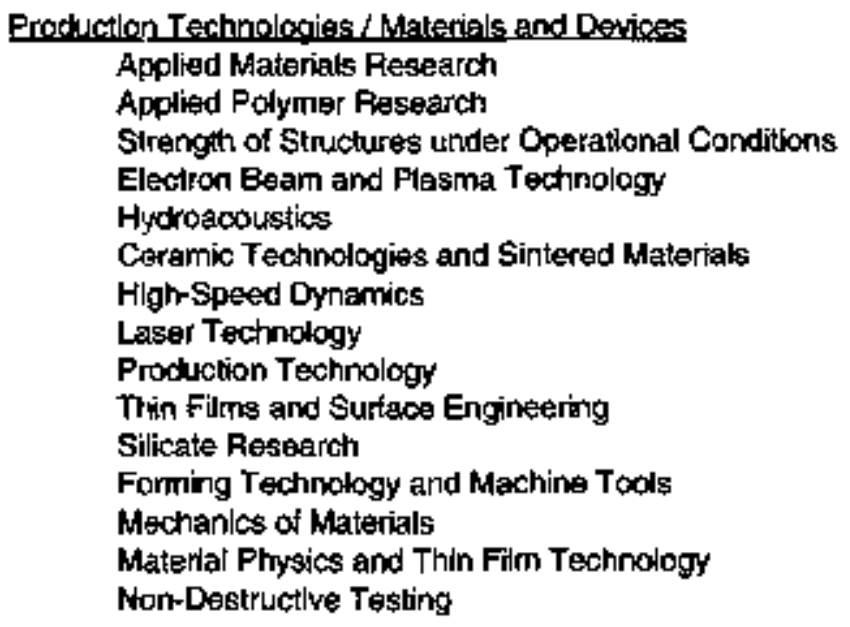 & $\begin{array}{l}\text { IfaM } \\
\text { LAP } \\
\text { LBF } \\
\text { FEP } \\
\text { FHAK } \\
\text { KTS } \\
\text { ENI } \\
\text { LT } \\
\text { IPT } \\
\text { IST } \\
\text { ISC } \\
\text { IIJW } \\
\text { WMM } \\
\text { HWS } \\
\text { IZfP }\end{array}$ \\
\hline 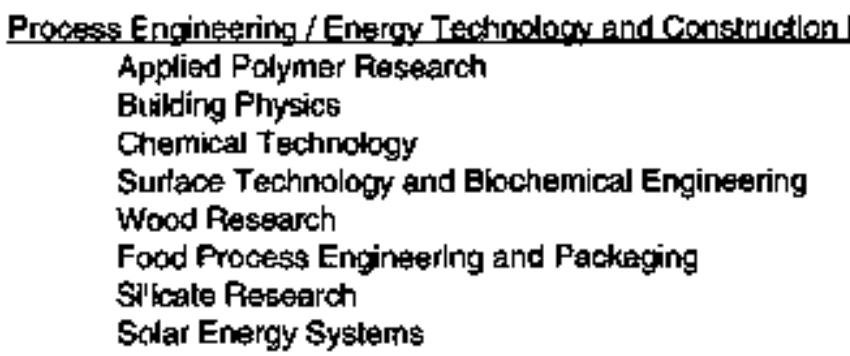 & $\begin{array}{l}\text { IAP } \\
\text { BP } \\
\text { ICT } \\
\text { ICB } \\
\text { WNI } \\
\text { ILV } \\
\text { ISC } \\
\text { LSE }\end{array}$ \\
\hline $\begin{array}{l}\text { Enylronmintal Ressarch and Healih } \\
\text { Atmospheric Enwronmentel Research } \\
\text { Blomiolical Engineering } \\
\text { Toxicology and Aerosol Research } \\
\text { Erivironmental Chemlstry and Ecotoxicology }\end{array}$ & $\begin{array}{l}\text { IFU } \\
\text { IEATT } \\
\text { ITA } \\
\text { IUCT }\end{array}$ \\
\hline $\begin{array}{l}\text { Studes and Technical Intomation } \\
\text { Technological Trend Analysis } \\
\text { Sysiems and Innovation Rieqsearch }\end{array}$ & $\begin{array}{l}\text { INT } \\
\text { ISA }\end{array}$ \\
\hline
\end{tabular}


Air and surface transportation

New materials and technologies

Geosciences

$4.9 \%$

Biotechnology

$2.8 \%$

It is indicative of the weak industrial orientation in 1994 to note that the words industrial, manufacturing and production are not used. In a doser examination of the Basic Research in Information Technology Program at the Jülich Research Center (KFA), the projects reflect a materials and device orientation with little manufacturing emphasis, and are justified based on the potential for future product innovation. [2.56] The projects include:

- Epitaxy of Si/Ge, Si/silicide structures and III-V semiconductor layer systems.

- Structuring of semiconductor layer systems.

- Supexconductor-layer systems for potential applications in quantum interferometers, high-frequency components, vortex registers, etc.

- Superconductor-seniconductor hybrid structures.

- Layer materials for magnetic and maggetic-optical information storage.

- New types of components and quantum structures.

- Crystal growth for compound semiconductors.

At the Karlsruhe Nuclear Research Center (KfK), the small project in Microsystems Technology (a project under the Information Techrologies Program) could ultimately become useful to advanced manufacturing in general. The project's stated goals include development of reliable miniaturized sensors and actuators as well as their integration into complex manufacturing systems. [2.57] This project may be largely successful due to $\mathrm{KfK}^{\prime}$ 's experience in cooperating with other institutes and industry on manufacturing R\&D. From 1984 to 1987, KfK managed Phase 1 of the Project for Manufacturing Technology. The goal of this project was to demonstrate that flexibility and productivity could be simultaneously erthanced by applying advanced manufacturing technologies. [2.22] After 1987, project emphasis switched from developing flexible manufacturing systems to installation of CAD/CAM systems as $74.2 \%$ of the funding was devoted to installing hardware, $12.3 \%$ on personnel, $5.5 \%$ on consultations, only $3.7 \%$ on R\&D, and $3.7 \%$ on training. [2.57] The demonstration laboratory and availability of training and advice resembles to some degree elements of the U.S. Mantech Program of the same time period. Phase 1 was successful in installing Computer Integrated Manufacturing (CIM) capabilities in SMEs involved in the machinery building industries. By 1989, a total of $\sim$ DM300 million ( $\$ 160$ million) had been approved for this purpose. [2.58] Between 1989 to 1991, similar efforts were extended to SMEs in 
eastern Germany due to a "pressing need" to modernize production processes. From 1988 to 1992, the project was expanded to include the Bremen Institute of Industrial Engineering and Applied Ergonomics (BIBA) where efforts were made to speed up the transfer of CIM research developments to SMEs. [2.59] In 1990, 90\% of the firms receiving support had fewer than 1000 employees, exported $60 \%$ of their production, and specifically produced key engineering equipment for industry. [2.58] Between 1992-1995, an additional DM100 million is being spent in the CIM program.

Another BMFt program designed specifically to boost the competitiveness of German SMEs is the 1992-1996 Quality Assurance Program. The relatively large level of support totals DM350 milion (\$210 million), which includes basic research support for development of methodology of only $\sim$ DM7 million ( $\$ 4.5$ milion). [2.60] Again, this program is designed for technology transfer from German institutes to SMEs. A thircl advanced manufacturing project scheduled from 1993 to 1996 involves the technology transfer of advanced surface treatment and coating technologies, again formulated specifically towards improving the capabilities of SMEs. Phase 1 of the program emphasized research of surface analy:sis and coating process development (with total public funding of DM135 million, $\rightarrow 80$ million). Phase 2 is designed to promote surface treatment and new coating technologies in specific applications related to the production of manufacturing equipment (i.e, machine tools), large surface area applications, or coating ceramics and plastics (with total public funding of DM150 million, $\rightarrow \$ 90$ million). [2.59] A toutth BMFT advanced manufacturing technology project sponsors neurocomputing for integration of manufacturing processes into a flexible system. The funding level through 1995 is approximately DM50 million (\$32 million). The emphasis is on applications for factory automation to control industrial robots during manufacturing processes. [2.59] German institutes are involved in the MITI-led Real World Computing (RWC) program related to this technology. A small but promising advanced manufacturing project is sponsored by the Federal Ministry of Education at the Technical University of Clausthal and the University of Hannover. The investigators seek to define the basic principtes controlling the shaping and joining of thin sheet steel from a production engineering per'spective. [2.61] Two other projects are scheduled to continue. The Laser 2000 project supports development of various uses of lasers in manufacturing (for example, surface modification). Development of materials for oroduction engineering under the separate New Materials for Key Technologies Program will attempt to improve the service life of materials used in tools and machine parts.

One of the reasons that production engineering was not a stand alone program for several years was that the BMFT supported discrete but 
related efforts in manufacturing production under the European Union programs at relatively modest funding levels. During the eariy 1990 s, these projects emphasized process automation for five pervasive problems:

- Sheet metal forming (as pointed out above).

- Massive forming (requiring large, controlled deformation of materials).

- High precision machining.

- Fiber composite forming.

- Processing of high performance ceramics.

The European Union programs in which German institutes, universities, and companies participate with small levels of BMFT support on the above five problems included the EUREKA- subprogram FAMOS (flexible automated assembly line systems) which has evolved to contribute mostly to European standards in consumer electronics; ESPRIT II which has concentrated on CDM and CIME technology exchange; and the BRITE/EURAM program which was established to support research in advanced materials, especially sutface modification, materials joiruing, and forming processes. [2.56] The effort is well planned from a technological standpoint. However, the problem arises that in the production engineering area, a large portion of the funding must come from industry. In this situation, little new technology is actually developed and shared with competitors even if they are within the EU. Most of the effort is spent exantining availabile technologies and applying them to specific problems. Again, the effort has evolved to center on applying existing advanced manufacturing technologies to specific needs rather than developing bassic manufacturing technologies. These EU manufacturing R\&D programs are not effective as currently administered. [2,62]

A new BMFT program initiative, Production 2000, will be announced in 1995. [2.60] The impetus for this initiative is continuing complaints by German industry that the existing BMFT and EU programs are not effective in helping to enhance manufacturing competitiveness. It is expected that the new initiative will be based on industrial recommendations. Funding is projected to be DM100 million ( $-\$ 60$ million) annually. [2.63] Although the initial activities are termed "New Manufacturing Technologies," the low funding level and the appearance of significant management and organizational studies indicates that the focus is not innovation in basic machine and materials technologies specifically for advanced manufacturing. [2.60] The initiative is likely to evolve into a rallying effort to encourage change in SMEs. 
Eleven initial priority measures [2.60] have been identified as follows:

1. German Firms' Strategies for the Future in an Increasingly Rapidly Changing World: "to improve German industry's strategies for the future against the background of an increasingly rapidly changing business world. Experience, problems, and know-how and concepts derived from industrial practice and various scientific disciplines will be brought together and pooled in a joint brainstorming and consultation process." [2.60]

2. Joint Networking Models for SME Structures: to encourage interaction between companies on employee training, company organization, production technology, and products.

3. Cyclic Economy: to develop automated dismantling and sorting systems for recycling materials.

4. Systematic Selection Criteria for Composite Materials: to set criteria for ecological requirements in selecting which materials to use.

5. Dynamic Production and Organizational Structures in a FastMoving Market: to examine corporate business practices, coordination, and involvement of employees in planning, decision-making, and implementation processes for decentralizing corporate units.

6. Integrated Product/Process Models: to develop a tool for universal process planning to improve efficiency, quality, reliability, and cost planring.

7. Quasi-finished Casting Taking the Crankshaft as an Example: to improve neax final shape forming in steel casting "considering the overall process chain from the technological, economic, and sociological points of view." [2.60]

8. Method for Producing Complex Broadband Communications Assemblies using Housed Micro- and Optoelectronic Components and Multichip Modules: to examine unsolved problems with series motunting, wining, and testing processes.

9. Dry Processing: to use machine tools without cooling lubricants as lubricants " represent a health hazard and are difficult to dispose of in conditions of economic viability." $[2,60]$

10. Method for Fabricating Passive Optical Components: to develop fabrication for polymer fiber networks.

11. Development of Universally Compatible Modules for UserOriented Open Control Architecture Operation: to standardize adaptable machine control systems.

These projects are all likely to support manufacturing. However, the underlying message is the absence of a concerted German research 
program in advanced manufacturing technology. The proposed priority projects are ad hoc in nature and those few which are technically based appear to be in response to special interests. The program as described will not promote manufacturing competitiveness on a national level and thus is doomed to decreasing government interest and an unwillingness by industry to match funding. This situation would change dramatically if Japan or the U.S. were to develop serious advanced manufacturing technology programs.

\subsubsection{JAPAN}

\subsubsection{Goals}

The major goal of Japanese $R \& D$ initiatives is changing. There is continuing interest in promoting global competitiveness by Japanese manufacturers. However, the effects of the present recession are not reversible and the new business environment will remain. [2,64] As a result, the Japanese government is being driven to modify R\&D initjatives by the growing public interest in domestic and personal consumption. Modification of the Japanese industrial policy is reflecting these changes. The interdisciplinary nature of R\&D and the international exchange of researchers are the new Japanese mottos of the 1990s. This is viewed as an outgrowth of the successful MITI-sponsored industrial consortia of the 1970 s and 1980s. The new R\&D "Technoglobalism" being promoted by Japanese government ministries as well as business leaders seeks full and open international cooperation on science and technology R\&D to benefit all of mankind. [2.65] It is indicative of the continuing importance of manufacturing that the fore-runner program being pushed internationalty by MTT is IMS, the Intelligent Manufacturing Systems project.

Until the late 1980s, Japart's government emphasized the export of manufactured products as the major contributor to economic growth and prosperity. This was in response to the historic recognition of the nation's dependence on imported raw materials. Large manufacturing industries have been responsible for setting directions and performing viable product and process technology $R \& D$. The strong relationship between politicians, bureaucrats, and business leaders (often neferred to as the "iron triangle") hejped to meet the long-term interests of all three groups while the Liberal Democratic Party (LDP) remained in power for decades. The government's main role was to protect and stabilize mass-production markets. [2.22] In recent decades, the Japanese govemment has played a limited role in directing $R \& D$. As a recent U.S. Department of Commerce publication noted: "International technical experts generally agree that none of the national $\mathrm{R} \& \mathrm{D}$ programs achieved momentous breakthroughs in state-of-the-art technology, but program expenditures and subsidies allowed companies to commit to long-term development of vital 
technologies, boosted technological capabilities of firms across an array of industries, and increased the country's competitiveness." [2.66] A]though the inajor contributions of the government ministrics to marsufacturing were not specifically in $R \& D$, the strategies of the ministries have had a dramatic impact on manufacturing competitiveness and the philosophy of Japanese corporate R\&D. Often these strategies were initially proposed by industrial leaders.

In an effort to protect domestic interests in large manufacturing companies, Japanese industrial policy has emphasized cheap loans, net transfers (i.e., explicit subsidies), trade protection, and substantial tax retief measures. The curious point is that in distributing these incentives, Japanese policy-makers did not pick winners. In fact, it has been shown that most support has been given to "slow-growth" industries. [2.67] In looking at the combined efforts, one could conclude that Japan's "policy was a mess," unless government efforts were not directed at picking wirners at all. Until the late 1980s, government industrial policy attempted to "ease the pain associated with eliminating excess production capacity in declining industries." [2.68] R\&D in large Japanese corporations is of two types: R\&D related directly to the existing product sector designed to keep current products competitive; and R\&D outside the principle joroduct sector directed toward creating new industries. [2.69] This has been termed "internal corporate venturing" as new industries are usually built within existing corporations and not as small start-up businesses. [2.69] The tremendous support given to declining industries, then, is to aid in technological diversification.

Diversification is seen by the adaptable Japanese as the main survival strategy in a competitive marketplace. From the infrastructure built due to this survival strategy, the Japanese strength in "technology fusion" has grown. Technology fusion refers to appropriate combinations of diverse groups of existing technologies. As Fumio Kodama" has stated: "In the high-tech era, the key issue of technology strategy has becone not how to break through technological bottienecks but how to put existing technology to the best possible use ..." [2.4] Because of the different emphasis placed on technology development, Kodama concludes that corporate $R \& D$ also has a different emphasis. Three basic principles guide corporate $\mathrm{R} \& D$. First, the market or customer drives the R\&D agenda, "not what the technologist has produced in the Jab." [2.4] Secondly, a tremendous surveillance effort is made to identify existing usable irnovations both inside and outside of the corporation. MII estimates that "during the 1960s and 1970s, Japanese manufacturers devoted over one-quarter of all their R\&D investments to 'digesting' imported techunologies." [2.4] Third, technology fusion is encouraged by long-tem interdisciplinary efforts and may include several companies.

The Japanese government began major programs that sponsored basic $R \& D$ projects oriented towards high technology products in 1981 for two 
reasons. First, the Japanese government became sensitive to a need to encourage creativity. [2.70] Second, funding basic R\&D is an attempt to ward off criticism from trading partmers (especially Germany and the U.S.) that Japanese companies were only applying inventions and technologies developed elsewhere. From 1981 to 1991, eighteen projects were started in a program on basic technologies for future industries. [2.71] The government-sponsored, product-oriented, basic R\&D is performed by universities, public institutes, technology extension centers, private nonprofit institutions, and to a diminishing extent by industry.

The JFY94 budget indjcates the importance placed on government sponsorship of industrial R\&D: $46.7 \%$ of the total S\&T budget is dedicated to the Ministry of Education, Science, and Culture (Monbusho), $25.7 \%$ to the Science and Technology Agency (STA), and only $12 \%$ to the Ministry of International Trade and Industry. [2.72] There are other indications that the impact of MITI's programs on manufacturing R\&D will continue to be minimal. As competition between large Japanese companies increases, $\mathrm{R} \& \mathrm{D}$ independence in developing processing methods is becoming more desirable. Although it appears that the distinction between basic science and application is becoming blurred, in reality MITI R\&D programs are dropping application and following those of the STA toward a high-risk, "pre-competitive," basic science orientation. [2.73]

MITI has once again reorganized. The New Energy and Industrial Technology Development Organization (NEDO) contracts project research out mainly to companies and universities. The Agency of Industrial Science and Technology (AIST - an organizational arm of MTTI) opened a new National Institute for Advanced lnterdisciplinary Research (NAIR) in 1993. The laboratory is chartered to promote point basic research between government, industry, and academia; the research is to be of an interdisciplinary nature; and the laboratory is to encourage international exchange of researchers. [2.74] The new Director has stated that the "mission of Japanese national laboratories serving as a window through which to introduce foreign technologies has successfully been accomplished." [2.75] AIST defined the mission of basic research slightly differently as "aimed at raising the standard of living in Japan to that of other advanced countries... a 5-year plan was enacted in June to have the standard of living in Japan match that of the major powers in the world in terms of building an economy in which people experience a real sense of being rewarded for their work. This has been the result of both reexamining the mass-production, consumer-oriented society that Japan has created, and, together with that, recognizing the importance of

\footnotetext{
6 Fumio Kadama is a woll-respocted voice in Japanese policy and won the 1991 Yoshino Prize (Japan's highest award for books in history and the social sciences] for hls book Analyzing Japanese High Technology.
} 
establishing a foundation of growth built on a harmonious relationship between the environment and society." [2.74] As the govermment continues to refocus public interest from export market domination to societal concerns, manufacturing companies will be greatly impacted.

\subsubsection{Interactions}

Japanese public-private research consortia have developed as a government policy tool specifically to diffuse technology to industry. This is different from U.S. policy (and related consortia), which has typically sought innovation. [2.76] As Japanese policy evolves to respond less to international competitiveness and more to domestic and environmental issues, government support in industrial research consortia will probably play a less critical role. The Japanese consortia appear to be natural successors to "zaibatsu": confederations of many large firms coordinated by finance companies, which dominated large-scale manufacturing in the $1960 \mathrm{~s}$ and 1970s. Trade associations, professional societies, and national laboratories are involved with the consortia to increase the technology diffusion. MITI-sponsored national institutes, in particular, provide benchmarking and technology evaluation. Gerald Hane stressed the urique strategy of Japanese consortia in the following: "Diffusion (of information) occurs at the start of a project when firms are standardizing evaluation methods and gathering information about the international state of the art; it occurs through the national laboratories in the evaluation of progress; and it occurs during science projects in which basic $R \& D$ is undertaken and commercial appropriation is uncertain. Still, it is procompetitive coordination, not precompetitive cooperation, that is the organizing strategy." [2.77]

The distinction between precompetitive and procompetitive is important. Precompetitive R\&D involves emerging technologies at a point prior to when competitive interests in the technologies have been defined. The technologies may be so far from application that companies are willing to cooperate on R\&D. To organize a consortium based on precompetitive R\&D, the parties involved must "pick winners." With procompetitive $\mathrm{R} \& \mathrm{D}$, the argument is made that the consortia actually promote competition between comparies to speed application of R\&D. [2.77] MITI has often suggested the formation of consortia. The Ministry's role is both instigator and mediator of public-private research consortia. Due to subsidies and incentives at its disposal, MITI has been able to convince key companies to participate. The integration and operation of cortiortia is typically plarined and executed by MTTL. Largely due to MITI, the Japanese research consortia have been successful in diffusion of technology. The question of if and how the consortia helped the key members that; needed convincing to participate has not been answered.

There is an increasing trend for Japanese small- and medium-sized enterprises (SMEs) to manufacture and market products independently of 
large corporations. Local technology centers, "kohsetsushi," are likely to become more important as this independence grows. Although large corporations dominate manufacturing $R \& D$, the overall competitiveness of Japanese manufacturing is also dependent on the efficiency of small supplier enterprises. In the now famous Keiretsu organizations, smail supplier companies were often dependent on large compantes for general technology and training support. [2.78] In some cases a small company became highly specialized in a particular product and manutacturing activity so that the large, diverse companies also could gain specialized training and technology information from the small company. This private technology exchange and the accompanying customer demands are probably of major impact on SME capabilities in manufacturing.

Kohsetsushi are funded largely by local governments and fees. Only 10$20 \%$ of kohsetsushi budgets are funded by the federal government. [2.79] The local funding has resulted in centers that have concentrated on providing specialized services for local manufacturers. [2.79] The activities of each center may be very different. The overall goal of all industrial centers, however, is to transfer information to SMEs so that the level of technology and productivity in rural manufacturing companies can be up-graded to the standards set by highly industrialized metropolitan areas. [2.80] The effectiveness of these centers appears to vary widely. The first centers opened in the $1920 \mathrm{~s}$, and the technologies used by SMEs in rural areas are still reputedly not at the standards desirable. [2.80] The services these centers provide range through installation of $\mathrm{CNC}^{7}$ machines, training, and technical jibrary access. In retrospect, these types of services are often private business opportunities for companies and consultants in the U.S. The technologies that the kohsetsushi provide appear to be proven and highly developed. [2.80] They are not necessarily cutting edge or innovative. Therefore, there is minimal risk for the small company associated with putting these technologies in place, and any advantage can be rapidly assessed. In conjunction, favorable loans, credit guarantees, tax incentives for capital investment, and equipment leasing programs are available specifically for SMEs. [2.79]

Many programs were started in the $1980 \mathrm{~s}$ by Monbusho, MITI, and STA to encourage interactions between research groups in both universities and institutes with industry. [2.81] The current interactions on research are not meeting expectations. The AIST organized the Conference on Technical Cooperation of Industry and Academics to provide a forum for discussing improvements. The resulting recommendation was a call for increased federal funding for uriversity research. [2.82] As was shown in

\footnotetext{
7 Computer Numericaly Controlled machinee (CNC machines) are an example of a modem manufacturing technology that provides flexlbility in machining for small companies.
} 
Figure 2,3, however, the percentage of $R \& D$ budget performed at universities is essentially equivalent to that of Germany and the U.S. Industry is beginning to look more towards universities and institutes for basic research. As the Chaiman of Mitsubishi Heavy Industries recently stated: "We (industry) can spend our own money for the kird of research which will make us a winner in business competitions but we simply don't have the money reserved for basic research. ... In onder to remove the stigma attached to Japan as a copycat, our universities must do their utmost in the field of basic nesearch." [2.82] Universities will continue to gradually increase cooperative activities as new taculty are hired, more engineer's and scientists seek advanced degrees, and successful research interactions attract attention. The research links between universities and national research institutes are similarly weak and mostly result in providing graduate students access to laboratory facilities. In the last few years, formal partnershups between specific universities and national laboratories were designated for PhD programs. [2.81] Over a period of time, these tics are likely to result in improved researth interactions. Both MITI and STA institutes are active in basic research. It is interesting that when a recent STA survey asked 88 Japanese government labs "does your organization consider the technology transfer from government labs to industry an important responsibility?" only $22 \%$ responded "yes." [2.83]

The ground work for encouraging government efforts in industrial policy to pursue internationalization of R\&D efforts ("technoglobalization") was laid in the mid-1980s. At that time, industrial leaders forming commissions were encouraging the government to deregulate the Japanese economy to resemble those of the U.S. and Europe. [2.84] Concurrently, Japanese corporations were escalating direct overseas investment and the formation of multinational corporations. [2.84] The labyrinth of multinational agreements in the automobile industry (as shown in Figrre 2.7) is a prime example of international interactions in manufacturing that transcend government involventent. With increasing science research required to compete in advanced technology product markets, the thrust appears to be to follow the trend of industrial globalization across international boundaries with globalization of research, especially in technologies of concem to industry.

Since that time, overseas production has become increasingly important to Japanese industrial competitiveness. Japan's total investment overseas reached $\$ 67.5$ billion for 1989 . After several years of reduced investment, an increasing trend again started in 1993 that is expected to continue as production is moved outside of Japan. [2.85] Such investment related to the manufacturing sector has been beneficial in the U.S. as the influx of Japarese investment in the $1980 \mathrm{~s}$ engendered modemization of plants, and business for suppliers who "assisted" this transition. [2.86] It is suggested that few domestically-owned U.S. companies that were competitive have been sold. In fact, the 1992 JETRO survey points out that half of the Japanese-affiliated manufacturers in the U.S. reported losses. 


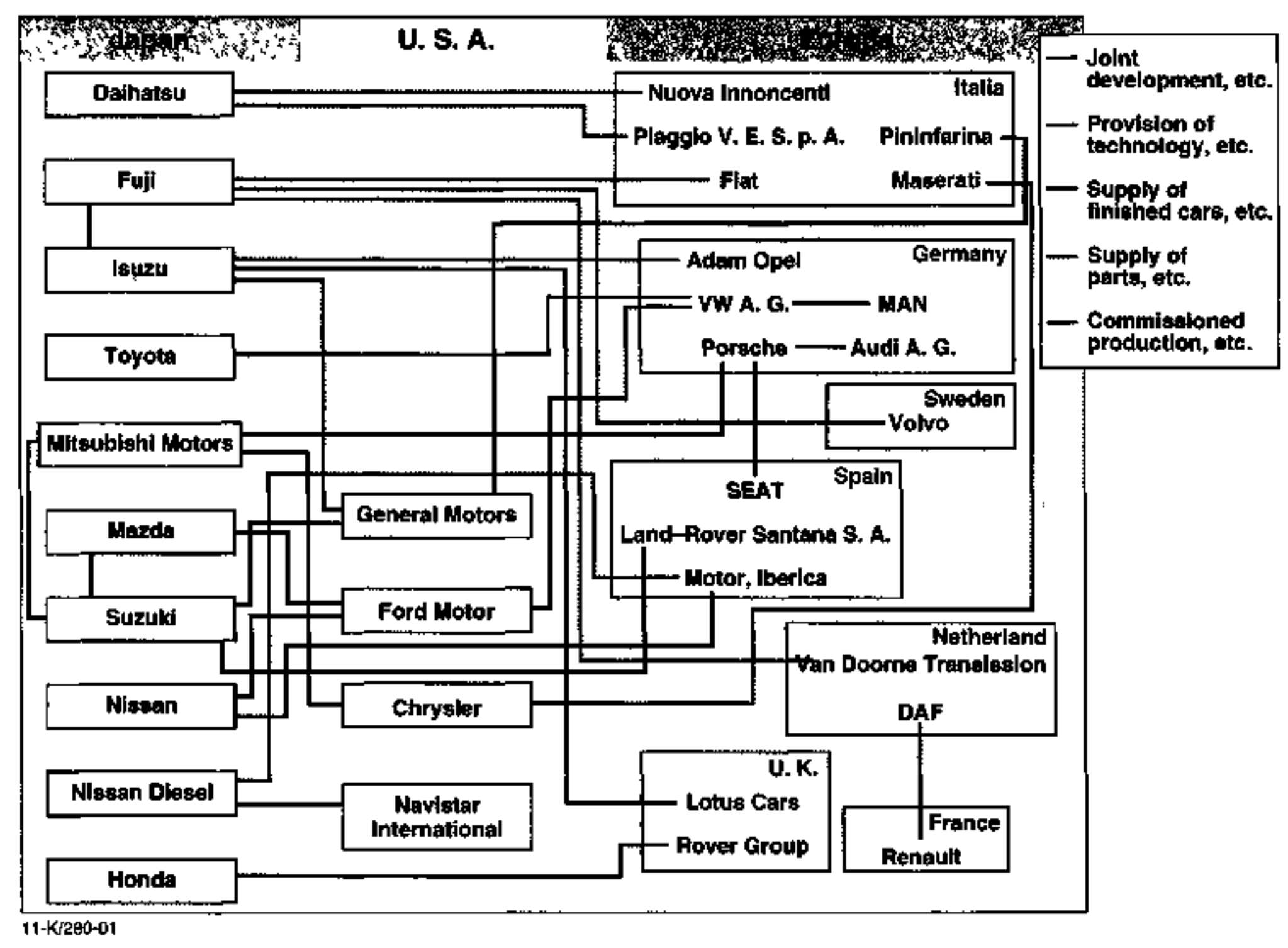

Figure 2.7. Technology-related cooperation among Japan, the U. $S$. and Europe in the automotive industry. Compiled by AlST, Technology Research and Information Division from "Automobile Industry in Japan" (Japan Automotive \& Manufacturexs Association, Inc.). 
[2.87] The 1990s have brought a decreasing trend in such investrients by japanese corporations in high-wage countries. This is not expected to be reversed. R\&D-related facilities, however, show a different trend. Perhaps first gaining support by Japanese corporations involved in international production and marketing to help adapt products to local markets, such facilities are now observed to be operating more independently in developing products. [2.88]

Japanese corporations are strong stupporters of foreign university research as research can be leveraged from ongoing programs paid largely by domestic governments. [2.89] Some large Japanese industries are offering one-year contracts to koreign researchers. International research interactions have been so successful for Japanese industry that MITI has engaged in a multitude of special programs that encourage foreign researchers to participate at national institutes. [2.90] There are intergovernment agreements that establish frameworks for cooperative relations in the development of techrology that lead to agency-agency technology interactions at the federal level. ${ }^{8}$ Furthering the advance of technoglobalism, U.S. firms are encouraged to join MITI research consortia. [2.91] There have been long-term, serious efforts by MITI to establish centers in countries performing $R \& D$ that transfer a variety of information, from status of technology support in the U.S. [2.92] to promoting industrial trade and techrology cooperation in Russia and Central-Eastem Europe. [2.93] It is chear that the most visible effort by MITI in the evolving Japanese industrial policy is to emphasize technoglobalism.

\subsubsection{Programs}

Japanese government-sponsored R\&D programs are charging focus. Programs that are now developing emphasize basic science research, precompetitive technologies, and industrial products with potential application much further in the future. The emphasis and structure of these research programs does not support $R \& D$ on basic manufacturing technologies. Although there is some chance that linited manufacturing techniques may be advanced by pursuing development of specific industrial produsts, serious development of manufacturing technology will be completely dependent on Japanese industry initiatives and foreign sources. Historically, major programs tended to sponsor areas of identified technological weakness. The results of those programs were applicationoriented with expected near-term use designed to boost competitiveness of particular industrial sectors.

A good outline of Japanese government-5ponsored R\&D programs is available. [2.66] The six major science and technology programs that may influence advanced manufacturing competitiveness in the future are coordinated by the Science and Technology Agency (STA) or the Ministry

${ }^{8}$ See, for example, reference [2.85]. 
of International Trade and Industry (MTT). The STA sponsors two of these programs. The Special Coordination Funds for Promoting Science and Technology is a grant program with a total budget of $-\$ 1$ billion in 1993. The grants sponsor basic science research, newly formed centers of excellence in science, and international workshops tor exchange of research information. The Exploratory Research for Advanced Technology Program (ERATO) is much smaller at $\sim \$ 50$ million in 1993. The "open-ended" research projects sponsored through ERATO jnvolve precompetitive technologies and tend to last five years. [2.94] The results of these programs are expected to have little noticeable effect on manufacturing competitiveness. MITI restructured and combined programs in 1993 to form the Industrial Science and Technology Frontier Program (ISTF) which appears to be very similar to the ERATO program. [2.95] The ISTF program was funded at $-\$ 200$ million in 1993 and the AIST National Laboratories played a major role in the research. Projects are typically funded for ten years. Although MITI represents the program as basic research in industrial technologies, the emphasis clearly continues to be placed on new materials, biotechnology (especially involving gene rearrangement), and "new function elements" for information technologies. [2.96] The orientation appears to be toward developing the basic science which may be used in future new products. The stated goal is to improve human welfare and quality of life.

The remaining three major research programs are also sponsored by MITI and will have greater impact on manufacturing. The New Surshine Project receives $-\$ 1$ billion per year and will continue through the year 2000 . The goals of the project include developing environmental technologies to reduce production and emission of greenhouse gases, and to supply products using these technologies to other countries in the Asian Rim. The New Sunshine Project results will have little effect on advanced manufacturing competitiveness but will probably help manufacturers to meet new constraints and regulations on environmental emissions. The Real World Computer System Project (RWC) and the Intelligent Manufacturing Systems Project (IMS) were designed by MITI for international research cooperation specifically with technologically advanced nations. The main goal of the RWC program is to extend artificial intelligence via neural networks to the point where a system could gather information and make complex decisions. [2.97] The, RWC is funded at $-\$ 50$ million per year for ten years and presently includes participating research institutes in Germany, Sweden, and Singapore. The fruition of this sort of information processing on a ten year horizon is judged to be critical for next-generation intelligent machines.

The stated goal of the IMS project is to improve the global competitiveness of manufacturing by sharing technology innovation costs and risks. There is also a drive to encourage standardization in the use of various technologies throughout manufacturing. The IMS project was introduced in 1989 and will become "full-scale" in 1995 after several compromises have been made, especially regarding intellectual property 
rights. [2.98] The project was funded by MITI at $-\$ 8.5$ million in 1993 although the full-scale program is slated at $\$ 1$ billion for ten years. Several feasibility studies were run between 1992 and 1994. As listed in Table 2.8, the topics of these studies range from clean marufacturing in the chemical industry to rapid prototyping. [2.99] The precedent of various projects with different themes and participants is likely to continue. Each study had many international partners from universities, institutes, and corporations. Participants were from Japan, Germany, the U.S., France, Canada, Australia, Finland, Switzerland, the U.K., Italy, and the Netherlands. Detailed discussions of the program status and philosophy are available. [2.100], [2.101]

Table 2.8. List of IMS Technical Themes and Test Studies. [294]

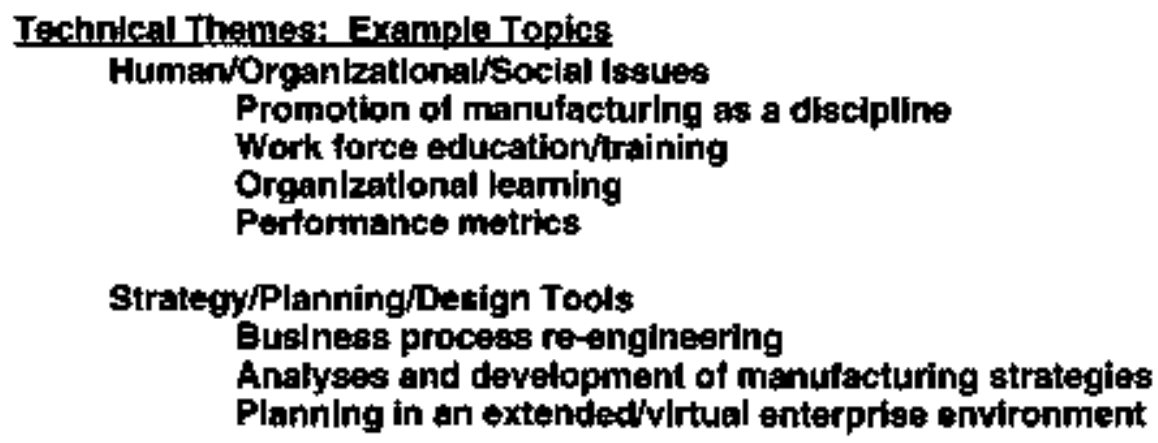

Total Product Lufe Cycle

Models for future manufacturing systems

Environmental protection

Network systems for informatlon processes

Economic models

Virtualifextended Enterpriae lesues Information exchange across the extended enterprise Team work

Archltecture for support of angineering cooperation Assignment of cost, risk, and rewards

\section{Iechnlcal Tegt, Situdie:}

Cloan Manufacturing in Procoss Industrios

Concurrert Engineering for Global Manufacturing

Globeman 21: Enterprise Integration

Hołonic Manufacturing Systems

Rapid Product Development

Gnosis: Systemization of Knowledge 
The IMS Program can be viewed as an experiment in international cooperation on technology development which if properly implemented, might give a participating manufacturing company a competitive edge. It is difficult to predict how successful such a program will be in furthering technology development for any one participant. Perhaps understanding the level of sophistication of the advanced technologies (i.e., the capabilities of a competitor) is the most important gain in itself. This is the same gain that spurred Japanese companies to compete through MITI-sponsored procompetitive consortia in the 1980s. It is clear, however, that an open exchange of information on technologies will place less emphasis on technology development for competitiveness and more importance on effective and strategic implementation. In this environment, advanced technology development in itself is no longer an effective competitiveness goal. This is precisely the environment in which Japarese manufacturing companies can be most effective. It will be instnuctive to follow the progress of the $\mathrm{MS}$ project over the next years. 


\subsection{References}

[2.1] Industrial Policy in OECD Countries: Annual Review 1991. Organization for Economic Cooperation and Development, Paris: p. 123.

[2.2] Industrial Structure Statistics: 1992. Organization for Economic Cooperation and Development, Paris.

12.3] Akjo Morita, Renewing the globat free-market frawework. Japan Echo 20(2) Summer 1993: p. 48-54.

[2.4] Funtio Kodama, Technology fusion and the new R\&D. Harvard Business Review, July-August 1992: p. 70-78.

[2.5] Science and Technology Indicators. NSB 93-1, National Science Foundation, Washington, D.C. 1993.

[2.6] Michael K. Wolff, Where we stand. Bantam Books, NY: 1992.

[2.7] Selected characteristics of manufacturing establishments that export: 1987. Analytical Report Series AR87-2, U.S. Department of Commerce, Washington, D.C.

[2.8] Paul $R$ Krugman and Robert Z. Lawrence, Trade, jobs, and aages. Scientific American, April 1994: p. 44-49.

[2.9] James K. Jackson, Effects of trade on U.S. jobs and wages. CRS Report for Congress 94-69E, Congressional Research Service, The Library of Congress, Washington, DC: January 28, 1994.

[2.10] Milton Friedman, Why Government is the Problem. Hoover Institution Press, Stanford, CA: 1993.

[2.11] Michael E. Porter, The Comperitive Advantage of Nations. The Free Press, New York: 1990.

[2.12] Therese Eiben, U.S. exporters keep on rolling. Fortune, June 14, 1993: p. 130-131.

[2.13] Frank M. Kastelic, Exporting is Easy. Manuf. Eng. August 1993: p. 104.

[2.14] David J. Cantor, Import penetration of selected U.S. markets for manufactured products: 1975 and 1989. CRS Report for Congress 92-301E, Congressionfl Research Service, The Library of Congress, Washington, DC: March 23, 1992.

[2.15] Main Science and Technology Indicators: 1993. Orgaruzation for Economic Cooperation and Development, Paris.

[2.16] Science and Engineering Indicators: 1993. Appendix table 4-39, National Science Foundation, Washington, D.C. 
[2.17] Japanese R\&D funding suffering real cutbacks. NTIS Alert, 94(5), 1994: p. xvii.

[2.18] RED spending update. Res. Tech. Man., December 1993: p. 6.

[2.19] Edward B. Roberts, Strategic management of technology: global benchmarks. PA Consulting Group, Cambridge, MA, December 10, 1992.

[2.20] U.S. RED may need a shot in the arm. Manuf. Eng, April 1993: p. $26-30$.

[2.21] 'Radical rethinking' needed for competitiventess. FBIS / Europe Economic Review, 2(40), September 23, 1993.

[2,22] Michael J. Piore and Charles F. Sabel, The Second Industrial Drvide. Basic Books, Inc., NY: 1984.

[2.23] James Fallows, How the world works. Atlantic Monthly, December 1993: p. 60-87.

[2.24] Germany's patent medicine. The Economist, November 20, 1993: p. $73-74$.

[2.25] German industry asks Bonn to rethink policies as critics coll technology too costly, too late. Res. Tech. Man., September/October 1993: p. 2-3.

[2.26] German leaders differ on reforms for large research institutes. Science \& Technology / Europe-Intemational, JPRS-EST-93-041, December 16, 1993: p. 22.

[2.27] Research ministry policies criticized by German Chamber of Commence. NTIS Alert, 94(5), March 1, 1994: p. xv.

[2.28] Country seen lagging in industrial innowation. FBIS / Westem Europe, 3(16), April 21, 1994.

[2.29] Riesenhuber presents BMFT 1992 Budget. Tech Concatenated Database/ Berlin, Ing. Digest, October, 1991.

[2.30] Germany: BMFT funds RED in SME firmts. Science \& Technology / Europe-Enternational, JPRS-EST-93-038, November 29, 1993: p. 1.

[2.31] Werner Meske, The restructuring of the east German research system- a provistonal approach. Science and Public Policy, 20(5), October 1993: $\mathrm{p}$. 298-312.

[2.32] Christian Patermann, The German case. Understanding Government R\&D Investintent, Washington, D.C., June 2, 1994.

[2.33| Jonathan B. Tucker, Science and technology in a united Germany. Issues in Sci. and Tech., Winter 1990-91: p. 74-81.

[2.34] Feature: problems with automobile indusfy competitioeness. FBIS / Foreign Media Note, FB PN 93-379, September 15, 1993. 
[2.35] Germany: Research minister calls for more RED innoution. Science \& Technology / Europe-Interrational, JPRS-EST-93-038, November 29, 1993.

[2.36] Race bourards practical application of silicon optoelectronic components. Stride: Science and Technology in Gemany, R 141631Z: December 1993.

[2.37] FRG: politicians, industrialists view problems in innoontion. Science \& Technology / Europe-Intemational, JPRS-EST-93-041, December 16, 1993 : p. 25.

[2.38] John R. Blau, GeThany's non-profit RED groups boost private sector manufacturing as slowdown looms. Res. Tech. Man., January/February 1993: p. 2-3.

[2.39] Jobst Conrad, Reflections on science and technology policy advice to government in Germany. Science and Public Policy, 20(2) 1993: p. 97-104.

[2.40] Germany: SPD Opposes Juelich Nuclear Research Center Budget Cuts. Science \& Technology / Europe-International, JPRS-EST-93-041,

December 16, 1993: p. 10.

[2.41] John Blau, German-Russian science cooperation increasing, Res. Tech. Man., July/August 1993: p. 3-4.

[2.42] Dusseldorf HANDELSBLATT, March 11, 1991: p. 1.

[2.43] U.S. firms' access to Cerman RED programs. NTIS Alert 94(21), November 1, 1994: p. i.

[2.44] EC's Ruberti calls for agreement on research program. Science \& Technology / Europe-International, JPRS-EST-93-038, November 29, 1993: p. 5.

[2.45] Germany: pharmaceutical indusiry takes research abroad, Science \& Technology / Europe-Intemational, JPRS-EST-93-041, December 16, 1993: p. 7.

[2.46] Manuel G. Serapio, Jr. \& Donald H. Dalton, Foreign RED facilities in the U.S., Res. Tech. Man., November/December 1993: p. 33-39.

[2.47] Klaus Brockhoff \& Alexander von Boehmer, Global R\&D activities of German industrial firms. J. Sci. Indust. Res., 52, 1993: p. $399-406$.

[2.48] Science Council a cornerstone of German S\&T planning. NTIS Alext 93(16), August 15, 1993: p. xiii.

[2.49] Recent SET Developments in Germany: Controversy ooer future mission of German National Laboratories. NTIS Alert 94(20), October 15, 1994:

p. xvii.

[2.50] Germany's Federal Research Minister Kruger's first year in office. NTIS Alert 94(14), July 15, 1994: p. ix. 
[2.51] Feature: Problems with automobile industry competitiveness. FBIS / Foreign Media Note, FB PN 93-379, September 15, 1993.

[2.52] Germant national research labs fuce significant changes. NTIS Alert 93(15), August 1, 1993: p. iit-iv.

[2.53] The National Laboratories of the Lnited Kingdom, France, and Gerntany in Transifion: Implications for the Department of Energy Laboratory System. Federal Research Division, Library of Congress, Washington, D.C.: July 1994.

[2.54] Germany: Controversial report on large research institutes. Science technology / Europe-International, JPRS-EST-94-015, June 30, 1994: p. 15.

[2.55] German national Laboratories turn leaner and greener. NTIS Alert 94(13), July 1, 1994: p. i.

[2.56] Major research establishments. Science \& Technology/ EuropeInternational, JPRS-EST-93-040, December 1, 1993: p. 38.

[2.57] John Bessant and Howard Rush, Gotermment stipport of monufacturing innovations: two country-leuel case studies. IEEE Trans. Eng. Man., 40(1), 1993; p. 79-91.

[2.58] New Manufacturing Technologies. Science and Technology / Europe, JPRS-EST-94-019, August 18, 1994: p. 65-66.

[2.59] Junko $A_{+}$Japan: MIT] expands regional large scale project. FBIS / S\&T Perspectives 8(4), March 31, 1993: p. 20-21.

[2.60I Germany: BMFT outlines future manufacturing sirategies. Science and Technology / Europe, JPRS-EST-94-023 September 16, 1994: p. 11-17.

[2,61] Germany: German Research Society supports special research projects. Science \& Technology / Europe-International, JPRS-EST-93-038, November 29, 1993: p. 12.

[2.62] Study calls RED subsidy benefits poor. Science and Technology / Europe, JPRS-EST-94-021 August 25, 1994: p. 1.

[2.63] Germany: Controversial report on Large Research Instikutes. Science and Technology / Europe, JPRS-EST-94-015 June 30, 1994: p. 15-16.

[2.64] Christopher Wood. The bubble economy. Atlantic Monthly Press, NY: 1993.

[2.65] A skmmary of a report 'Toward the Globalization of Science and Technology'. S\&T in Japan, 10(36), February 1991: p. 48.

[2.66] Japan: government-sponsored RED programs and mechanisms. Japan Technology Program, Dept. of Commerce, Washington, D.C.: 1994; and 
U.S. firms' access to Japanese R\&D programs. NTIS Alert 94(20) October 15, 1994: p. vii-xii.

[2.67] Richard Beason and David Weinstein, Growth, Economies of Scale, and Targeting in Japan (1955-90). Harvard Institute of Economic

Research, Discussion Paper 1644: 1993.

[268] Tadashi Saito, Prospects for change in Japan's industrial structure. JEI Report10A: March 11, 1994.

[2.69] Fumio Kodama, Technological dizersification of Japanese industry.

Science 233, July 18, 1986: p. 291-296.

J2,70] Leonard Lynn, Japanese research and technology policy. Science 233, July 18, 1986: p. 296-301.

[2.71] SET Policy 1991: Japan. Organization for Economic Cooperation and Development, Paris: p. 177-178.

[2.72] Japanese government SET budget update for IFY94. NTIS Alert, 94(13) fuly 1, 1994: p. vi.

[2.73] Stephen Mercado, Japan* Overview of MITI's industrial technology R\&D system. FBIS / Foreign Media Note, FB PN 93-366: August 26, 1993.

[2.74] 1993 AYST Laboratory research plans. Science \& Technology / Japan, JPRS-JST-94-010, June 27, 1994: p. 1.

[2.75] Stephen Mercado, Japan's National Institute for Advanced Integrated Research Setting a new course in RED. FBIS / Foreign Media Nole, FB PN 93-365: August 26, 1993.

[2.76] George R. Heaton, The truth about Japrnese cooperative R\&D. Issues in Sci. \& Tech., Fall 1988: p. 32-40.

[2.77] Gerald J. Hane, The real lessons of Japanese research consortia. Issues in Sci. \& Tech., Winter 1993-1994* p. 56-62.

[2.78] Kenichu Miyashita and David W. Russell, Keiretsu: Inside the hidden Japanese contglometates. MoGraw-Hill, NY: 1994.

[2.79] Philip Shapira, Lessons from Japan: Helping small manufacturers. Issues in Sci. \& Tech., Spring 1992: p. 6672.

[2.80] Stephen Mercado, Japan: Using regional technology alliances to help small manufacturers. FBIS / Foreign Press Note, FB PN 93-040: January $28,1993$.

[2.81] Jon Sigurdson, Science and technology in Japan - 2nd edition.

Longman Group UK Limited, 1991.

[2.82] MHI Chairman inkerviewed on industry-university $R \& D$. Science \& Technology / Japan, JPRS-JST-93-101-L, December 10, 1993: p. 4-5. 
[2.83] The Japanese government laboratory sysiem. National Institute of Science and Technology Policy (NISTEP), \$TA, Japan: October 1993.

[2.84] Tadashi Saito, prospects for change in Japon's industrial structure. ]EI Report 10A, The Japan Economic Institute: March 11, 1994.

[2.85] Japan's ooerseas direct intestment up 5.5\% in FY93. FBIS / Pacific Rim Economic Group, 3(12), FBPSP 94-012: July 15, 1994.

[2.86] Martin Kenney and Richard Florida, How Japanese industry is rebuilding the rustbelt. Tech. Rev., February/March 1991: p. 25-33.

[2.87] IETRO's anntual sturvey of Japanese-afflinted manufacturers in the United States. News From Jetro, Japan External Trade Organization, NY: 1992.

[2.88] Maxina Papanastassiou and Robert Pearce, The internationalization of research and deoelopment by Japanese enterprises. R\&D Man. 24(2) 1994: p. 155-165.

[2.89] Firms active in R\&D at U.S, universities. The Nikkei Weekly, July 18, 1994: p. 14a.

[2.90] Japan, U.S. work together on many SET fronts. NTIS Alert 94(05) March 1, 1994: p. ví.

[2.91] David Swinbanks, U.S. firms joining Jopanese nationol consortia for aerospace, energy, and materials research. Res. Tech. Man., March/April 1993: p. 2-3.

[2.92] Ritsuko Gray, Japan: spotight on Japan external trade organization (JETRO). Foreign Media Note FB PN 94-092: August 8, 1994

[2.93] Steve Mercado, Japan: Spotlight on Japan association for trade with Russia and Central-Eastern Europe. Foreign Media Note FB PN 94-063: May 5, 1994.

[2.94] David K. Kahaner, Research Development Corporation of Japan (JRDC). Scientific Information Bulletin 18(3), NAVSO P-3580, Office of Naval Research; July/September 1993.

[2.95] Industrial Science and Technology Frontier Program (ISTF). Science and Technology / Japan, JPRS-JST-94-011: July 20, 1994.

[2.96] 11th AIST Tsukuba General Symposium. Science and Technology / Japan JPRS-JST-93-016: April 12, 1993.

[2.97] David Lammers, New Japan Computing Project Set for Autumn. Electronic Eng. Times, July 6, 1992: p. 16-18; David K. Kahaner, US to Participate in Japan's Real-World Computing Program. Computer, 26(3), March 1993: p. 94.

[2.98] David Swinbanks, New Japanese proposal for intemational R\&D. Res. Tech. Man., January/Febtuary 1993: p. 4-5. 
[2.99] Intelligent Manufacturing Systems: An international partnership in the pursuit of manufacturing excellence. Techoology Administration, Department of Commerce, Washington, D.C.: 1994.

[2.100] IROFA-led roundtable discussion on IMS. Science and Technology $/$ Japan, JPRS-JST-94-031 September 23, 1994: p. 1-9.

[2.101] IROFA Official on state of IMS project. Science and Technology 1 Japan, JPRS-JST-94-031 September 23, 1994: p. 12-17. 


\section{Advanced Manufacturing: \\ Technology and International Competitiveness}

\section{Part 3. Component Technology R\&D}

February 1995
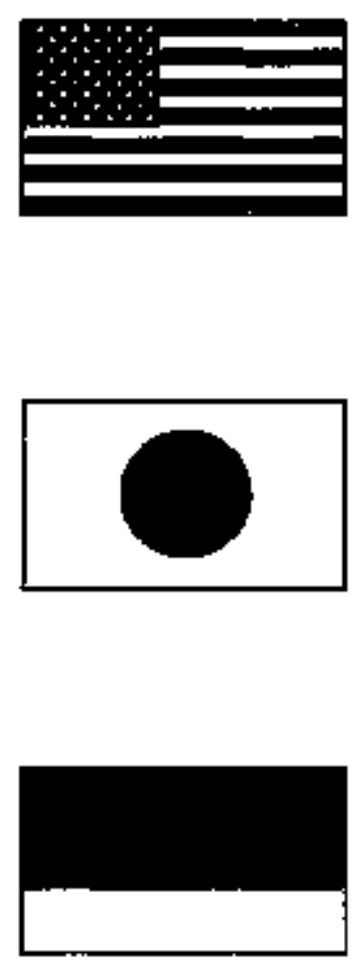


\section{Contents}

3.1 Key Judgments ......................................................................................... 1

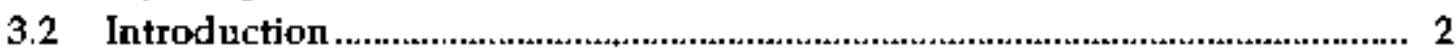

3.3 Component Technologies ......................................................................... 3

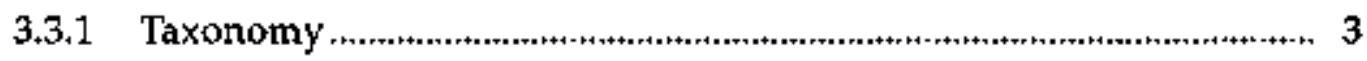

3.3.2 Expert Assessments ......................................................................... 7

Product, Process, and Enterprise ......................................................... 9

Rapid Prototyping/Concurrent Engineering ......................................16

Information Technology in Support of Advanced

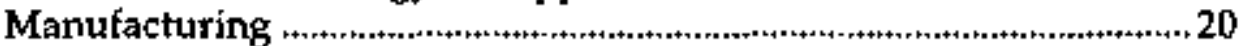

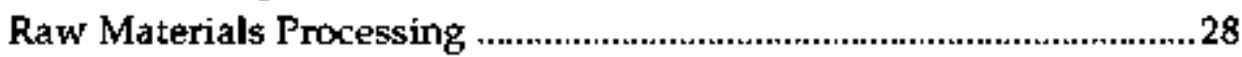

Chemical Processing ............................................................................31

Workpiece Fabrication ......................................................................34

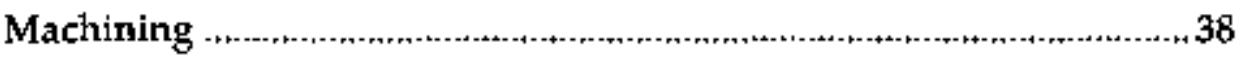

Surface Coating and Modification ....................................................42

Joining and Assembly Technology ....................................................45

Reliability: Maintenance and Repair Technologies ............................48

Machine Tool Technologies ................................................................52

Intelligent Machines in Manufacturing: Sensor and Control

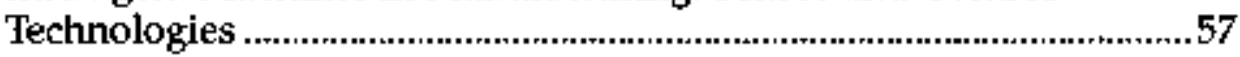

Environmental Integration and Technologies ...................................60

Safety Design Considerations ..........................................................64

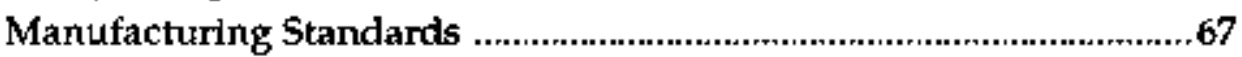

Appendix: List of Contributing Experts ........................................72

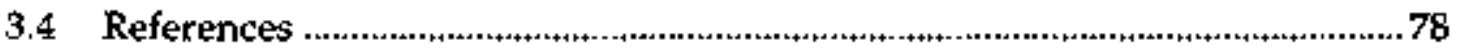

\section{List of Tables}

3.1 Major Industrial Segments Have Common Manufacturing

Technology Needs ..................................................................................... 4

3.2 Taxonomy of Technologies for Advanced Manufacturing R\&D.................... 5

3.3 List of Manufacturing Component Technology Areas ....................................... 6

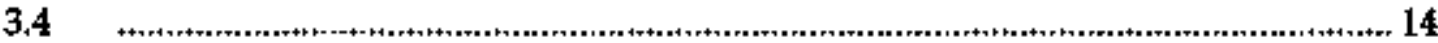

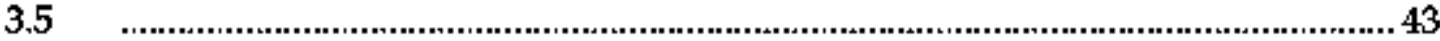

3.6 Rankings of Sensor \& Control Technologies ....................................................... 58

\section{List of Figures}

3.1 Relationship Between Core and Emerging Technologies 


\section{Part 3: Component Technology R\&D}

\subsection{Key Judgments}

By comparing the German, Japanese, and U.S. R\&D investments in manufacturing technologies without focusing on specific product sectors, the following key judgments were developed.

- Development of manufacturing technologies can be discussed from a component technology framework without specifying a product. This permits a broad based examination of technology investment for manufacturing in general.

- Advanced manufacturing technologies are nearly uniformly available across national boundaries. Diffusion of technology between Germany, Japan, and the U.S. occurs by rapid international communication of R\&D results, global marketing of equipment and materials associated with advanced techologies, and formal examination by foreign delegations of manufacturing techrology status.

- Advanced manufacturing is extremely dependent on the integration of component technologies. As a result, implementation of technologies in a manufachuring system is currently viewed as more critical for U.S. companies than $R \& D$ for competitive advantage. $R \& D$ can be effective by providing technology demonstration which permits each company to invest in implementation appropriate to their specific requirements.

- Technology advantages are termporary. Continuous assessment of developing technologies and those presently implemented can lead to strategic "sustainable development". AIl indications suggest that Japanese manufacturers excel in such assessments.

- Industrial support by the German government sponsors public laboratories to implement advanced manufachuring technologies in companies, especially SMEs, in efforts to modernize their production capabilities.

- The emphasis on technology development varies widely between emerging and mature technology areas, which are both receptive to major changes and small, incremental improvements.

- New emphasis is being placed on manufacturing technologies which support people in integrating information and making decisions.

- Development of machinery used in manufacturing is identified as critical in all fifteen manufacturing technology areas discussed.

- The uriversal goal of manufacturing technology R\&D is to modify the manufacturing process for inproved performance, responsiveness, and reliability, at reduced cost. 


\subsection{Introduction}

Research and development of advanced manufacturing technologies will be examined in Part 3 using a general framework. Thus assessment attempts to grasp the technical directions of manufacturing research. Understanding the status of technology, assessing the benefits of implementation and operation of the technology, and forming an intemational market perspective of competitive position are the three critical ingredients in R\&D investment strategies.

Two major reasons companies implement advanced manufacturing technologies are (i.) the technologies allow new or improved products to be manufactured; and (ii.) the technologies provide an economical advantage. Six key conditions have been proposed for assessing the potential value of a technology [3.1]:

- relative cost advantages,

- technical maturity and reliability.

- safety for producers, users, and third parties,

- the range of possible applications (especially military applicability),

- the power position of its promoters and implementers, and

- especially today, environmental compatibility

The manufacturer must assess the potential value and the cost of implementation as part of an $R \& D$ investment plan. Implementation into a manufacturing system often costs several times more than the original R\&D. The ease of technology transfer into operation depends on many factors but especially on the experience of the people involved and the maturity of the technology. There is no guarantee of the full benefit predicted. For example, several studies suggest that implementation of $\mathrm{CAD} / \mathrm{CAM}$ systems have not been roubinely successful in reducing direct labor in the design and machining processes. [3.2, 3.3] However, implementation of these technologies can significantly reduce product design to market time and error in analyzing sophisticated problems; and it can improve integration of engineering decisions. After examining the diffusion of advanced manufacturing systems in Japan, Mori emphasized that "while initial reasons for implementing advanced technologies were economic, other reasons (e.g., quality, customer service) have cone to the fore and the technologies are now being applied to assist firms to move into new market areas and improve their overall business performance." [3.31

As discussed in Part 2, R\&D investment in advanced manufacturing technologies can result in developments which simultaneously benefit 
many industrial sectors. Part 3 provides assessments of the component technologies now receiving such investment. Current discussions of research are usually directed towards applications in specific products and generalized information is typically found only in techrical books. We decided to take the approach of asking researchers recognized as experts in their fields to provide original input. This joput represents a tremendous amount of collective experience in R\&D. It is included in the following rather than risk misinterpreting this original information through rewriting it. The vanguard efforts identified are not necessarily representative of technologies implemented in the majority of manufacturing companies in any country.

\subsection{Component Technologies}

\subsubsection{Taxonomy}

A set of expert assessments on component technologies is presented to develop an appreciation for the competitive status of advanced manufacturing. The terms component, pervasive, and cross-cutting can be used interchangeably to describe technologies which are implemented in many different manutacturing industries. The matrix shown in Table 3.1 is a recent example of common technology areas identified with several industrial sectors. [3.4] A thorough taxonomy for a generic manufacturing process is shown in Table 3.2. [3.5] Under each technology area caption are examples of more specific technologies. This taxonomy is the basis of the list of fifteen technology areas provided in Table 3.3. In the following section, information which individual experts and groups have provided regarding component technologies in each of the sixteen areas is presented.

The experts were asked to succinctly address the following three questions:

I. Direction of benefit

Concentrating on component technologies that span several product sectors:

a. What are the most important steps to be taken / innovations under development in this technology area? (i.e., list ten most important technology problems).

b. Which of Germany, Japan, and the US are seriously working (i.e., have advanced programs) on these problems?

2 Homogeneity of technology

How similar / different are the component technologies used and being developed in Germany, Japan, and the US? 
- Table 3.1. Major Industrial Segments Have Common Manufacturing Technology Needs.

\begin{tabular}{|c|c|c|c|c|c|c|c|c|c|}
\hline \multirow{3}{*}{ Mndustry Moods } & \multirow[b]{3}{*}{ Austomolive } & \multirow{2}{*}{\multicolumn{5}{|c|}{ Endugtrial Segments }} & \multirow{3}{*}{$\begin{array}{l}\text { Materiaks: } \\
\text { Metals, } \\
\text { Coramios, } \\
\text { Polymass }\end{array}$} & \multirow{3}{*}{$\begin{array}{l}\text { Computing } \\
\text { Communication }\end{array}$} & \multirow[b]{3}{*}{$\begin{array}{l}\text { Textiles' } \\
\text { Papert' } \\
\text { Container }\end{array}$} \\
\hline & & & & & & & & & \\
\hline & & $\begin{array}{l}\text { Aorospacel } \\
\text { Engines }\end{array}$ & $\begin{array}{l}\text { Electricalt } \\
\text { Elestronics }\end{array}$ & 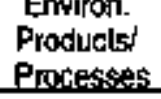 & $\begin{array}{l}\text { Chemicals' } \\
\text { Processing }\end{array}$ & $\begin{array}{l}\text { Machene } \\
\text { Toots' } \\
\text { Envioment }\end{array}$ & & & \\
\hline \multirow{2}{*}{\multicolumn{10}{|c|}{$\begin{array}{l}\text { I. Information Infrastruciure for } \\
\text { Papid Product Reallzation }\end{array}$}} \\
\hline & & & & & & & & & \\
\hline A. Information Management & 0 & 0 & $\sigma$ & 0 & d & 0 & D & 0 & 口 \\
\hline $\begin{array}{l}\text { B. Simulation and Modeling } \\
\text { of Product and Processes }\end{array}$ & 0 & 0 & 0 & $\mathbf{D}$ & 0 & 0 & 0 & 0 & 0 \\
\hline C. Product Design & a & 0 & 0 & 0 & व & 0 & D & 0 & व \\
\hline D. Rapid Protolyping & 0 & 0 & 0 & 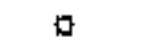 & $\theta$ & 0 & $\mathbf{a}$ & 0 & d \\
\hline \multicolumn{10}{|l|}{ II. Manufacturing Processes } \\
\hline A. Integration of Advanced Materials & 0 & 0 & 0 & $\theta$ & 0 & 0 & 0 & 0 & $\mathbf{a}$ \\
\hline B. Mechanical Process Iriprowements & 0 & 0 & 0 & 0 & 0 & 0 & 0 & 0 & 0 \\
\hline C. Chemical Process Improvements & 0 & 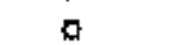 & 0 & 0 & 0 & $a$ & 0 & 0 & 0 \\
\hline D. Micro- and Nano- Fabrication & a & $\square$ & 0 & $a$ & a & $\theta$ & $\theta$ & 0 & 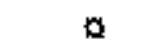 \\
\hline \multicolumn{10}{|c|}{ IIf. Production Equipment and Systems } \\
\hline A. Hight-Precision Technology & $\mathbf{a}$ & 0 & 0 & a & a & 0 & D & 0 & $\mathbf{0}$ \\
\hline B. Robotics and Intelligenl Machines & 0 & a & a & 0 & $\hat{\theta}$ & a & o & g & o \\
\hline C. Advanced Senaors and Conlrob & 0 & 0 & 0 & 0 & 0 & 0 & 0 & 0 & 0 \\
\hline \multicolumn{10}{|l|}{$\begin{array}{l}\text { IV. Environmentally Conscious } \\
\text { Manulacturing }\end{array}$} \\
\hline A. Total Litg-Cycle Accountability & 0 & 0 & a & 0 & 0 & घ & 0 & 0 & 0 \\
\hline B. Regreting Technology & 0 & 0 & 0 & 0 & 0 & a & 0 & 0 & 0 \\
\hline C. Emissions Control Technology & 0 & o & 0 & 0 & 0 & a & D & $\mathbf{a}$ & 0 \\
\hline $\begin{array}{l}\text { D. Energy Efficiency and haterials } \\
\text { Conservation }\end{array}$ & 0 & 0 & a & 0 & 0 & 0 & 0 & 口 & 0 \\
\hline \multicolumn{10}{|l|}{ V. Quality Realization } \\
\hline A. Test and Evaluation & 0 & o & 0 & 0 & 0 & a & 0 & 0 & b \\
\hline B. Dlagnostics & $\theta$ & 0 & 0 & $\theta$ & $\theta$ & 0 & D & a & $\theta$ \\
\hline C. Failure Avoidance & प & 0 & 0 & a & 0 & 0 & 0 & $\mathbf{p}$ & a \\
\hline D. Siandards & a & $a$ & a & 0 & a & $\theta$ & t & o & a \\
\hline VI. Education and Training & D & 0 & D & 0 & d & 0 & ם & a & a \\
\hline
\end{tabular}


Table 3.2. Taxonomy of Technologies for Advanced Manufacturing R\&D.

\begin{tabular}{|c|c|}
\hline 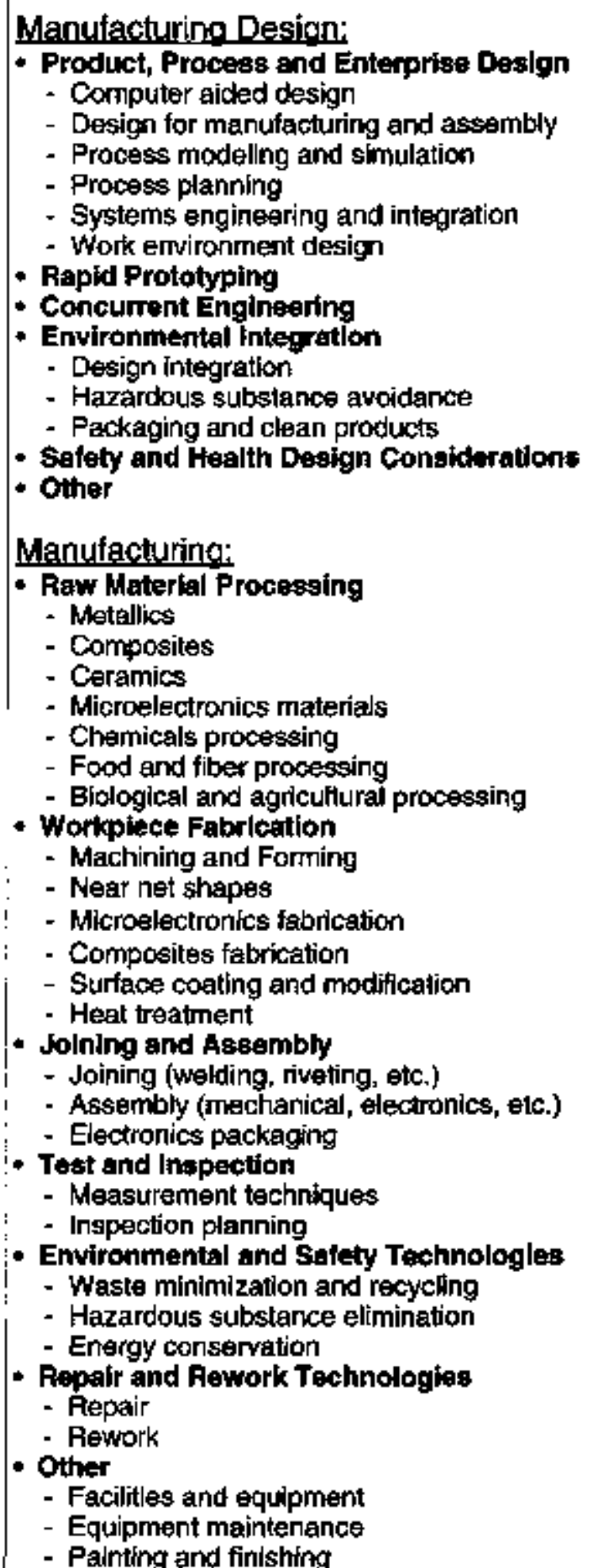 & 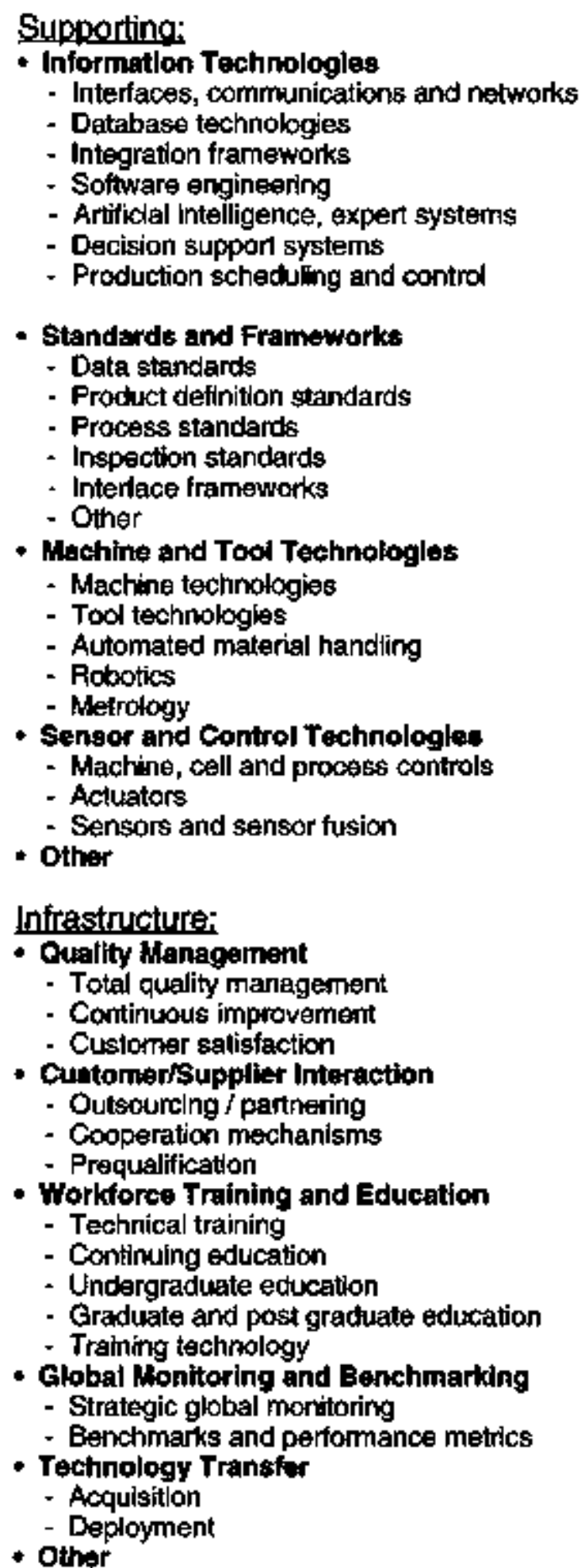 \\
\hline
\end{tabular}


Table 3.3. List of Manufacturing Component Technology Areas.

Manufacturing Systems Realization:

(1.) Product, Process and Enterprise Design

- Computer aided design

- Systems engineering and integration

- Design for manufacturing and assembly

- Process modeling and simutation

(2.) Rapid Prototyping

Concurrent Engineering

(3.) Information Tochnologies

- Interfaces, communications, and networks

- Database technologias

- Integration frameworks

- Sotware engineering

- Artificial intelligence / expert systems

- Decision support systems

- Production scheduling and contro

Manufacturing:

(4.) Raw Material Proces:sing

- Melals / intermetallics / semiconductors

- Ceramicsi

- Plastics

(5.) Chemlcal Processing

- FoodiBiological processing

- Peiroleum processing

(6.) Workpiece Fabrictation

- Near net shapes

- Composites fabrication

- Mutil-dimensional fabrication (multilayers, interconnects, etc.)

(7.) Machining: cutting / shaping / finishing

(8.) Surface Coeting and Modification

- Heat treatment for modification

(9.) Jolning and Assembly

- Joining (welding, riveting, etc.)

- Assembiy (fixturing, etc.)

(10.) Test and Inspection

- Measurement techniques

- Inspection planning

- Feedback for process control

(11.) Repair and Rework Technologles

- Repair

- Pework

- Condition-based manufacturing

\section{Supporting:}

(12.) Machine and Tool Technologies

- Machine technologies

- Tool technologies

- Automated malerial handling

- Metrology

(13.) Sensor and Control Technologles

- Machine, cell, and process controls

- Actuators

- Robotics / intelligent machines

- Sensors and sensor fusion

(14.) Environmental Technologles

- Design Integration

- Hazardous substance avoidance

- Waste minimization and recycling

- Energy conservation!

- Clean manufacturing

(15.) Satety and Health Design Consideratlons

(16.) Standards and Framework:

- Data standards

- Product definition standards

- Process standards

- Inspection standards

- Intertace frameworks 
3. Status of techrology

How mature would you suggest the component technologies are, and who (German, Japanese, US manufacturing companies) is leading in
a. Technology development / research.
b. Implementation in manufacturing.

\subsubsection{Expert Assessments}

Systems Realization:

1. Product, Process and Enterprise Design

p. 9

2. Rapid Prototyping / Concurrent Engineering

p. 16

3. Information Technologies

p. 20

Manufacturing:

4. Raw Material Processing p. 28

5. Chemical Processing p. 31

6. Workpiece Fabrication p. 34

7. Machining p. 38

8. Surface Coating and Modification p. 42

9. Joining and Assembly p. 45

10. Repair and Rework Technologies p. 48

Supporting:

11. Machine and Tool Technologies p. 52

12. Sensor and Control Technologies p. 57

13. Environmental Technologies p. 60

14. Safety and Health Design Considerations p. 64

15. Standards P. 68

$\begin{array}{ll}\text { Appendix } & \text { p. } 72\end{array}$ 


\title{
PRODUCT, PROCESS, AND ENTERPRISE DESIGN
}

\author{
Farrokh Mistree and David Rosen \\ Systems Realization Laboratory, \\ Georgia Institute of Technology
}

\section{Frame of Reference}

At the end of April 1994 we were asked to brief a high level delegation from Japan. A senior executive of a well-known North American company was drawing three circles on the board-one to represent technology, the other people, and the third resources. Then he put arrows to show connections between circles. He described the symbolism and then he posed a series of questions to his Japanese audience: "In Japan how do you prioritize your efforts? Do you go with technology, then management, then resources? What do you do?" The leader of the delegation replied-but he did not answer the question. The question was repeated and this time the circles were redrawn with some overlap. And the North American ended with- "Does he understond the question?" This too was dutifully translated and heads nodded in the affirmative. Again the delegation politely refused to answer the question. One more time the American posed the question. . .and. . .the American went on to give his answer "... some time ago we thought that technology was the answer. We learnt that it was not. Now in progressioe companies we invest in people. ." The American sounded frustrated as he waited for the Japanese to answer.

Perhaps the notion of circles connected by arrows or even overlapped is akin to trying to reassemble the fragments of a broken mirror- and futile. Life comes as a whole. It is only the analytic lent that we impose that makes it seem as if problems can be isolated and solved. The boundaries that we have put around design and manufacturing are fundamentally arbitrary. Product, Process and Enterprise Design must be viewed as a whole-viewed from a systems holistic perspective. Our mission, therefore, in this doctument is to recognize the isolated paris and articulate a direction that is in keeping with the whole. We outline several emerging technologies that explicate our view. U.S. design practices are benchmarked against Japanese and German practices using traditional design technologies. Although Japanese companies lead in some areas, we believe the concepts of open systems and learning organizations provide a framework for the investigation and implementation of our emerging technologies in U.S. companies. In our opinion, the proposed framework will enable companies, to become globally competitive in changing marketplaces without having to play "catch up." 


\section{Open Systems}

Open Engineering Systems are systems of industrial products, services, and processes that are capable of indefinite growth and development by both incremental technological advance and major technological change stemming from an existing base. [3.6] The basic premise, in designing open engineering systems, is to get a quality product to market quickly and then remain competitive in the marketplace through continuous development of the product line. An example of an open engineering system is the [BM PC. Several generations of PCs were developed (generations built around the Intel 286,386 , and 486 chips) and variations also occurred within each generation. Other examples of open systems include the Boeing 700 series of airplanes, stereo systems (a juke box is a closed system), and the B52 bomber series.

The U.S., despite possessing abundant resources and having at one time "made half the manufactured products sold anywhere in the world, ${ }^{t t}$ [3.7] now faces an agile and unforgiving global marketplace in which the concept of economics of scale is now obsolete. We believe that industrial competitiventess in harmony with the emerging notion of sustainable development is critical. Furthermore, we believe the open systems concept provides a framework to avoid "reassembling the fragments of a broken mirror." Goals in achieving open systems are to:

- Develop the expertise and technology to realize, sustain, and retire a family of systems that satisfy the changing needs of customers in a global marketplace.

- Reduce cumulative resource expenditure for the realization of a family of systems.

- Reduce time-to-market for a system after a change in the market has occurred.

- Increase quality by a customer-sensitive, holistic, and integrated approach to system realization and marketing.

\section{Core Technologies for Realization of Open Systems}

We believe that mass customization will provide the competitive edge in globally competitive markets of the future. Already. Japanese companies offer bicycles and shoes that can be custom ordered and produced the same day. The 3-day car is receiving serious attention. Such an environment necessitates a paradigm shift in the product development process. Open engineering systems provides a framework for this paradigm shift. In this marketplace, a company's ability to conceive, engineer, and produce a family of products will be their key to competitiveness. In our opinion, their greatest challenge over the next 10 years is to effectively and efficiently use information throughout the 
product realization process-from need recogrition to manufacture and delivery through service and disposal. What is the common element pervading each stage and each facet of the enterprise? Learning-nore importantly team learning. From machines that monitor their operation and learn to recognize their own maintenance needs to enterprises that learn to adapt to change, learning is pervasive in successful organizations.

Much has been made of the "wall"t between design and manufacturing in recent years. Concurrent Engineering has been offered as a means to get rid of this "wall." The key insight is not to talk about eliminating all walls, but to provide well-defined ports in these barriers that enable bridges-communication and cooperation channels- to be rapidly constructed. Virtual corporations can be constructed with this model. Each group that is necessary to design, produce, and maintain a product has its own barrier with defired ports through which bridges can constructed as needed. Product realization systems can grow, adapt, and disband over time to best suit the marketplace and the companies in which the groups are housed.

So here is our list of "core technologies" that need to be developed for the realization of systems:

1. Laming Technologies. Denotes technologies that enable individuals and /or groups to learn in a given domain or context-technologies that support "learning organizations." [3.8] Research issues:

- software tools that support learners, not just users;

- tools for both real-time and off-line collaboration.

2. Virtual Prototyping. Virtual (software) prototypes require far fewer resources than hardware prototypes to develop and execute. The challenges are to:

- increase the fidelity of simulation results from these prototypes, particularly for multiple, interacting physical phenomena (e.g** heat transfer effects on rotating machinery);

- enable analysis and simulation early in the design process; and reduce the burden on people to generate virtual prototypes.

3. Decision Making under Uncertain and Inconplete Information. Humans make decisions every day for a wide variety of tasks. Strategic decisions made by organizations are often subject to incomplete and uncertain information. Two strategies are available for supporting such decision making:

- reducing the incompleteness and uncertainty of the information;

- reducing the effect of the incompleteness and uncertainty.

The latter is similar to Taguchi philosophy of reducing effects of noise on product performance. A strong appreciation for when 
decisions must be made along the product realization time-line and what information will result from these decisions will enable an explicit product realization process.

4. Design of Product Families. Many companies have a rich product suite: several different product lines, each with product families that are updated over time as new technologies and options become available. Marketing, research, design, and manufacturing functions must be integrated beyond individual components in order to be competitive. Some of the issues that must be balanced include goals of:

- wide market coverage;

- component reuse across the product family;

- assembly line flexibility to handle product variants.

5. Design for Discontinuous Improvement. Continuous improvement of products and processes has received much attention in recent years. Sustained competitiveness over the long term canuot depend solely on incremental improvements. Rather, abrupt improvements in products, processes, and product families are needed to engender new markets. The manufacturing enterprise itself must be an open system. Some of the elements for discontinuous improvement are:

- flexible organization that can adapt to changes;

- information infrastructure providing the right information when it is needed;

- access to emerging technologies and the ability to exploit them.

The rejationship between the preceding (emerging) technologies and the core taxonomy list is captured in Figure 3.1. The relationstip being modeled is "is necessary for." For example, Systems Engineering \& Integration is necessary for Learning Technologies. Note that Design of Product Families is an emerging technology that is strongly related to all of the core technologies. It truly requires a holistic, system-orjented approach for long-term success.

\section{Homogeneity of Technology and Status of Technology}

We estimate the current state-of-the-art in Japan, Germany, and the U.S. with regard to core techmologies as shown in Table 3.4. There is much parity in the Computer-Aided Design (CAD) and Manufacture Process Planning technologies across countries. [3.9, 3.10] Some of the largest companies in each country are ahead of other companies since they have developed their own CAD and process planning systems in-house. This does not mean that companies are satisfied with CAD and process planning systems; most are not. Major capabilities missing across the 
Emerging Technologles

\begin{tabular}{|c|c|c|c|c|c|}
\hline $\begin{array}{l}\text { Denotes strong relationship } \\
\text { Denotes medium relationship }\end{array}$ & 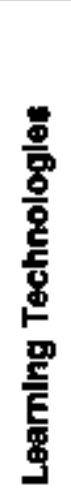 & 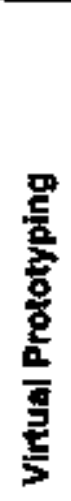 & 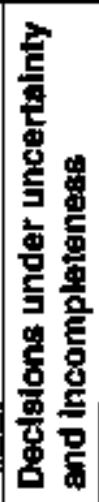 & 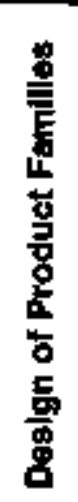 & 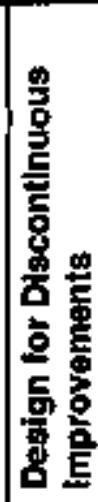 \\
\hline \multicolumn{6}{|l|}{ Computter-Aided Dessign } \\
\hline \multicolumn{6}{|l|}{ Design for Manufacturing and Assembly } \\
\hline \multicolumn{6}{|l|}{ Mantifacturing Procese Modeling } \\
\hline \multicolumn{6}{|l|}{ Design Proceks Modeling \& Simulation } \\
\hline System Englnewing \& Integration & & & & & \\
\hline
\end{tabular}

11-Thop6-01

Figure 3.1. Relationshlp Between Core and Emerging Technologles.

board include complete product data modeis, tolerances, data management, realistic assembly modeling, and an emphasis away from geometric construction as the primary metaphor for CAD systems.

Design for Manufacture and Assembly (DFMA) has been widely used in Japan as part of the product development process without explicitly being recognized as such. In the last 10 years, there has been increased usage of specific DFMA tools in Japan as well as other countries. There is a tremendous amount of research underway in the DFMA area to investigate new manufachuring processes and apply DFMA to new areas. As Whitney says of Japan, "One-third ( 5 companies) of the companies visited have developed their own design for assembly (DFA) methods and software; in some cases DFA is used in the traditional way to simplify the product's assembly, while in others it has been reformulated and elevated to a new status of enabling new manufacturing strategies or focusing conceptual design efforts."

The concept of making product realization processes (Design Process Planning and Simulation) explicit, then improving them over time, seems to have originated in Japan. This is widely practiced and is deeply entrenched. Many German and U.S. comparies have explicit design processes (and have had for years), but may not have a commitment to 
Table 3.4.

\begin{tabular}{|c|c|c|c|}
\hline Technology & Japan & Germany & $\underline{\mathrm{US}}$ \\
\hline $\begin{array}{l}\text { Compuiter-aided Design } \\
\text { 2D, 3D CAD Solid } \\
\text { Modteling Parametrics, } \\
\text { and CAE applications } \\
\text { (FEA, Dynarnics) }\end{array}$ & $\begin{array}{l}\text { Mary large companies } \\
\text { devetop their own CAD } \\
\text { systems. Most other buy } \\
\text { from US CAD } \\
\text { companies. }\end{array}$ & $\begin{array}{l}\text { Most companies buy US } \\
\text { or French CAD systems. }\end{array}$ & $\begin{array}{l}\text { Most companies buy US } \\
\text { or French CAD systems. }\end{array}$ \\
\hline $\begin{array}{l}\text { Design for Manufacture } \\
\text { \& Assembly }\end{array}$ & $\begin{array}{l}\text { Part handling and } \\
\text { insertion analysis widely } \\
\text { established. } \\
\text { Advanced anatysis in a } \\
\text { few companies (e.g. } \\
\text { product groups analysis } \\
\text { relative to existing } \\
\text { facilities). }\end{array}$ & $\begin{array}{l}\text { Part hendling and } \\
\text { insertion analysis widely } \\
\text { established. }\end{array}$ & $\begin{array}{l}\text { Part handling and } \\
\text { insertion analysis widely } \\
\text { eslablished. Some more } \\
\text { advanced analysis is } \\
\text { practiced. }\end{array}$ \\
\hline $\begin{array}{l}\text { Manufacture Process } \\
\text { Planning \& Simulation }\end{array}$ & $\begin{array}{l}\text { Planning is widely } \\
\text { available tor traditlonal } \\
\text { processes } \\
\text { Some simulation. }\end{array}$ & $\begin{array}{l}\text { Planning Is widely } \\
\text { available for traditional } \\
\text { processes } \\
\text { Some simulation. }\end{array}$ & $\begin{array}{l}\text { Planning is widely } \\
\text { available tor traditional } \\
\text { processes Some } \\
\text { simulation. }\end{array}$ \\
\hline $\begin{array}{l}\text { Design Process } \\
\text { Planining \& Simulation }\end{array}$ & $\begin{array}{l}\text { Continuous improvernent } \\
\text { of explicit process widely } \\
\text { practiced and deeply } \\
\text { entrenched. }\end{array}$ & $\begin{array}{l}\text { Improvernent of explicht } \\
\text { design processes ís } \\
\text { becoming established. }\end{array}$ & $\begin{array}{l}\text { Imptovement of explicit } \\
\text { design process is } \\
\text { becoming established. } \\
\text { US probably ahead of } \\
\text { Germany. }\end{array}$ \\
\hline $\begin{array}{l}\text { Systems Engineering \& } \\
\text { Integration }\end{array}$ & $\begin{array}{l}\text { Concurrent engineering } \\
\text { is widely practiced and } \\
\text { deeply entrenched. } \\
\text { Keiretsu organizations } \\
\text { deeply entrenched. }\end{array}$ & $\begin{array}{l}\text { Concurrent engineering } \\
\text { is becoming widely } \\
\text { practiced. }\end{array}$ & $\begin{array}{l}\text { Concurrent engineering } \\
\text { is becoming widely } \\
\text { practiced, US is probably } \\
\text { ahead of Germany. } \\
\text { Supplier } \\
\text { relationships are being } \\
\text { reconceptualized. }\end{array}$ \\
\hline
\end{tabular}

continuous improvement of these processes. The need to rethink design processes to be globally competitive in terms of increased quality, reduced costs, and redlaced time to market is now widely recognized. Many companies do not necessarily know how to improve their processes, and management strategies (fads) abound, particularly in the U.S., that seek to help. German companies may have a tendency to ignore the need to reorganize their design processes before integrating CAD software into their processes. Japanese companies typically have systematic, step-bystep product design processes which undergo constant review. The idea is to carefully identify the information that each design step needs from prior ones and provides to later ones, plus when that information is needed or available. 
We can reasonably include marketing, funance, design, manufacture, and service, with an information infrastructure, in an integrated, systems enterprise. The practice of soliciting input from customers and other concerned constituencies throughout the product realization process has been practiced in Japan for the past two decades and is becoming standard operating procedure in many U.S. and German comparies. But the jdeas of systems engineering and integration go beyond $\mathrm{CE}$ teams and Quality-Function-Deployment charts. The Keiretsu organizations of Japan provide vertical and horizontal integration structures that are unprecedented in the U.S. and Germany. One important result of relevance here is the close nature of supplier relationships within a Keiretsu. Large companies can trust their suppliers to deliver quality components on time. This has a tremendous impact on the business strategies available to large companies in terms of component out-source ratios, product options mixes, and product tum-over rates.

Regarding the use of information technology to automate or integrate task, Whitney states that the Japanese ". . tend to develop a process manually first and understand it thoroughly before attempting to computerize it. This contrasts sharply with a U.S. tendency to computerize things right away." German companies cannot be categorized quite so nicely since both practices have been reported. Companies in all three countries highlight the need for computer-based information infrastructures that fully support product realization by providing more complete and certain information. At the same time, they point out that such information infrastructures are a long way from reality. Lack of sophisticated information infrastructures prevents some new product realization practices from being completely successful.

\section{Closure}

US companies can continually play "catch up" with Japanese companies and others. This will be a losing battle. Or, the U.S. can set new strategic directions that "leap frog" the capabilities of our global competitors. What could these strategic directions be? We introduced some of these: open engineering systems, learning organizations, and what we see as our emerging technologies. We related these directions to product realization practices and the given core technologies. From a brief benchmarking exercise, we find parity amongst US, Japanese, and German companies in some areas, but Japan is ahead in others. It is not sufficient to concentrate individually on techrology, management, or manufacturing - to continue to subscribe to a framework for reassembling the fragments of a broken mirror. Rather, learning to integrate all three is critical for competitiveness. We believe that with a holistic, systems approach embodied in the open systems and learning organizations paradigns, US companies can achieve global competitive-ness in engineered product markets. 


\title{
RAPID PROTOTYPING/ CONCURRENT ENGINEERING
}

\author{
Allan J. Lightman \\ University of Dayton
}

\section{Introduction}

Concurrent engineering (CE) is generally grouped into the encompassing context of Integrated Process and Product Development (IP\&PD). This general framework includes all aspects of the manufacturing process covered by the phrase "art to part." Using time as a competitive element in the business strategy is one of the underlying driving forces in the implementation of IP\&PD. The goal is to deliver better designed and manufactured products more quickly and at lower cost.

Rapid prototyping $(R P)$ is a key enabling technology in the implementation of IP\&PD. Practice has shown that designers need to reduce their concepts to physical prototypes during the design phase for subjective evaluation based on sensory feedback, principally look and feel. Video display has so far proven inadequate to provide these qualitative evaluations. There are many ways of realizing parts by RP. Fabrication can be divided, in a gross sense, into material subtractive and material additive processes. The former refers to traditional fabrication: milling, turning, and so forth. The latter is usually referenced to a relatively new form of manufacturing that was introduced commercially circa 1987 . As of early 1994 , there ane 14 companies worldwide offering varying realizations of material additive manufachuring with many more preparing to enter the marketplace. Although the name specifies prototyping, however, this is a misnomer; all the systems are currently restricted to model making. A principal focus of the effort worldwide is to develop processes capable of producing true prototypes (i.e., parts made from end-use materials by production techniques). Such prototypes will enable testing and evaluation directly and will speed ap product development.

All present RP systems share one common technology requirement-the data must be provided from a three-dimensional (3D) computer aided desigr (CAD) model. 2D computer drafting and hand drawings ate incompatible with the needs of the systems. In addition, several of the systems require that the data be extremely accurate, with more stringent surface continuity requirements than for other manufacturing processes. Consequently, many $\mathrm{CAD}$ vendors have had to improve the performance of their design systems. These improvements have led to vendors converting from surfaced wire frame representation to solids based modeling. In the former approach the design was constructed as a frame of 
spars. Surfaces were then attached to the spars. Problems arose where surfaces mated. Often minor mismatches occurred, leading to minor gaps which were cleaned up in the post processing following traditional fabrication. In the new RP processes, these small gaps will result in the failure of several techniques to be able to produce anything usable.

Driven in part by the needs of RP, there continues to be a rapid improvement and enhancement of the computer design software. This has far-reaching benefits to the entire manufacturing process and is a major driver in the implementation of IP\&PD. Having the electronic database for the part design promotes integration with the other computer-based capabilities that are being developed concurrently, including featurebased design, enterprise modeling, mechanical analysis, and so forth. These capabilities are essential for the future ability of manufacturing industry to compete. This need is the starting point for most government efforts to aid their manufacturers. The hardware and software to perform these functions come principally from the US. American 3D CAD systems based on solids modeling dominate the world market.

\section{Japan}

In Japan, the commercial implementation of RP is led by the Ministry of International Trade and Industry (MITI), in conjunction with the Japan Association of Rapid Prototyping Industry (JARI), and transferred through $12 \mathrm{RP}$ centers and the more numerous technology transfer agents set up by the two largest RP suppliers* : CMET (principally Mitsubishi but also NTT, Asahi Denka Kogyo, Toyo Denki Seizo, and YAC) and D-MEC, a subsidiary of JSR working with SONY. With MITI support, they are attempting to develop a grassroots acceptance for $3 \mathrm{D} C \mathrm{CAD}$ and $\mathrm{RP}$ in a proactive program where agents visit smaller manufacturers and develop test cases to demonstrate the advantages of the technology. Those industries purchasing hardware and/or software will accrue tax credits15 percent was mentioned. This program also involves INCS (the 3D Systems representative in Japan), Teijin Seiki, and Denken Engineering, each a supplier of RP systems. There are no universities directly participating, but the association advisor is Professor Nakagawa, University of Tokyo.

University funding comes from MITI and the Ministry for Science and Technology (MST). The university programs focus on the devejopment of precompetitive technology (such as the micromanufacturing efforts at UT and at Kyushu Institute of Technology) and working with industry when

\footnotetext{
* Both companies are marketing SLA machines that are similar to those of 3D Systems (U.S.). As of July 1994, D-MEC is restructuring and its role may be reduced, leaving CMET as the dominant market maker in Japan at this time.
} 
the program has a more inmediate application (such as the medical applications focused at INCS involving six universities and the liaison interaction at Hokkaido University with the STEP program). University personnel are also participating (leading) significantly in programs at Riken (somewhat equivalent to NIST in the US.) which could significantly impact their RP/CE effort (3D CAD with application to 5-axis machining, numerical simulation of sheet metal flow in successive draw-die forming, etc.). These efforts are tied in with their RP activities.

In summary, the Japanese effort is highly focused. Program definition takes direction from industry. The university role is directed to the fundamental developments or to gathering and disseminating information about external programs that might impact their efforts. The Japanese have selected particular areas where they will compete and they have very advanced programs in these topics. The universities and government laboratories also function to maintain an awareness among industries of the capabilities of each participant, perthaps so each can measure its own progress against that of the others but also to develop consensus performance criteria.

\section{Europe}

The European RP programs somewhat mirror the political transformations currently underway. There are European Community (EC) programs with administration at one facility and with $R \& D$ centers in many EC countries (BRITE EURAM, EUREKA, etc.); there are programs between traditional alliance countries (NOR-SLA program of the Nordic colmtries); and there are programs in individual countries (CREATE and ESSTIN [France), WISA [Germany], CENTRE for RP [UK], etc.). While there is much effort and the individual program results are quite impressive, there does not appear to be much interaction between the programs.

The European RP programs emphasize the creation of tools for manufacturing, perhaps a reflection of their manufacturing heritage from the guilds. There has been limited RP technology development, and commexcial hardware offerings bear a strong resemblance to earlier equipment from the U.S. (Technology improvements/modifications and cioser interaction with the customer have helped to develop markets.) RP dissemination is proceeding in both France and Germany through technology outreach programs similar to those in Japan. The initial thrust is in 3D CAD, but both countries also operate RP facilities that can demonstrate the process. Also, interested companies can access the larger program results to evaluate their application to the company's needs.

A major German effort is the WISA program with principal focus in the Fraunhoffer Institutes around the nation. The Institutes interact strongly with industry and can serve as test-beds for new technology. They 
perform the field service and demonstration facility function similar to the program in Japan. The Institutes also develop new technology to address their industry partner needs. Two programs (Bremen-Stuttgart and Aachen) are gaining awareness addressing direct RP production in metals with the goal of producing functional prototypes rather than models.

\section{Homogeneity}

The development of the fundamental knowledge base underlying high technology advances is accompanied by presentations in international forums. As a result, there is considerable homogeneity in the programs worldwide. Also, the development of a global economy has resulted in the rapid dissemination of new technical capabilities. The key to competition is to maximize the velocity of development and to maintain a keen awareness of the progress made in competing countries.

\section{Status}

There are several technologies about to be released in the U.S. (e.g.r Soligen, Sanders Prototypes, etc.) for which no equivalents have yet been described elsewhere. This potential advantage is temporary. Similarly, the direct metal RP production in Germany and the micromachining projects in Japan stand alone at the moment. More important than technology development is market implementation. In this area, the technology transfer programs in Japan and Europe appear better structured than the scattered, uncoordinated efforts in the U.S. This may change as the NIST MECs come on-line and address this need. Market intelligence on IP\&PD implementation, both product and process, is another critical element. Both Japan and Europe sponsor university/ industry delegations that visit foreign technology centers and attend meetings, and then report to their industries on the status of foreign efforts, usually at national meetings. Their approach is more focused than any effort in the U.S. where knowledge gathering and dissemination is a random activity. 


\title{
INFORMATION TECHNOLOGY IN SUPPORT OF ADVANCED MANUFACTURING
}

\author{
The International Liaison Office \\ MCC
}

\section{Introduction}

Manufacturing intrinsically involves materials (the stuff out of which products are made) and machines (the shapers and assemblers of products). To be a world leader in manufachuring, however, now requires much more than the best materials and the best machines. Increasingly, the cribical elements in achieving competitive advantage in manufacturing axe the skillful management of formidable streams of information, the timely application of the knowledge of human experts to product and process design problems, and the integration and coordination of the movement of materials and behavior of machines. To be world class, a firm must therefore effectively apply information technology (IT) - computers, software, and telecommunications-to manufacturing work. As we approach the 21st century, companies compete in a world in which the most important ingredient in a ${ }^{\text {tt}}$ physical ${ }^{*}$ product is the digital data that comprises its design and that coordinates the movement of the machines which shape it. The basic challenges that confront researchers and engineers in the U.S., Germany, and Japan as they seek to apply information technology tools to problems in manufacturing are shared. There is variety among the three countries, however, in the set of technologies that may currently be identified as national strengths, and in the particular challenges and problems that R\&D efforts address. This report will identify 10 common areas of challenge in the application of IT to manufacturing, and then outline the characteristics of advanced work in the three countries, with emphasis on Japan and Germany.

\section{Key Challenges}

The primary challenges and problem areas that confront industry around the globe as firms seek to apply information technology fall into three areas: design and coordination challenges; process challenges; and humanfactors challenges.

Design and Coordination Challenges: Using I $T$ to allow human experts to function in teams across organizational and geographic boundaries; making the manufacturing facility flexible. 
1. The creation of integrated software environments that link product designers, manufachuring engineers, and end-users to support rapid prototyping and very short product development cycles.

2. The linking and integration of geographically separate production facilities within a company to support the manufacture of any product or component in any factory.

3. The development of enterprise integration capabilities that allow manufacturers to interact quickly and efficiently with component suppliers and downstream users, so that, in effect, the supplier and the customer are "inside the extended company."

4. The development of software support for FMS flexible manufacturing systems equipment that maximizes scalability, portability, adherence to standards, and rapid modifiability of manufacturing nodes.

Critical Enabling Technologies Region

CAD/CAM; Database;

Wide-Area Networks; Japan

Computer-Supported Cooperative Work CSCW;

Object-Oriented Software

\section{Ranking by}

1. U.S.

2. Germany $/$

Process Challenges: Using IT to make the manufacturing process produce what the customer wants, when the customer wants it.

5. The support of production processes that enable flexible production in sinall batches and "quantities of one" to meet customer requirements, including support for: the minimization of set-up time; the automation of machine configuration and adjustment; and the minimization of waste and re-work.

6. The implementation of self-regulating SPC statistical process control that can't go "out of control," through the development of production machines that include the embedded capability to monitor, test, and adjust their own operation.

7. The linking of autonomous agents of production robots and intelligently controlled machines into interconnected communities of production agents that communicate with one another.

8. The management of materials and scheduling of processes so as to optimize the use of materials and the results achieved through the application of labor time.

Critical Enabling Technologies Computer-Integrated Manufacturing CIM; Local Area Networks; Wireless
Ranking by Region

1. Japan

2. U.S. 
Commurucations; Expert Systems;

3. Germany

Fuzzy Logic; Database; Neural Networks;

Embedded Systems

Human-Factors Challenges: Using IT to make people and machines work better together. Note: 9 and 10 are not contradictory goals, although the boundary that separates them may move over time as technology grows more sophisticated.

9. The creation of highly automated manufacturing environments which are easily understandable to human operators user friendly, and the performance of which can be tuned through the application of human expertise.

10. The emulation of the judgment and learring capabilities of skilled human operators through the application of automated systems.

Critical Enabling Technologies Ranking by Region

CAD; Expert Systems; Machine Vision; 1. Germany/Japan Sensor Terhnologies; Virtual Reality; 2. U.S.

Fuzzy Logic; Neural Networks

\section{Japan}

Japanese prowess in manufacturing technology, induding in particular heavy emphasis on the use of production robots, attracts much attention in the press. The emergence of Japan over the last two decades as a world leader in manufacturing derives not from the application of raw technology, however, but from a steady commitment to the integration of technology human expertise, and organizational methods. The japanese, for instance, lkt by Toyota, introduced just-Tr-Time (JT) manufacturing, a largely organizational rather than technological system in which inventories of components and finished products in the factory are cut to the bone, and reliance placed on trusted suppliers who provide rapid production of high-quality parts on demand. The goals of JIT are, by eliminating slack and surplus in the manufacturing process, to expose all weaknesses in the system and fix them, and to drive production "backward" from market demand, rather than forward from corporate production plans. Other key concepts in Japanese manufacturing are lean production, in which all waste and fat are identified and eliminated along the route from product design to fabrication to assembly to distribution, and "kaizen", best understood as a commitment to fix something before it is broken, and then to continue to improve its performance in steady increments.

Japanese firms have been in the forefront in the shift from mass production to large-variety, medium-lot systerns based on flexible manufachuring system (FMS) technology, which has fed a strong Japanese market for factory automation (FA) equipment and systems. While firms like Fanuc are indeed world leaders in robotics, most Japanese firms stress 
the development of manufacturing facilities where skilled workers can control and hone the production process. In the Japanese view, a major task for the future will be to connect all the computers in use at each plant via local area networks and to create a CIM (computer-integrated manufacturing) system that extends from the time of order all the way through manufacturing and shipping.

Key Trends and Deoelopment Activities in Japan As noted, Japan is the world leader in the application of information tectunology to challenges in manufacturing processes. Areas of particulariy intense activity center around challenge (5)-the flexible production of small batches and "quantities of one" to meet customer requirements; and challenge (8)-the management of materials and scheduling of processes to achieve optimal results. Key trends include.

1. Heavy use of expert systems (ES) in industry, with a tendency away from applications in problem diagnosis and tooord applications in production planning systems and design. (Status: mature).

- Fuji Xerox has developed an expert system which allows plant personnel to instantly revise daily production plans based on changes in the volume of onders reported. The software runs on Unix workstations, was installed at Fuji Xerox's Iwatsuki plant in late-spring 1994, and has reduced from four days to one-half day the time required to prepare production plans.

- Chiyoda Chemical Engineering and Construction has developed an ES-based system that automatically calculates an optimal layout for the connection of process equipment with piping in chencical plants. The system is said to reduce the design time required to lay out a new chemical plant, in comparison to more conventional 3-D CAD systems, by 90 percent.

2. Increasing use of CAD/CAM (computer-aided design/computer-aided manufacturing) fechnology, including exploratory applications that enhance $C A D / C A M$ environments with stereolithographic prototyping capabilities. (Status: Relatively mature)

- Mazda is a leader in the Japanese automobile industry in the application of an integrated CAD/CAM/CAE (computeraided engineering) environment to the manufacture of auto parts. Mazda's new system, which addresses a full spectrum of activities from assessment before a final decision is made to produce a part to quality control after manufacture is complete, is said to have led to an overall reduction in developnent time of 50 percent on Mazda's 1993 models.

- While computerization of product component design is advanced in Japan, there are fewer examples of computerized 
design being applied in the electronic equipment industry. Sanyo, however, has developed its own computer-aided industrial design (CAID) system to both design products and control manufacturing processes.

- Photomolding systems, which produce solid, 3-D models from $\mathrm{CAD}$ data using photocured resins (plastics that harden when subjected to light rays), have been in use in Japan now for five years.

3. Emphasis in the use of CIM (computer-integrated manufacturing) technology on the integration of the flow of materials and information within the plant, with a high level of automation applied to materials distribution and equipment set up (Status: Early commercial).

- Kyocera, the world market leader in ceramic packages for integrated circuits, has developed an object-oriented POP (point of production) system which collects data from bar codes and serisors for the management of flow of stock and orders in real time.

- In late-1993, NEC, the giant computer maker, introduced a series of 11 "CIMKit" software products that support computer-integrated manufacturing in various industries, including chernicals, pharmaceuticals, food processing, and cosmetics.

4. Extensive use of fuzzy logic and neutal networks in adoanced manufacturing, particularly for (1) equipment diagnosis and preventatize maintenance, and (2) production process control; much integration of fuzzy and neural approaches with expert system technology. (Status: Early commercial)

- Omron, the Japanese leader in fuzzy logic for industrial control applications with over 1,000 patent applications filed through 1993, has developed fuzzy-based controllers for conveyor belts that permit irregularly spaced components on two conveyors to be brought smoothly together for joining operations.

- Hutachi has developed a CIM system for use in a Sanyo manufacturing operation which incorporates neural networks that are "trained" to rapidly produce near optimal production plans. Using this system, Sanyo claims to have achieved a 50percent increase in productivity in an existing factory, with only minor modifications to the prior equipment base.

5. Ambitions long-range work in virtual reality and "tele-existence" for the support of industrial kasks (Status: Precommercial R\&D).

- The Advanced Telecommunications Research Institute (ATR), a research consortium funded largely through Japanese government sales of NTT stock, has developed a "virtual 
teleconferencing" system that permits engineers and designers in remote locations to use their workstations to manipulate and discuss "virtual objects" (buildings, vehicles, etc.) which appear to the user to have three dimensions.

- Professor Susumu Tachi, of the Tokyo Institute of 'Technology, has done pioneering work in the creation of robotic systems that allow a user to both control the actions of an anthropomorphic robot via a telecommunications connection, and, using a head-mounted display, see what the robot "sees" with its camera eye. Such tele existence systems (Tachi's term) have applications in hostile and dangerous environments, such as, for instance, maintenance operations in nuclear power plants or the handling of toxic wastes.

\section{Germany}

Germany is Europe's leader in the introduction of advanced manufackuring techniques and technologies, especially in its large automobile industry. In recent years, the re-integration of East and West Germany, combined with a recession and increased international competition, have caused German companies to close plants, lay off workers and restructure industries. Lakor unrest, fluctuating currencies, and the creation of the Europe-wide market have all had their impact on the German manufacturing sector. Nevertheless Germany maintains its status as Europe's largest and most vital manufacturing country; at over 30 percent of GDP, it derived a greater proportion of national wealth through manufacturing in the early-1990s than either Japan or the U.S.

German manufacturers participate broadly in European cooperative research programs, providing significant support to Esprit, the European Community's flagshìp research program; Eureka, the near-market umbrella funded by industry participants; BRITE, created to revitalize European industry through basic research in design and manufacturing technologies, and others. German companies, universities, and research institutes are represented in nearly every project in the Esprit Computer Integrated Manufacturing and Engineering initiative; the Eureka Robotics/Production Automation activity has a major German presence, especially in the FAMOS (Flexible Automated Assembly System) projects. The new Fourth Framework Program (1994-1998) will support research in advanced manufacturing as part of its "Industrial and Materials Technologies" (IMT) activity. Budgeting for IMT has already been approved, at about $\$ 400$ million.

\section{Key Trends and Development Activities in Germany}

Germany has strengths in CAD/CAM applications, as well as in the general field of design technologies. Areas of particularly intense activity center arotund challenge (1)-the creation of integrated software environments that link product designers, manufacturing engineers, and 
end-users-and challenge (3)-the development of enterprise integration capabilities that allow manufacturers to interact quickly and efficiently with component suppliers and downstream users: Key trends include:

1. Softuare systems for product design and manufacturing support are a fertile field for young, innowative German softuare companies, and may help to build the German software industry, is well as advancing manufacturing capabilities. (Status: Relatively mature, but field for innovative competition)

- Itedo Software of Sieburg, Germany has developed a technical drawing package, called IsoDraw, which is in use at

Volkswagen and other Gecman auto compantes. The package employs an isometric grid to help the user draw, and offers a large selection of standard shapes including ellipses, Bezier curves, outer and inuer threads, and polygons.

- Cincom Systems GmbH has recently introduced "Control Manufacturing," an integrated system for the support of manufacturing, distribution, and financial management in manufachuring environments.

2. Enterprise integration networks are emerging as an avenue not only to achieve competitize adzantage in daily operations, but to guide the design of nexk-generation products. (Status: Commercially viable, but immahure)

- Bremer Vulkan Verbund AG, a German shipbuilding firm, has developed a computer-based diagnostic system to collect data on a ship at sea, and then transmit this information via satellite to the home port to use in the scheduling of cost-effective maintenance. Future plans call for the shipbuilder's designers to analyze this data and use it as the basis for improved ship desigris.

3. In designt soffurre, German firms are paying athentiont to issues of standards and inter-firm compatibility early in the evolution of the genre. (Stahs: Precommercial R\&D)

- Daimler-Benz, Deutsche Aecospace, Mercedes-Benz, and AEG are leading a multinational consortium of European firms (British Aerospace, Renault, and Fiat are also involved) to produce a new generation of standardized software systems for the use of manufacturers (over 25 percent of European manufacturing firms currently report that they are "dissatisfied" with their software suppliers). R\&D activity will concentrate on product and process modeling, concurrent engineering for the development and manufacture of new products (especially when engineering is conducted at multiple sites), production control, and logistics support. 


\section{Summary}

While the U.S., Japan, and Germany face the same set of challenges in applying emerging information technologies to advanced manufacturing, strengths and R\&D emphases vary by country. In general, approaches are not homogenous. At the pre-commercial R\&D level, the U.S. is strong in design technology and enterprise integration initiatives; Japan leads in technologies that coordinate, support, and monitor actual fabrication and assembly processes; while Germany has strengths in design, and, to some extent, human factors work.

To take full advantage of information technology in modem marufacturing requires not just technological capability, but the willingness to constantly re-think and re-design the processes of production and the organizations that conduct manufacturing. In this regard, the Japanese show a steady commitment to incremental experimentation and improvement; the Americans demonstrate a sometimes surprising capacity to rapidly adopt new ways when convinced that this is necessary; and the German record is mixed. Broader implementation of enterprise integration will be a future trend, and will require agreements on standards across industry segments. The application of fuzzy logic to automated process control and of virtual reality to the support of human abilities to control industrial processes are areas to watch. 


\title{
RAW MATERIALS PROCESSING
}

\author{
Anne Kresak \\ Precision Surfacing Corporation
}

\section{Introduction}

Raw materials processing is a mature field. The development of production and processing technologies is a serious engineering endeavor. As this review will show, the diversity of processing requirements and continuing production innovations exemplifies that "maturity" in no way implies diminishing development activity. On the contrary, it suggests that engineers now have tools to pursue raw material processing to achieve expected results. The health of a manufacturing system critically depends on the reproducibility and quality of raw materials processing. The expensive and time consuming work of developing controlled industrialscale processes is driven to meet materials property specifications and to make the material cost effective. In Germany, Japan, and the U.S., this work is funded by large industries. The automobile industry in all three countries is heavily involved in advanced raw materials processing. Other outstanding investments in raw materials processing include the preeminent composite efforts by the U.S. aerospace industry, the tremendous ceramic processing efforts by the Japanese electronics industry, and the sophisticated polymer processing efforts by the German chemical industry. The results of these efforts have translated into international competitive advantages and higher levels of product capabilities.

The similarity in raw materials processing technologies under development and in tuse in these three countries is high. All three countries have large, active, public-funded programs in materials development.

Because industry depends on equipment supptiers which are internationally accessible and university research which in no stretch of the imagination operates in a vacuum, technology information is quickly exchanged; especially if the technology provides clear benefits. Often the bottom line for industry is that the composition (what the materials are made of) is open knowledge, but the speciftc processing (how the material is made) and the comparable benefits are carefully guarded information. The country which leads in each raw material processing technology is the one who's ind sstries gain the most value-added through use of that technology.

\section{Technologies}

The processing history defines the final composition and the microstructure of a material, and this in turn determines its properties. 
Composition-structure-property relationships are worked out in detail to allow fine tuning for the best properties. Extensive modeling and experimental testing are used. In this manner products having specified material characteristics can be formed. Advarked processing techniques are providing higher performance materials required for more demanding applications. On the basic level, there are many processing methods which are adaptable for use with metals, ceramics, and polymers. For instance, powder metallurgy uses some of the same models as ceramic powder processing, and injection molding is used for both polymers and cetamics. Each material and product design, however, presents particular processing challenges. As manufacturing processes become increasingly atutomated for improved control, the level at which processing information must be known increases. Other drivers include reduction of waste emissions, increased energy efficiency, the utilization of inexpensive ingredients, and robust machinery. The major technologies in this engineering endeavor are described below.

1. Gauging Flexibility in Composition. To allow for sporadic changes in raw material composition and possible use of lower grade, complex minerals without degrading properties.

2. Particulate Symthesis. To form particles of reproducible purity and constitution. Purity requirements and processing which does not introduce contaminants are increasingly significant. Control of the particulate constitution is critical to subsequent consolidation methods. Examples of synthesis processes include: precipitation from solutions, decomposition of salts after separation of solvent, spray drying of solutions, hydrothermal processing, sol-gel processing, solid-state reactions, gas phase reactions, and melting for ceramics; polymerization, condensation, emulsions, suspensions, solution reactions, precipitation, and gas phase reactions for polymets; and gas atomization, vacuum atomization, hydro-atomization, mechanical separation, direct reduction of ore or mill scale, carbonyl process, precipitation processes, electro-chemical processes and electrolysis for metals.

3. Potuder Conditioning. To control the powder size distribution and to tailor powder blends. Powder conditioning technologies include pulverizing, washing, drying, granulation, dispersion, and defocculation for ceramic powders; blending, kneading, granulating, conditioning, and preforming for polymer powders; and comminution, sifting, gas evolution, and blending for metal powders.

4. Processing Additizes. For effective use in modifying material behavior during processing, additive technologies include catalysts, sintering agents, parting agents, antistatic agents, conductive additives, flame retardants, plasticizers, emollients, frothing agents, and slip suspension agents. 
5. Control of Bond between Composite Constituents. Particulate filler. whisker, and fiber surfaces are engineered for use in a particular composite matrix. The bond at the interface between the filler and the matrix can greatiy influence the propertles of the final cormposite.

6. Compaction / Densification. Important challenges related to densification of powders include "neat net shape forming" of monoliths, sintering to form complex components, and realization of high density while maintaining control of grain size, diffusion of doparts, oxidation / reduction atmosphere, etc. The related techniques include foaming, isostatic pressing, pressurized slip casting, injection molding, transfer molding, extrusion, sheet casting, sintering, hot pressing, hot isostatic pressing, shock consolidation, and shock-activated sintering.

7. Casting. The need to control solidification to produce specialized microstructures (for example, strong anisotropy or amorphous metals) is ensouraging continued development of high-speed processes, continuous casting, and cast rolling processes.

8. Heterogeneous Materials Forming. Composites, graded or layered structures, and other nonhomogeneous structures require specialized processing. The technologies under development include winding, pressing pultrusion, braiding, injection, infiltrations, diffusion welding, and directional solidification.

9. Defect Defection. Reliable and efficient detection of defects (especially bulk defects) and internal stresses in semi-fitrished components is of continuing importance for both process control and product quality assurance.

10. Processing Equipment. Raw material processing equipment is exposed to hot, corrosive, abrasive, and/or high stress environments. As processing conditions become more extreme, increased demand is placed on technology development for refractory resistance, tooling lifetimes, and machine capabilities. The lumits of materials processing are determined by equipment constraints.

11. Automation. Process control is enhanced by computer control of machinery coupled with higher precision sensors for temperature, pressure, atmosphere adjustment, batch mixing and materials handling, inspection of stoichiometry and purity, etc.

12 Modeling and Simulation. Modeling can provide predictive design of processing parameters. Modeling the effects of processing parameter variations on microstructure can be used as a tool in designing efficient experiments. Process modeling is becoming more important as automation increases and multiple paramefers are varied simultaneously. 


\title{
CHEMICAL PROCESSING
}

\author{
John G. Wilder \\ Lawrence Livermore National Laboratory
}

\section{Introduction}

Chemical processing is fundamental to the existence of a modern industrial economy. Chemicals are an essential part of almost all facets of modern living. The chemical industry supplies fertilizers and insecticides for agriculture, containers for food and the processing and preservatives that allow food to be used where and when it is needed. It supplies fibers and dyes for clothing along with the detergents to keep them clean. The industry supplies fuel for transportation and heating, refrigerants for cooling, vitamins to maintain health, and pharmaceuticals to fight disease. Chemicals are big business. This assessment will examine technology status in the chemical industry, as most chemical processing in manufacturing is related to processes developed by chemical induștries.

The chemical industry is a "mature" industry. "Mature" industry means that it is highly efficient with supply and demand in equilibrium. Real growth requires a reduction in costs, improvement in quality, development of new products, or some combination of the three, to encourage increased usage. Improved manufacturing technology or discovery of new chemicals or chemical processes are the onily way to achieve real growth. Its evolution through the rigors of the market place has resulted in one of the most cost efficient industries in the world. Fierce competition has spawned many chemical producers that are highly specialized. Major chemical products are made by only a dozen or fewer companies. This reflects the high capacity and capital intersive nature of the industry. The very nature of this specialization runs counter to component, pervasive, or a cross-cutting technologies concept. The industry is characterized by incremental improvements that reduce costs and improve quality. If one compares the chemical industry in Japan, Gemany, and the United States, the United States is the largest and the healthiest of the three. It enjoys the lowest labor costs, the highest employee productivity, and the greatest trade balance surplus (\$15.7 billion for 1993). This surplus, though large, has declined from previous years. High-volume bulk active and basic intermediate chemical production has been shifting to Asia (less Japan, with China being the largest and fastest growing producer) due to lower wage rates and lack of environmental regulation. This is having an effect on government supported R\&D. 


\section{RED}

Increasingly, chemical process development $R \& D$ is driven by regulatory restrictions and waste minimization over simple production cost considerations. General R\&D goals include breakthroughs in new products and processes. Comparisons of $R \& D$ type and expenditures between Japan, Germany and the United States is complicated by the multinational composition of many large chemical companues. An example being Hoechst Celanese (Germany) recently terminated some of its research on non-linear optics and moved it to Hoechst's research group in Japan.

$R \& D$ expenditures are about $4.5 \%$ of total sales in the U. S. and $5.7 \%$ in Japan; however, spending varies significantly among different sectors. More mature product sectors spend well below the industry average (the petroleum industry spends only about $1 \%$ of sales) while the high tech (pharmaceuticals and biotechnology) spend as much as $50 \%$. The industry in general is channeling most $R \& D$ effort towards more advanced synthesis technology where scientific breakthroughs and advanced manufacturing techniques promise the greatest economic return. Both. German and lapanese government R\&D programs now exclusively sponsor basic science devoted specifically to inventing new pharmaceutical and biotechnology products. A nine year, multimillion dollar Japanese program seeks to discover new chemical products from marine organisms.

\section{Technologies}

Advances in chemical processing are made either as major and unpredictable breakthroughs in chemical reaction control, synthesis pathways, or as incremental improvements in manufacturing system integration. The following technologies are useful tools:

1. Process Control Systems. Sensor and processes control/monitor technology systems are "pervasive" to the industry. In most cases new digital/computer systerns are replating older analog systems. Often the functions remain unchanged except improved economy and precision is realized. In some cases real time automated chemical analysis aliows improved chemical processes to be used that were unavailable in the past. An example is the production of totally chlorine free (TCF) paper. Chlorine is by far the most widely used pulp bleaching chemical in the pulp industry. Regulatory pressure is driving the industry to look for other processes. Chlorine is cheap, powerful, and doesn't degrade fiber strength. Altematives include using mixtures of chlorine and chlorine dioxide, oxygen, hydrogen peroxide, and ozone. The successful implementation of these processes is very sensitive to process controls and has been historically impractical, but may now be viable with new control/sensor technologies. 
2. Catalysts. Catalysts by their very nature are a specific chemical agent for a specific step in a chemical process. Researchers are on a never ending search for new catalysts that can create molecules that now do not exist, create economically materials that are presently prohibitively expensive, or create catalysts of greater efficiency and longer useful life. The majority of catalyst R\&D is directed toward advanced chernicals rather than basic intermediates or high-volume bulk actives. Most industrial catalysts are associated with petrochemicals. Some challenging catalyst R\&D includes de-sulfurizing feedstocks and synthesizing products traditionally derived from petroleum (gasoline, kerosene, etc.) from natural gas. Pollution control is another field of catalyst R\&D. Restrictions on nitrogen oxide emissions has resulted in reducing these compounds with fuels. A direct reduction to the elemental components (nitrogen and oxygen) is thermodynamically favorable but no catalyst as yet exists.

3. Flexible Designs. The cost of capital equipment becomes a major factor for small scale production so there is an effort to design chemical production systems that are adaptive to a multitude of synthesis requirements. Flexible, multuse plant design is desirable for the production of a variety of customized specialty chemicals.

4. Simulation. Computer simulation is a useful tool in predicting conditions for the formation of chemical structures and reaction paths. Increasingly, these techniques are being used in engineering and process design.

5. Safety. Chemical handling often demands sophisticated tools for safety. Pneumatic controls and electrical equipment are continuously improved to operate in reactive environments. Remote control systerns and robotic technologies may be necessary precautions in complex and hazardous operations (such as paint spraying). Designing containment vessels for corrosion resistance, and predicting and monitoring the engineering lifetimes of containment materials are continuing technology issues.

6. Waste Reduction. Additional objectives are reduced waste streams with the ultimate goal of only clean water being discharged. Innovative design may allow reintroduction of waste effluents for secondary use in the originating process or in a separate but symbintic process. Where recycling is not possible, detoxification prior to disposal is required. Catalyst recycling and rejuvenation is replacing disposal at many manufacturing facilities. Complicating these objectives are changing economic and regulatory conditions. For example, chlotine use is being discouraged as demand for sodium increases. The problem for manufacturers is that these two products are presently produced simultaneously from one process. This represents a new challenge which will only be solved by the development of a new manufacturing process. 


\title{
WORKPIECE FABRICATION
}

\author{
John Berkowitch \\ National Textile Center
}

\section{Introduction}

This documeint highlights the findings of U.S. experts who have broadly canvassed thirty Japanese enterprises, ten universities and five research institutes, and half as many German counterparts, to assess the state of advanced manufacturing. Emphasis is placed on Japan, and to a lesser degree Germany, reftecting their position as leaders in the field. Personal observations of the author are included.

Spurred by the rise of the yen and growing competition from low-wage countries, factory automation in Japan is undergoing a radical transformation. Traditional concepts of manufacturing are being rendered obsolete and replaced by advanced production systems, permitting large gains in productivity, quality, and cost reduction compared to their stateof-the-art factories of only ten years ago. The new product development cycle is often down to one year or less, quality improved by $20 \%$ or more, and cost reduced by 10 to $15 \%$. The resulting ultra-efficient factories offer, in addition, the flexibility and short lead times needed to manufacture diverse specialized product in small lots. These new capabilities have allowed the heavy, medium and precision segments of the industry to stem the loss of market share to imports. They also provide the means for transplants abroad to maintain high quality, and low cost production, even with an unskilled work force, thereby fostering globalization. Automatic inspection and testing on line, in particular, go a long way toward insuring production unifornity under adverse conditions. Progress in global communication further makes it possible to optimize production orı a worldwide basis.

The focus is no longer on the development of individual components or partial automation, but rather on automating the entire production by means of a multi-hierarchy computer control system, blurring the boundaries between business planning, product development, and factory floor. Procurement, design and marketing are integrated into the system as well to fulfill quick response requirements. In this context, a global assessment of competitive strategies in workpiece fabrication increasingly reads on cross-cutting technologies and practices pervading the whole manufacturing complex regardless of product sector. 


\section{Methods and Priorities}

Many large Japanese companies take a total view of manufacturing by vertically integrating skills and facilities needed for product realization, feeling that it is too important to be left to vendors. They develop most of their software and build a substantial part of the critical manufacturing equipment, while they buy many low-value-added components going into their products. Their systemic approach reveals a strong commitment to communucation between product and process designers and to manufacturing excellence, giving production engineering high visibility at the corporate level. This end-to-end capability is regarded by many as a competitive advantage over the U.S, which mostly follows the opposite strategy, i.e. makes the components and purchases the equipment, showing thereby a greater product-line orientation. Getmany stands in between. However, both the U.S. and Germany can show some product realizations matching those of their best lapanese competitors, thus tempering the validity of general conclusions.

Management techniques, the product of decades of "corporate learning" (that foreign competition cannot buy), are given credit for many of the production efficiency standards Japan has set for the world. Large scale use of computers often takes second place. Processes are frequently developed manually and understood before being computerized. Deșign improvements, crucial to business performance, include determining early on which process areas will need them, identifying trade-offs, mustering experience and finally converting that experience into algorithms. This leads to practical solutions, often the source of major innovations, which reveal significant long range thinking. It contrasts sharply with the tendency of U.S. industry to computerize things right away and that of U.S. and Japanese academic research in robotics to focus excessively on far advanced technology.

\section{The Technologies}

Advanced workpiece production systems are emerging from the relentless search for ways to eliminate waste and inefficiency. They appear in increasing number and level of sophistication in fields ranging from the construction of engines and machinery to the fabrication of precision electronic equipment and the particularly challenging making of tailored apparel. Current efforts focus particularly on (1) merging engineering, computer-assistance and computer science in the development of expert systems for design, process control, product quality monitoring, maintenance support, and cost analysis, using artificial intelligence, especially distributed control and fuzzy logic, (2) recognizing the impact on production realization of business management issues, such as cost prediction, risk factor, design for product famulies, and simplicity of 
product assembly, which, following redesign, has led in several cases to rely exclusively on vertical part insertion, (3) developing multi-functional robots capable of ever more complex and accurate tasks frequently requiring deeper insights into material mechanics, as exemplified by the positioning and joining of cloth pieces with a three-dimensionally driven mobile sewing head, (4) rajsing the speed of reprogramming manufacturing lines, from procurement to shipping, for small lot production, down to one of a kind in some instances, (5) expanding "grass roots automation" to improve the efficiency of medium-sized supplier enterprises by introduction of the just-in-time concept, (6) rapidly processing growing amounts of complex data to furrish real-time feedbacks, and (7) introducing new techniques in man-machine interaction, such as equipment voice-activation. The cumulative impact of hundreds sukh innovations undergird the advanced factories of Japan.

\section{The Key Players}

Large Japanese manufacturing enterprises see themselves as responsible for the main skills of product realization and have made major investments in technology and people to prove it. Their endeavors in both development and implementation place them ahead of the U.S. They tend to take time, anywhere from five to fifteen years, molding their employees to their tiking, which is facilitated by the lack of concentration in engineering education. It is easy to cross-train such engineers in design and manufachuring. Smaller enterprises can keep up in technology with heip from their larger brothers, usually their customers, and the government. The first offer training and sell them technology, while the second, primarily the prefectural government institutes, have in place large field services on new tectunology and software, much in the way the U.S.'s Agricultural Extension Service assists farmers. Japanese university research in robotics, in the main, has been aloof from industry, while, in computer assisted design and manufacturing, it had concentrated unti] recently on traditional topics like metal cutting. Industrial consortia of late vintage are improving through the support of private universities.

Most U.S. manufacturing enterprises address selected aspects of manufacturing and leave the rest to vendors. GM terminated the R\&D programs in robotics and sculptured surface software they had in the 1960 's. Today, no U.S. machine tool or robot supplier has the resources Toyota or Nippondenso, an automotive part producer, can bring to bear on their product R\&D. U.S. industry and government agencies find little relevance to funding university design \& manufacturing research. Nor have there been until recently any government field services to assist medium and small erterprises stay abreast of the state-of-the-art in advanced manufacturing as in Japan and Germany. As a result, they lag considerably behind their Japanese counterparts, particularly in the use of 
flexible manufacturing cells, handling \& assembling robots, automatic inspection and warehousing equipment. Recent U.S. government initiatives, resulting from the growing concern about industry competitiveness and the downsizing of defense-oriented R\&D, bring promise of closer ties between industry, government and university.

Some large German enterprises (Bosch, Volkswagen, Siemens), like their Japanese counterparts, develop manufacturing and computer assisted design technology intemally. They and the government invest heavily in human resources through national apprentice programs which are without par. Universities and institutes, on the other hand, have a tradition of strong ties with industry which has staffed them with many of its designers and engineers. Products of this collaboration typically involve high technology end-items, like robot microcomputer controllers and flexible manufacturing system scheduling software, which Japan generally gets from vendors. European enterprises of similar size exhibit wide differences in the maturity of design methods and tools, while their Japanese equivalents, having essentially adopted the same approaches and philosophy, have learned to live with constant change.

In conclusion, the Japanese industry appears the overall leader in both development and implementation of advanced workpiece production due in a large measure to their systemic approach, reliance on past experience, constant commitment to quality improvement and long term focus. Germany comes out second and the U.S. third, neither one matching the scope and degree of the Japanese advances. 


\title{
MACHINING
}

\author{
J. Tlusty \\ University of Florida
}

\section{Introduction}

1 was asked to write about $R \& D$ in machining technology. This inevitably includes the process, the tools and the machtine tools. The latter part is however listed also in another section of the overall document. I am, therefore, trying to emphasize in the following the other two aspects but I had to refer to some particular machine tool developments, anyway. So, just at the start, I will use the machine tool industry to provide the background for the comparison of the three countries being discussed.

The latest statistics provided by the Association for Manufacturing Technology is from 1992. Total production of cutting (machining) machine tools and of those exported in parentheses, was in Billion: Japan: 6.56 (exp. 54\%), Gurmany: 5.19 (exp. 90\%), USA: 1.96 (exp. 52\%), Japan made 3.3 times and Germany 2.6 times the volume of machine tools than the US. The high export percentage for Germany can only be due to their technical quality.

\section{Status of Technologies}

In the following I am listing a number of "hot" advanced technologies. All three countries are involved in all of these and all are contributing to published research. In many aspects the Germans do the most systematic and mature work. However, the Japanese bring most of them the fastest onto the market. The Germans still dominate the export market which is probably due to the fact that the market is conservative and takes its time to accept the innovations.

1. Machining (tuming, milling, drilling) of difficult materials. hardened steel, ceramics (silicon nitride), Ni alloys, metal matrix composites, ceramic matrix composites, polymer matrix composites. Using ceramic tools, PCBN (polycrystalline boron nitride) and PCD (polycrystalline diamond) tools. Laser assisted machining of $\mathrm{Ni}$ based alloys, of Ti, Al alloys of ceramics. Development of tools and investigation of tool geometry, modes of tool wear, cutting conditions is needed. Most of the research is done in Germany. US tool manufacturers (Valenite, Greenleaf, Kyocera, Kennametal) are active in these developments but no systematic research is going on at universities or private industry. Applications in automotive, jet engine, aircraft and other industries. 
2. High Speed High Power Machining. Some of this is relatively straight forward such as speeds up to $3000 \mathrm{fpm}$ in using silicon nitride to machine cast iron; e.g. face milling of engine blocks. Most other applications are in end milling of pocketed aluminum aircraft structures, of titanium compressor blades, of hardened steel dies, of cast iron scroll pumps. Carbide and CBN (cubic boron nitride) tools used. R\&D concentrates on development of HS spindles with hybrid ball bearings, with air and magnetic bearings and on development of controls and drives for fast feed rates and accurate path control. Research in Germany (Aachen, Darmstadt, Stuttgart), USA (UF, Setco, NIST), machine tools developed in Japan, Germany. Initial development in US (Lngersoll).

3. High Speed Grinding. Use of CBN grinding wheels at speeds of $300-600 \mathrm{ft} / \mathrm{sec}$. Applications in grinding ball bearings, gears, automotive parts. Grinding of ceramics with diamond wheels. Modeling of the process, use of Acoustic Emission to control dressing of the whel and control the grinding cycle. Research in Japan, Germany (Bremen, Hannover, Bramschweig), USA (Norton, GE, Landis, NIST, ORNL, U of CT).

4. High Precision Machining. Use of CNC (computer numerically controlled) lathes and machining centers to achieve accuracy of the one micrometer order: improving metrology, controlling thermal deformations of machine tools, use of sensors, neura] networks. Most research done in USA (Purdue, UM, UF, NST) but no industrial use yet.

5. Ultra Precision Machining. Accuracy of the ten nanometer order. Single point diamond turring of $\mathrm{Al}$ and $\mathrm{Cu}$; pioneering work done at LLNL. Further development in Japan, Germany (Aachen), several private companies in USA. Diamond wheel "ductile" grinding of glass, ceramics: HPSN (hot pressed silicon nitride), silicon, with applications to microelectronics, optics, ceramic computer hard discs, automotive engine parts. Massive R\&D in Japan (development of electrolytic wheel dressing), in Germany. Machine tools with hydrostatic bearings and hydrostatic gujdeways.

6. Advanced Dynamics of Machine Tools. Improving removal rate and precision by suppressing chatter vibrations: systems for detection and speed control, active and passive dampers in structures (quiet machine tools). Research in USA (UF, Ut, UM, Bell Labs) no industrial applications yet. Advanced CNC controllers with feedforward corrections, for high speed machining. Research in USA (UC Berkeley, UM, UF, NIST), Germany (Stuttgart), 
development in Japan (Fanuc), in USA (Delta Tau). Initial movement towards "Open Architecture Controller).

7. Sensor Based Control of Machining. Use of intelligent sensors of cuttivig force, of vibrations, of acoustic emission to detect and control chatter, tool wear, breakage of tools in turning milling, drilling. Research USA (UC Berkeley, UF, . .), Germany (Berlin, Aachen); no real applications yet In Japan sensors included in machine tools but with little use yet. This whole field needs development to improve quality of production and permit unsupervised machining.

8. 5-axis CNC Machining. Most of aircraft parts need it, many other applications such as die making and others would strongly benefit. It includes tracing and digitizing of models and $\mathrm{CAD}$ / CAM software development. Some of this available from Japanese Machine tool makers, some software already available in US. Needs massive efforts.

9. Other Machining Technologies. Of the large variety of machining operations, of special interest are indications of various developments in the most common operations: drilling, reaming and tapping in cast iron, in aluminum, in titanjum and in composites. Efforts concentrate on improving tool life, sensing and preventing tool breakage, improving accuracy of reaming and speeding up these processes. A separate field, also in development, is drilling of deep holes: large (cylinder of plastic injection machine) and small (automotive crankshafts).

\section{RED Investment}

Germany has the longest tradition. Large research labs at universities in Aachen, Berlin, Stuttgart, Darmstadt, Munich, Hannover, and some others currently employ about 800 doctoral research assistants in the machining ard machine tool field. These labs are equipped with abundant first class equipment. After graduation these Dr-Ing's work in industry at various levels of manufacturing engineering functions which is the best techolology transfer mechanism. The current governmental support for Production Engineering (PE) Research at the universities amounts to $\$ 96$ million. In the USA, twenty years ago thete was almost no $P E$ research at the universities. It has been developing and currently the North American Manufacturing Research Institution has about 200 members, mostly from academia, mostly junior faculty. The number of PhD research assistants in the machining tool field is currently about 150 and NSF support for these projects is about $\$ 6$ million. A third to one half of the graduated $\mathrm{PhD}$ s end up as professors, another portion work in industrial labs and very few in actual production engineering. We are now producing Mechanical Engineers better educated in PE and this leads slowly to upgrading the industrial population responsible for 
technology development. How much help for the nondefense work can be obtained from national labs with their very costly hourly rates after the current heavy subsidies discontinue will have to be seen. There is an old industrial tradition in this country but that may not be enough against the German and Japanese competition. Finally, for Japan, their acadernic labs are no better equipped then those in the USA. In preparing this survey it became evident that currently most of the high quality work concentrated on ultra precision machining. The Japanese machine tool industry is large and aggressive and fast in implementing innovations. For illustration, let's use item 2 above and specifically high speed machining of hardened steel dies. Two years ago this technology did not exist in industry. In Germany, research work was going on in Aachen. But at the 1992 International Machine Tool Show, among several thousand exhibited machine tools only two were demonstrating this technology, both Japanese. And if you want to see the best Computer Integrated Manufacturing example in USA visit the Mazak (lapanese import) factory in Kentucky. 


\title{
SURFACE COATING AND MODIFICATION
}

\author{
Frank K. Uxban III \\ Florida International University
}

\section{Introduction}

Surface coating and modification is applied during manufacturing of products as diverse as automobiles, microelectronics, architectural glass, food packaging, and solar energy collection - to name a few. The surface of a manufactured part is critically important because it is what is seen and touched, where the "rubber meets the road." A specially engineered surface on bulk parts can provide an enormous increase in materials performance. For example, surface modification may provide increased lifetime (corrosion protection), improved functionality (machine tool coatings), energy performance (heat reflecting glass), and beauty (decorative coatings). Surface may be physically covered by a thin layer of another material (thin films) or modified by treatment of an existing thin surface region by ion bombardment, laser treatment, chemical processing or various other means.

Although the existence of thin films has been known for over a century, surface engineering for desirable properties has lagged because measurement methods suitable for such thin layers (from few atoms to thousands of atoms thick) were rot available. Recent breakthroughs in measurements are partly responsible for the current explosion in understanding and use in manufacturing. The field is in its infancy and can be expected to have an extraordinary impact on manufacturing as it matures. Technical leadership would be extremely valuable across a wide range of industries.

The very wide range of the field and the breadth of the requested assessment linnits what follows to brief descriptions of a number of important technology areas. The summary is divided into advanced film applications, selected emerging deposition techrologies, and several global issues.

\section{Advanced Films}

Advanced films, which are more complex in structure or use new materials, should be considered an area overarching new and existing deposition technologies. Key examples of emerging techniques, material systems, and advanced applications are listed below: 
Table 3.5.

\begin{tabular}{|c|c|c|}
\hline Fllm & Materials & Appolication \\
\hline Graded Layers & oxides & optical cable (information superhighway) \\
\hline Multilayer Film & metals & $x$-ray mirrors \\
\hline Multico & $\begin{array}{l}\text { semiconductors } \\
\text { various }\end{array}$ & $\begin{array}{l}\text { microelectronic materials } \\
\text { adaptive hich T lubricants }\end{array}$ \\
\hline Hard Coati & $\begin{array}{l}\text { diamond } \\
\text { carbide, nitride }\end{array}$ & $\begin{array}{l}\text { wear, friction, themmal, missile radomes } \\
\text { friction (first principle design) }\end{array}$ \\
\hline Conductive Oxides & oxides & automotive window defogging \\
\hline Non-conducting & various & $\begin{array}{l}\text { transparent moisture barrier for } \\
\text { microwavable food packaging }\end{array}$ \\
\hline 'Smart Films' & $\begin{array}{l}\text { photo \& electro- } \\
\text { chromic }\end{array}$ & $\begin{array}{l}\text { environmentally adaptive films, darken } \\
\text { with light or electrical command }\end{array}$ \\
\hline $\begin{array}{l}\text { Photographic } \\
\text { Variable Index }\end{array}$ & $\begin{array}{l}\text { organic } \\
\text { oxides }\end{array}$ & $\begin{array}{l}\text { printing industry, medical, amateur } \\
\text { variable incex of refraction uses }\end{array}$ \\
\hline
\end{tabular}

\section{Emerging Techniques}

The Role of lons: While it has long been known that energetic ion bombardment can result in improvements in deposited films, advances in atomic scale measurement technology has recently enabled study and exploitation of these effects. The ion topic is very wide, from small area, high value films (e.g. microelectronics) to large area, low specific value films (food packaging). The specific methods of employing ions also are many - including ion guns, plasmas, and arcs to produce bombarding ions of inert gasses, reactive gasses, and the depositing species, itself. While there seems to be no national level US programs focused specifically on ions, $R \& D$ is progressing in a number of university, industrial, and government laboratories under separate support. By contrast, there are a number of national and regional programs in Japan, such as the Ion Engineering Center outside of Osaka which was recently set up to assist industries in high risk, high return research not yet economically reasonable for industrial labs to take on alone. The lab is well equipped with film deposition and analysis equipment and provides technical assistance at a subsidized fee. There are European programs known to the author in Germany, Sweden, Italy and Austria. Research activities are relatively homogeneous across these world regions and its is unclear where the lead will go. Maturity level in ion technologies ranges widely depending on the specific technique and application, while overall it must be judged as adolescent with major potential value throughout manufacturing as it fully matures. 
Clusters: An example of new technology under development in the US, Japan, and Germany is deposition of coatings by clusters of atoms rather than single atoms or molecules. The hope is that, being different, this method will prove to be valuable in manufacturing. The idea of cluster beam deposition originated at Kyoto University in Japan in 1972. It still receives significant industrial and government attention and support. Other pioneering work is supported in Germany at the Institute of Nuclear Studies where critical breakthroughs have been made. US researchers, including the author, are also active in developing the process to a workable coating technology. At present the lead is in Germany but so much remains to be done that this could easily change in the next few years. The maturity level is immediately prior to birth, with the potential yet to be clearly recognized.

Arc Vaporization: Another emerging technology is arc vaporization in which the material to be deposited is very rapidly vaporized by moving electric arc. The potential for very high rate, large area, low cost coatings has rapidty been necognized. Process problens are being dealt with and it seems to be a healthy baby in its infarcy.

Other new deposition technologies in the conceptual to development stages include, for example, laser treatment and advanced sol-gel processing. These technologies are starting to be applied in specialized manufacturing activities.

\section{Global Coating Issues}

Finally, the main global issues include improving film density morphology, adhesion, coating and surface properties, while reducing the processing cost and scaling to large planar and three dimensional coatings. As of 1994, Europe (specifically England), is becoming more competitive while the US is holding, and Japan seems to be falling back. Part of the reason is tied to the economic success of the manufacturers of coating equipment, especially the vacuum coating equipment industry. Overall, surface coating and modification is felt to be at about $20 \%$ of maturity and moving onto the steep part of the development curve, where major, valuable advances will be regularly applied in manufacturing. 


\title{
JOINING AND ASSEMBLY TECHNOLOGY
}

\author{
John C. Lippold \\ Edison Welding Institute
}

\section{Introduction}

Jointing and assembly techrology encompasses a broad range of processes and material issues that vary in importance and impact when considering the spectrum of U.S. manufacturing. This assessment has considered the primary joining and assembly techrologies that are perceived to be most critical in the context of current and future manufacturing issues that influence global competitiveness. In conducting this assessment, six industry sectors were considered, namely. automotive, aerospace, heavy manufacturing (off road equipment, shipbuilding, etc.), power generation, petrochemical/process, and electrorucs. With the exception of the electronics industry which has unique joining and assembly requirements, the component technologies described below span a number of industry segments.

\section{Critical Technologies}

The following joining and assembly technology issues are currently considered most critical relative to US. manufacturing competitiveness.

- Resistance Welding

- Arc Welding - Thick Section

- Arc Welding-Precision Processes

- Laser Welding - Low Power

- Repair Welding Technology

- Pipeline Welding Technology

- Surface Mount Technology

- Electronic Component Joining

- Plastic Joining

- Adhesive Joining

Each of these joining technology issues is discussed briefly in the following sections.

1. Resistance Welding. This technology is critical to the automotive, aerospace and electronics industries. The U.S., Japan and Germany all devote considerable resources to this technology and it is considered to be relatively mature in all three countries. No country holds a significant technological advantage. Future advances in this area will be incremental. Large R\&D investments in this area will not be rewarded by resultant techoological advantage. 
2. Arc Welding - Thick Section. This technology is critical to the heavy manufacturing, power generation and the petrochemical/process industries. This technology is relatively homogenous with the U.S. holdnng a slight advantage in certain "niche" areas. All countries have advanced programs in this area, with the U.S. and Japan leading in $R \& D$ investment and implementation. Although this technology is relatively mature, sustained R\&D funding could provide some competitive advantage, particularly in the shipbuilding and offroad equipment industries.

3. Arc Welding-Precision Processes. This technology spans all the industry sectors, but is most critical in the aerospace and power generation industries. Again, this technology is essentially homogeneous worldwide, with the U.S and Germany holding a slight advantage. R\&D effort is modest, with most effort placed on process control rather than process improvement. A significant technological advantage in this area can be translated into inproved product quality, reliability and competitiveness. R\&D investment in process control technology will reap long-tem beriefits.

4. Laser Welding - Low potwer. Laser welding using Nd:YAG or low power $\mathrm{CO} 2$ techrology is becoming increasingly important in the automotive, aerospace, and electronics industrics. Similar techmology has important implications with respect to cutting and surface modification. The U.S. and Germany currently have a slight technological advantage over Japan. Significant technological advances in this area will provide the U.S. with a manufacturing capability that will impact a wide range of industries. R\&D funding directed at novel energy generation and beam detivery systems will have the most impact.

5. Repair Welding. Although not considered a primary manufacturing technology, repair welding is critical to every industry sector except electronics. White relatively mature in the heavy manufacturing industry improved repair welding tectunology could provide significant economic advantage in the aerospace, power generation and petrochemical industries. The technology is globally homogeneous, with no country investing significantly in repair welding $R \& D$.

6. Pipeline Welding. This technology is critical to petrochemical and process industries. The U.S. is the world leader in this area and has invested significantly to gain that advartage. The technology is essentially mature, sustained investment will allow the U.S. to maintain its leadership against primarily European competition.

7. Surface Mount Technology. This technology is unique, and critical to the electronics industry. Japan leads both the U.S. and Germany in the development and implementation of SMT. All have devoted considerable resources to this technology and the U.S. will need to increase funding in this area to remain globally competitive in the electronic packaging arena. 
8. Electronic Component Joining. This broad technology includes a number of subtopics including wire bonding, resistance joining and die attach techniques. U.S. technology is essentially equivalent to that of Japan and Germany, and our introduction of technology into manufachuring is competitive. Research furding in the U.S. in this area is variable, depending on the specific: process. Sustained $R \& D$ support is needed in these process areas to maintain our global competitiveness.

9. Plastic Joining. Plastic joining technology is currently important and will become enabling in the automotive, aerospace, and petrochemical industries in the very near future. U.S. technology is equivalent to Japan's but slightly behind Germany's. Despite the perceived future importance of these materials the U.S. has devoted only modest R\&D funds to develop joining technology. Significant R\&D support will be required to increase U.S. capability and competitiveness in this important manufacturing area.

10. Adtresioe Joining. This technology is becoming increasingly important in the automotive, aerospace and electronics industries. The technology is extremely immature in the U.S. and we trail Japan and Gemany in both technological development and implementation. R\&D investment in the U.S. is increasing, but still lags our competitors. Significant gains can be achieved by increasing $R \& D$ support in this area.

\section{Summary}

This assessment has focused on the joining and assembly process technology. It should be recognized that materials technology significantly impacts joiring and assembly. For example, mature process technology developed for steels may be inadequate for advanced materials. Process adaptability is an important, and often overlooked, issue when considering materials joining. In general, the U.S. is a recognized leader in the development and implementation of advanced materials in manufacturing. This is especially true for advanced zerospace materials such as aluminum-, titanitum- and nickel-base alloys, intermetallic alloys, and composites. Our position is more tenuous with respect to structural steels and corrosion-resistant alloys where both Japan and Germany maintain a slight technological advantage. In terms of electronic materials, the U.S. is the recognized leader in the development of new and improved materials, but is not as effective in implementing these materials into manufacturing.

The issues of design and fitness-fot-gervice are also integral to joining and assembly technology. Improved design capability and the development of methods to predict the service life of welded components have serious implications with respect to product quality and associated competitiveness. While the U.S. has made recent progress in these areas, we still trail the Japanese and Germans in integrating joining and assembly technology into product design. This should be an area of concentration and increased $R \& D$ funding over the next few years. 


\title{
RELIABILITY: MAINTENANCE AND REPAIR TECHNOLOGIES
}

\author{
Landon Grady \\ Motorola Corporation
}

\section{Introduction}

The ultimate goal of R\&D in maintenance and repair technologies is to end product defects, rework, scrap, and production stoppage, all of which are manufacturing costs. Reducing manufacturing costs makes a product less expensive and more competitive. Development of maintenance and repair technologies is important because maintenance is currently considered the largest controllable cost in manufacturing. Not only is the quality of the product of concem, but disruption of tightly scheduled production reduces efficiency and causes problems for just-in-time customers. The ultimate goal will never be reached because machines loose adjustment and wear out. Planning and implementation of maintenance and repair technologies for isolated equipment has become critical for equipment suppliers. Their customers, the manufacturers, carefully consider these equipment features. Maintenance schemes for isolated equipment become ineffective as manufacturing processes become increasingly complex. Integration of equipment is requiring a systems approach to maintenance, often designed by the suppliers, the manufacturing company, and private consulting firms on a case-by-case basis. Implementing and upgrading maintenance and repair technologies requires a large investment that accounts for the wide diversity in the sophistication of technologies now in place throughout industry. The investment pays off through:

- Identifying equipment problems in the maintenance planring stage;

- Scheduling adjustments and minor repairs.

- Minimizing the amount of maintenance.

- Predicting remaining useful litfe of equipment, etc.

Krowledge of the reliability of the production system provides confidence in production capability. All of the related technologies used and under development in Germany, Japan, and the U.S. require different levels of knowledge regarding the marufacturing process. It is useful to consider this knowledge in three parts: process stabilization, process control, and process change/improvement.

Process stabilization includes monitoring, documenting, disseminating, and institutionalizing information. Control points are established for data collection. The key is an adequate system model. The model places data in 
context, making it useful as information. The model can be as simple as a manufacturing process flow chart. More complex models include guidelines for what machines are supposed to do, what sensor data should be, and how machine functions affect data changes. Sophisticated models include descriptions of the dynamics of components as well as micro-mechanical failure modes. Intricate system modeling is currently being promoted due to the trend towards full design on computers prior to actual prototyping or manufacturing. Researchers are discovering that software technologies used to control hardware are consistent with projecting hardware design performance using software.

Process control includes instrumenting, measuring, and analyzing the system for detection, diagnosis, and prognosis. Linking instruments (e.g., sensors) with reactive elements which change the sensor' reading (e.g., actuators) to give useful measurements can be complex. Recognition of the synergy among data from multiple sensors is important for signal processing and analysis as degradation may occur on various paths. In all cases operation criteria and performance thresholds are essential. Cause and effect diagrams are useful in analyzing these inherently multiparameter situations. The depth of interpretation of performance degradation (i.e., "failure trajectories") determines the finesse of reliability predictions.

Process changelimprooement includes decisions to act, make adjustments, confirm information, and automate improvements. Given information in the appropriate context, operators can make informed decisions in real time, recognizing not just the problem but also the cause. Approximate reasoning (induding "fuzzy logic") is a current research area. This research will enable an expert system to make operational decisions leading to machines capable of intelligent reasoning and control.

\section{Technologies}

1. Rework. Rework technologies are developed specifically to reduce product scrap generated when a process problem occurs. A typical sequence is inspection of product for rejects, sorting correctable rejects from scrap, and then reworking the correctable product. Rework technologies are necessary when manufacturing process problems are not understood or not corrected. Decades ago the difficulty may have been foreseeing the cost of solving the problem and any additional equipment cost for the company. Today manufacturers recognize that prevention of waste is more efficient in the long nun then "inspecting quality into the product". Rapid change in process equipment and product designs generates new problems that may be worked out iteratively on-line. Meanwhile delivery of product may be required. There are situations where rework will continue to be a necessary manufacturing technology. Flexibility in production equipment is encouraged especially for online error recovery strategies. 
2. Repair. Repair refers to a product which has failed after passing inspection. In the manufacturing environment, repair usually involves process equipment which has failed in use. The equipment anchitecture establishes the modularity and standardization of comporents for replacement. Repair by replacement of components is made efficient by considering potential problems during design. Preparing for a repair situation during design is facilitated by failure modes and effects analysis.

3. Failure modes and effects analysis (FMEA). Failure modes and effects analysis is important to both repair and maintenance. The development of a performance model to which sensor data can be refexenced is essential. The analysis attempts to identify sources of equipment malfunction and to collect pertinent information used in improving the design and maintenance procedures. Equipment suppliers are increasingly providing maintenance and repair manuals in PC software form. Problem solving techniques are generally included that ask questions and guide an operator. Significant prior FMEA and an understanding of the operation environment by the suppliers is required to prepare useful programs.

4. Maintenance. Maintenance attempts to keep or to restore equipment to a desired performance level. Simplicity of adjustments and adequate maintenance scheduling are important. Factors which lead to specification of excessive maintenance include low feedback on performance, changing operating environments, and unknown skill level of the operator performing the maintenance.

5. On-line predictize maintenance system (ONPMS). On-line predictive maintenance consists of a machinery surveillance system which both detects and monitors the progression of a symptom that has been deternined to be part of a failure trajectory based on a reference model. These systems can supplement or replace periodic monitoring. Prior to installation, methods to sense and monitor machine condition using signal analysis must be developed. The operator is provided with data regarding the onset of a suspected problem that is used to warn when maintenance is needed. These systems have proven useful in the chemical industry by eliminating hazardous incidents involving equipment failuxes.

6. Condition-Based Maintenance (CBM). The technologies required for on-line preventative maintenance are extended in condition-based maintenance to allow prognosis of operating condition and prediction of lifetime. The information and models used require a much greater degree of process defirition and operational certainty. Additional information is required regarding material properties related to failure propagation, machine control arrangements, wear mechanusms, model-based prediction techniques for dynamic systems, etc. The goal of CBM is to predict the extent of maintenance 
required at any specific time based on the condition of the system. Prognosis and prediction of operational lifetime provides a significant planning tool both for critical maintenance and for production volume-

7. Self Maintenance Machine (SMM). This technology is ideally suited for machines linked to $\mathrm{PC}_{5}$. Alternate physical pathways of operation are developed in the machine architecture. The machinecomputer combination is preprogrammed to choose an alternate path when adjustment and maintenance in needed through motitoring, fault judging, fault tolerance, and fault avoidance. Functional redundancy is provided by manipulation of two or more control parameters to sustain adjustment. Part redundancy in self maintenance machines enables continuation of successful operation once a failure occurs. Both provide for warning and time for repair to return the machine to the original operation mode without \$hutdown. 


\title{
MACHINE TOOL TECHNOLOGIES
}

\author{
Thomas M. Barlow \\ National Machine Tool Partnership Site Manager \\ Lawrence Livermore National Laboratory
}

\section{Background}

During the period of 1981-1991, the United States saw its machine tool industry slip from a position of leadership to fourth place, behind Japan, Germany, and Italy. While the US position slipped, that of its international competitors gained strength. According to a study by the MIT

Commisston on Industrial Productivity, several causes lay behind the industry's der-line:

- fragmentation or, in the case of conglomerate ownership, neglect;

- failure to invest consistently in research and development;

- short-term profit orientation of conglomerate owners of machine tool companies;

- pressure from the financial community toward shorter term investment;

- a cyclical market and the backlogging of orders to stabilize employment;

- lack ol a strong market demand for technological improvement;

- initially ovex-complex electronic control systems; and

- university curricula which emphasized science rather than manudacturing.

In contrast, the German and Japanese industries were strengthened by govermmental action. In Japan, the Ministry of International Trade and Industry (MIT) encouraged consolidation and specialization and the deployment of technology to its manufacturing industry. MITI also subsidized the machine tool industry to develop its export market. Germany similarly followed a central strategy to assure a position of leadership for its industry, emphasizing precision and specialty tools and employing ${ }^{t t}$ cooperative specialization, ${ }^{\prime \prime}$ in which firms specialize in a limited product line. The German industry developed and deployed its technology base. As with Japan-but in a different style-the Geman govemment supported its machine tool industry.

The national approaches can be summarized as follows: 
Today the US industry remains fragmented and short of capital. Some $85 \%$ of its companies employ less than 100 workers; in many of these, capital for maintaining a strong technical base and longer term development is either scarce or nonexistent. In contrast, the German and Japanese industries have established a worldwide presence and reputation for development. Japan has established "transplant" operations in the United States, and Germany has plans to establish Fraurhofer Institute sites in at least three areas of US manufacturing strength. The Japanese industry, having seen pressture on its "low-end" machines from developing nations, has expanded its exports to include flexible manufacturing systems and precision machiring capabilities-thus presenting a challenge to the German niche.

\section{Technologies and Technology Investment}

Although new technology is not currently a high priority for most US machine tool builder companies, they do generally recognize the need. According to the Association for Manufacturing Fechnology and other sources, the following are currently considered to be the most important areas in machine tool technology:

- materials, in the context of machine, tooling, and workpiece

- machine tool controls, specifically open-architecture control systems

- machine tool structures, including both statics and dynamics

- precision machining

- high-speed machining (tools and components)

- in-process sensing and control

- workpiece holding and handling

- predictive maintenance

- advanced drives

- environmentally responsible manufacturing

Japan-to the best of our knowledge-is active in most of these areas. The Japanese have continued to pursue advanced technology. Although they based their early success on reliable, low-priced, standard machines, they have since moved into more complex machines with a higher technology content and greater capability. Their corporate specialization has enabled them to virtually control some segments-such as controllers-thus providing the resources needed for development in those areas.

The German industry is perhaps best known for its work in developing precision machines and machining technology, but it, too, maintains a 
broad research program notably through its Fraunhofer Institutes. However, to the best of our knowledge, the German industry's primary focus continues to be that of precision.

In contrast, the US research and development program in machine tool technology-like the industry-is fragmented and underfunded. All but a few companies emphasize the short term. Technology development occurs primarily to meet specific purchase orders. Longer term research is conducted, for the most part, in the universities and government laboratories, which maintain high quality programs-albeit with limited funding. Increasingly, companies within the industry are entering into collaborative efforts, with both universities and national laboratories and through such industry/government-funded organizations as the National Center for Manufacturing Sciences.

Regarding the deployment and use of technology, many experts agree that the US ranks highly in its research and technology development effortswhen funding is available-but trails in bringing its technology to the marketplace. In contrast, both Japan and Germany seem exceptionally adept at implementing their technological developments. At this time, Germany appears to continue to hold the lead in the application of precision to machine tools-although the japanese are showing significant progress and several US companies have strong capabilities. Similarly, Japan has maintained its leadership in developing, manufacturing, and implementing machine tool controls.

In a general sense, comparable machine tool technologies are available worldwide because of the relative freedom of international trade and information exchange and the emphasis on exports. There is, however, a significant feeling in the US that both Japan and Germany hold back their latest technolngy from the world market, thus providing their manufacturing industries with an advantage over offshore competitors. 


\title{
INTELLIGENT MACHINES IN MANUFACTURING: SENSOR AND CONTROL TECHNOLOGIES
}

\author{
Del Tesar \\ Center for Robotics, University of Texas-Austin
}

\section{Background}

The overall objective of integrating advanced sensor and control technologies in intelligent machine systems is to provide a new generation of manufacturing capabilities. Today, virtually all of our manufacturing systems exhibit a technology similar to the monolithic, very expensive, and dedicated computer systems of the 1950 's (i.e, they are 30 to 40 years out of date). The goal must be data base driven systems recently conceptualized by "agile manufacturing." This is possible today because of the availability of computational resources which by the year 2000 will be represented by a 1000 megaflop system controller as a $\$ 5000$ commodity. This enables the system designer to revolutionize the infrastructure of intelligent machines, pursuing high value added tasks, broadening the application spectrum (say by $10 \mathrm{x}$ ), the speed of operation by $10 x$, overall performance by $1000 x$, and reducing life cycle costs by $3 x$. Heavy industrial manufacturing may be represented by machine tools. The equally important light industry (precision and high quality products) may be represented by the modem intelligent machine (conceptually, the industrial robot). For a machine to be intelligent, advanced sensor and control technologies must be effectively employed to ensure that the required performance (precision, speed, force, durability, etc.) is achieved.

\section{Companent Technologies}

To do so will require technical development in the following component technologies:

1. Modular Architectures. A true modular architecture can reduce life cycle costs (repair, tech mods, logistics spares planning, etc) and dramatically increase performance. It is ptoposed to assemble and reconfigure a broad spectrum of systems from a very small collection of proven and optimized modules at much lower cost (as is now the case for the personal computer). This would unfetter the system designer to more freely and quickly develop manufacturing systems to satisfy emerging market demands.

2. Foult Tolerance. Fault tolerance is increasingly used in aircraft, computers, nuclear reactors, etc. but it is virtually non-existent in 
manufacturing systems. It requires a whole new architecture which provides alternate physical pathways (at several independent layers) so that faults can be avoided while maintaining precision operation. A decision making system reconfigures resources (actuators, sensors, communication links, etc.) to avoid an imminent fault (or system failure). This architectural requirement must be the driver of all other technical development.

3. Fault Detection and Isolation. FDI represents the ability of an intelligent machine to detect and identify the location of a fault within its structure. It builds on the spectrum of data provided by its sensons, signal processing, and analysis of its performance relative to a real time mathematical model reference. A discrepancy triggers an identification procedure to locate the fault from within a predetermined and fitite fault tree.

4. Miniaturized Sensors. For a machine to be intelligent, it must be "aware" of its internal condition as well as the effectiveness of $i t s$ task performance. Present intelligent machines are operated on the basis of minimal real time parametric information primarily due to the high cost of the sensors and the computational demands required of sensor data fusion. Future systems will require an excess of postage stamp sensors distributed throughout the operational structure. These sensors will provide their own local data processing in a hierarchical information architecture.

5. Actuatiors. Present actuator technology for intelligent machines is largely unchanged since 1965 except for the utilization of rare earth motors and improved electronic controllers. The role of actuators in inteligent machines is equivalent to computer chips in computers. Advanced technologies must be integrated into a carefully designed class of actuator modules made up of dual motors, brakes, gear drives, clutches, sensors, electronic controllers, etc.

6. Electronic Controllers. An intelligent machine will involve the real time processing (in less than 5 millisec.) of an enormous amount of information to provide a comparative performance index for the required manufacturing tasks. Technology for the operator user interface, the system controller, and the information communication network can be leveraged from other aggressive fields of development. This is not true for the electronic controller for the actuator which must meet all the local data prosessing needs issociated with a fault tolerant, dual actuator capabie of enhanced performance (say 10x) without load saturation.

7. Task Performance. An intelligent machine must provide an assured level of task performance to meet requirements of a given manufactured product. To do so involves the real time integration (fusion) of numerous performance criteria (say 100) to yield an index of performance to compare with the required performance associated with the product. This fly-by-wire approach to 
intelligent machines is not only rare (almost non-existent) today, it is the only viable method of control for the future. This means that virtually all existing methods of control have to be removed from our present academic setting and a whole new class of operational control software must be developed.

8. Metrology. Performance criteria can have no meaning without an accurate model reference of the system which must be built upon an accurate parametric description of the "as built" stnicture (dimensions, compliance, mass, control gains, etc.) of the intelligent machine. This means that a full spectrum of measurement methods must be developed to accurately obtain these parameters for each and every component of every machine. Thus far, system metrology has proven to be too laborious and expensive. Use of metrology at the correct modular level will be required to economically treat this existing barrier.

9. Control Software. Conceptually, the purpose of control technology is to assure that a level of performance is being met.

Unforhunately, present feedback control is based on the simple concept of machine stability which is unrelated to a required level of performance normally associated with manufacturing. Feed forward control, model reference, criteria fusion, and sensor data integration are the future of inteligent machines but they all require a unique real time control software based on object oriented structures- quite removed from the simulation software experience of most engineers.

10. Man-Machine Interface. Increasingly the interface between the machine and the human operator is being recognized as a key resource to maximize overall performance and to train (skill) the operator. This can only be done if all of the resources of the intelligent machine (selection of on-board sensors, performance criteria, performance priorities, etc.) are put at the disposal of the operator through an advanced kinesthetic interface supported by a strong Graphical Usex Interface (GUI). Thus far, the operator has been considered as only incidental to the actual performance of the manufacturing system.

\section{Development Trends}

Based on the above ten component techrologies, it is possible to assess the relative technical activity in intelligent machines for manufacturing among three major industrialized nations: Germany, Japan, and the U.S. The rankings ( 3 ranks high while 1 ranks low) shown in Table 3.6 are an estimate of this relative activity. The low values of these rankings suggests that no country has aggressively attacked the required technologies associated with advanced intelligent machines for manufacturing. 


\section{Homogeneity of Technology}

Here an estimate will be given on the uniformity of the development of the component technologies found in the three countries under consideration (see Table 3.6). A value of 3 indicates a great similarity to the U.S. activity while a value of 1 means little or no common development activity with the U.S. The conclusion here is that Germany has some development in common with the U.S. but that Japan has little in common with the U.S.

Table 3.6. Rankings of Sensor \& Control Technologies.

\begin{tabular}{|c|c|c|c|c|c|c|c|c|}
\hline \multirow[t]{2}{*}{$\begin{array}{l}\text { Compontent } \\
\text { Technology }\end{array}$} & \multicolumn{3}{|c|}{ Development Trends } & \multicolumn{2}{|c|}{$\begin{array}{c}\text { Homogeneity of } \\
\text { Tochnology }\end{array}$} & \multicolumn{3}{|c|}{ Status of Technology } \\
\hline & Gomatioy & Japtin & U.S. & Corituriny & Japin & Cotmany & Jipant & U.S. \\
\hline $\begin{array}{l}\text { 1. Modular } \\
\text { Architecturess }\end{array}$ & 2 & 1 & 2 & 2 & 1 & 1 & 1 & 1 \\
\hline $\begin{array}{l}\text { 2. Fault } \\
\text { Tolerance }\end{array}$ & 1 & 1 & 2 & 1 & 1 & o & 0 & 1 \\
\hline $\begin{array}{l}\text { 3. Fault } \\
\text { Detection } \\
\text { and isolation }\end{array}$ & 2 & 1 & 1 & 2 & 1 & 1 & 0 & 1 \\
\hline $\begin{array}{l}\text { 4. Miniaturized } \\
\text { Sensars }\end{array}$ & 1 & 1 & 1 & 1 & $t$ & 1 & 1 & 1 \\
\hline 5. Actuators & 1 & 2 & 1 & 2 & 2 & 1 & 1 & 1 \\
\hline $\begin{array}{l}\text { 6. Electronic } \\
\text { Controllers }\end{array}$ & 1 & 2 & 2 & 2 & 2 & 1 & 1 & 1 \\
\hline $\begin{array}{l}\text { 7. Task } \\
\text { Perfomance }\end{array}$ & 1 & 1 & 1 & 2 & 1 & 0 & 0 & 0 \\
\hline 8. Metrology & 2 & 1 & 2 & 2 & 1 & 1 & D & 1 \\
\hline $\begin{array}{l}\text { 9. Control } \\
\text { Soltware }\end{array}$ & 1 & 1 & 1 & 2 & 1 & 1 & 0 & 1 \\
\hline $\begin{array}{l}\text { 10.ManMachine } \\
\text { Interface }\end{array}$ & 1 & 1 & 2 & 1 & 1 & 0 & 0 & 1 \\
\hline Average & 1.3 & 1.2 & 1.5 & 1.7 & 12 & 0.7 & 0.4 & 0.9 \\
\hline
\end{tabular}




\section{Status of Technology}

The Table also provides a relative ranking of the present implementation of the listed advanced component technologies for intelligent manufacturing systerns in Germany, Japan, and the U.S. The number 3 indicates a high level of implementation while 0 indicates virtually no implementation. The rankings provide an unusually pessimistic judgment on the actual implementation of the required technologies for an agsressive intelligent manufacturing infrastructure in these three countries. It may also suggest that proper investment in R\&D could be extremely rewarding at this time. In order to improve the U.S. competitive stance in manufacturing, it is recommended that a national program concentrate on intelligent machines operating with the full integration of advanced sensor and control technologies as outlined. 


\title{
ENVIRONMENTAL INTEGRATION AND TECHNOLOGIES
}

\author{
Guna Selvaduray \\ San Jose State University
}

\section{Introduction}

Germany, Japan, and the United States are all working very seriously on environmental technologies and integration into manufacturing. Also to be noted is the fact that there are a numbet of other countries that are also doing research and development in related areas. Overall, it is very difficult to determine if any one country is ahead of any other in these areas. Information exchange between countries on environmental research and technologjes is very open.

The manner in which environmental technology programs have been instituted and are managed differs from country to country. Of the three countries (U.S.A., Japan, and Germany), manufacturers in the U.S.A. probably have a distinct advantage in terms of information dissemination and technology transfer. In the U.S.A., computerized databases are rather common today, and most scientific personnel are aware of this and take advantage of it. Japan has notably poor information exchange among the manufacturing companies, and it is necessary for some government agency to take on this role. The Japanese model of centralized decisionmaking, with the Ministry of International Trade and Industry (MTT) taking the lead, has become quite well known throughout the world. MITI is dedicating a significant amount of resources to developing environmental techuologies for the manufacturing industry. While the U.S.A. does not have an agency equivalent to MITI, there are a number of other organizations in the U.S.A. that do provide dírection. These include the National Science Foundation, the National Academy of Sciences, and the Environmental Protection Agency, and the Department of Energy. There ane also state agencies that provide direction in this area, though their immediate goals tend to be focused on their respective states. In the case of Germany, especially in recent years, the direction for research and development in environmental technology is being provided at the "European level." This mears that the European nations are in the process of forging a common set of standards and goals for all of them to meet. Social pressures in Germany have led to a tremendous number of laws and regulations which are driving industry to develop and implement environmental improvements. 


\section{Technology Research Areas}

The area of environmental and safety technology presents a wide variety of research and development needs. While not intended to be comprehensive, the following is a listing of some areas that are considered to be important.

1. Process Improventents, Modifications, \& Optimization. Rather than attempt to clean the wastes from a manufacturing process it is most expedient to modify or improve the process so as to minimize the generation of waste. This attacks the problem at the source. Process improvements include attempts to obtain "100\% efficient" processes that produce no wastes. In such procesees, all by-products of unit operations would be utilized as feed materials for other unit operations ejther within the same process or in other processes. This should include improved manufacturing techriques, quality control techniques, and recycling techniques.

2. Process Design. There is a dire need to incorporate environmental concers and performance into processes at the facilities design stage to ensure construction of environmentally safer facilities.

3. Biotechnology \& Bionemediation. This is a newly emerging area that is very promising. Use of appropriate anaerobic and aerobic digestion techniques appear to be very promising for environmental cleanup of contaminated areas, with no apparent "side-effects."

4. Analytical and Sensor Technologies for Low Concentrations. There is a need to develop reliable analytical and sensor techniques capable of detecting low concentrations of heavy metais and organics in the field.

5. Productioe Use of Waste Materials. There is great opporturity for tuse of waste materials from one process or industry as a feed material for other purposes. One example is the use of waste glass as filler material in road construction. There is a need to do research on similar opportunities in other areas. One of the main sources of waste material today is from residences which frequently participate in community curbside recycling programs. The utilization of the materials collected, by industry, is still far from adequate. The City of San Jose has begun an ambitions program to develop a "green industry" base in the gxeater Sar Jose area, and this could be an example for other communities and manufacturers to follow.

6. Intorporation of Computer Technology. There are a number of areas where existing computer technology can be productively 
utilized. One such area is in simulations: computer models of environmental effects covering longer time spans and multiple sources need to be built. Artificial intelligence, combined with flexible robotics and sensors, needs to be developed for monitoring the environmental performance of manufacturing processes. Another potential area for application of artificial intelligence is process control and waste minimization. Networks can be used very effectively for dissemination of information and technology transfer. The construction of an environmental technology database with on-line availability will play a major role in determining the speed with which information dissemination occurs.

7. Alfernate Materials and Chemicals. The effect of carcinogenic solvents and CFCs, commonly used as industrial cleaners and refrigerants in manufacturing processes, is of great concern world wide. A number of aqueous-based cleaners have been developed, but with mixed results. There is need for further research in this area. The main alternative refrigerant at the present time is ammonia, which is toxic. There is also a need to develop envinonmentally conpatible refrigerants. Research into the use of alternate raw materials is required. Externsive use of certain raw materials can result in damage to the environment. A case in point is tropical hardwoods, where the development of alternate raw materials for manufacture of wood products will reduce the consumption rate of tropical hardwoods, and thus reduce the consequent environmental damage. Similarly examination of the degradation mechanisms of organic chemicals (including herbicides and pesticides) will continue to lead to alternate chemicals with shorter lifetimes which will not permanently damage the environment.

8. Altemate Energy Sources. The use of alternate energy sources has been a topic of restearch for many year's, with little fruition to date. Environmental pollution in Tokyo was greatly diminished by using natural gas instead of crude oil in building heating and cooling. Research aimed at commercializing non-polluting sources of energy and minimizing energy consumption in manufacturing processes is still a requirement.

9. Energy Storage Methods \& Materials. This area has also been the subjert of intensive reseanch for several years, with little fruition to date. There is a need to develop energy storage methods and heat exchangers, particularly those that will be compatible with alternate energy sources. This effort will rely heavily on materials compatibility research.

10. Total Life-Cycle Cost Analysis. An analysis of whether paying higher capital costs for advanced technology with low operating and/or environmental costs is advantageous over paying lower capital 
costs for conventional technology with higher operating and/or environmental costs will be necessary to convince manufacturing industries to pursue technologies that ate environmentally sensible. Part of this approach will need to address concepts of product life-cycle assessment and concepts of total/real cost to society, rather than simply direct cost to the company. This type of analysis can identify critical areas of concern so that as new beneficial technologies are developed, they can be quickly implemented. In general, larger companies are more selfmotivated to implement environmentally safe practices. Small and medium-sized companies generally lack the resources to develop their own environmental technologies. Availability of technologies suitable for implementation by small and medium sized companies, through consultants and technology transfer, should therefore by a priority.

11. Curriculum Development. Most institutions of higher education do not have adequate curricula for training their students in areas pertaining to environmental and safety technology. There is a need to pursue this aggressively, especially for engineers and scientists who will be employed in manufacturing and related R\&D.

\section{Summary}

Overall, the question of which of the three countries (U.S.A., Germany and Japan) is ahead of the others is not of great consequence. The effort in all three countries is significant. Given the current means of rapid information dissemination, especially the ready availability of databases, the environmental research that is underway and the accomplishments at manufacturing companies can become available to others within a very short time span. Rather than being concerned with competitiveness between countries, it is more important for each country to continue developing and implementing the environmental and șafety technology that is appropriate for its own society, according to its societal needs. 


\title{
SAFETY DESIGN CONSIDERATIONS
}

\author{
Peter J. Boden and M. Matthew Vlasaty \\ Underwriters Laboratories Inc.
}

\section{Introduction}

Safety design considerations involve reducing the risk of a hazard which could cause ham to a person or the environment. The pursuit of risk reduction should generally involve three stages: 1) attempt to eliminate the hazard, 2) guard against the hazard occurring and 3) warn the user about the hazard.

Safety must be addressed during the design, development, installation, use, and maintenance of a product or system. In reducing the risk of a hazand occurring, the potential for irjury and damage must be identified. Injury or damage generally occurs when a transfer of energy takes place between a product and a person. Energy can take on various forms such as mechanical, electrical, chemical, etc. In designing for safety, the first step often involves trying to design the hazard out of the product. For example, removing a sharp edge from a product eliminates a cut hazard. If for various reasons, the hazard cannot be designed out of the product, the next step un safety design is to guard against the injury occurring. A physical barrier to prevent or minimize contact with a sharp edge is an example. A third step that may be necessary is to warn a user that a hazard exists. For example, if a product has a sharp edge which must be exposed to pennit a product to function as intended, a warning of the existence, consequences, and avoidance procedures would be appropriate.

In determining what measures must be taken to reduce risk to an acceptable level, safety standards must be considered. At a minimum, these standards must include nationally recogrized standards applicable to all countries in which the product will be sold. Depending upon the product involved, some countries will have mandated standards to regulate products within critical product sectors such as transportation or medicine. Other standards may be voluntary, but by complying with such standards, the manufacturer can assure his customer that minimum: requirements for safety are being met. Such standards are important because they are typically developed through a process which involves a wide spectrum of suppliers, users, and regulatory interests. Standards developed in this manner permit safety to be addressed in a broad context. When safety is involved, customers often require a third party, like Underwriters Laboratories Inc. (UL) to "certify" and mark the product attesting that a manufacturer's product complies with a given set of requirements. 
In safety design, problems can occur when there is a shift from the use of proven methods to a new technology. This trend continues for the most important technological issues that designers face today. The trend of replacing electromechanical devices, such as switches and relays, with electronic devices and microprocessors has resulted in two of the most challenging technological issues, software safety and electromagretic compatibility (EMC). The use of software to perform safety-critical operations is changing the methods used to design and investigate the safety of products because software's analytical properties cannot be tested with the present methods used to test physical properties of nonsoftware-based products. Whether a product is designed to emit an electromagnetic field (e.g., a cellular communication device) or not, alt products using electronic devices can be sources of electromagnetic interference (EMI). As microprocessors and electronic devices are also susceptible to EMI, EMC is an important safety design consideration. Another safety issue that is currently challenging designers is the product's environmental impact; for example, the use of refrigerants that contain ozone depleting chlorofluorocarbons (CFCs). Due to the effects CFCs are reputed to have on the environment, designers are exploring recovery/recycling techniques, ușing alternate refrigerants, and designing products to make them more efficient with less refrigerant. These safety issues, EMC, software safety, and sensitivity to the environment, are viewed as being important safety issues at this time because of their potential to impact every aspect of our tives.

\section{Homogeneity of Technology}

To be competitive in today's global marketplace, manufacturers need to be aware of international product safety conformity assessment requirements. Many countries have specific safety requirements; however, international activity continues to develop and harmonize safety standards and conformity assessment practices. The ulbimate goal of international standardization is acceptance of a single product worldwide. Multinational acceptance of safety testing procedures and test data result in harmonization. This acceptance of procedures and data can be used to obtain safety certifications from many countries which allows manufacturers easier access to world markets.

Organizations in the forefront of developing international safety standards include the International Electrotechuical Commission (IEC) and the International Organization for Standardization (ISO). These international organizations work to develop safety standards for acceptance of products worldwide. The IEC and ISO develop consensus stardards based on the national interests of the member countries. The ISO Committee on Conformity Assessment, CASCO, develops guides dealing with the use of techrical standards in conformity assessment. A mission of the European Union (EU) is to ensure that only products that are deemed safe are allowed to be marketed in the member countries. 
U.S. and German testing organizations like UL in the U.S. and VDE and TUV/PS in Germany, are actively working together to establish mutual recognition of testing facilities and test data. This mutual recognition is one step in enhancing freer trade between the EU and U.S. markets and global acceptance of products. Marketing many products in Japan requires Japanese Miristry of International Trade and Industry (MITI) approval. $\mathrm{M} \Gamma \mathrm{TI}$ relies on Japanese testing agencies for safety testing in many product categories. UL is the first laboratory outside of Japan designated by MITI to condtuct product safety testing and factory surveys as a Designated Inspection Agency.

Working knowledge of how foreign countries deal with product safety has been collected and structured into a seminar given by UL called, "Globalability: The Key to International Compliance." With this seminar, manufacturers can gain an understanding of the homogeneity of safety requirements, standard harmonization, and product safety requirements in foreign markets including those in Germany and Japan.

\section{Status of Technology}

As evidenced by the quantity of safety standards published by numerous national and international organizations such as UL, IEC, ISO, VDE and others, the technology and techniques for safety design are at a high level of maturity for established products. This is not always true, though, for emerging technologies. Safety design and testing methods for emerging technologies typically lag behind the manufacturing aspects of the design for performance, reliability, and implementation. However, with computer assisted design and modeling, the ability to address potential risks early in the design process has become possible. While products using safetyrelated software are being developed worldwide, efforts related to the technology development and research on the design and evaluation of such software are predominant in the US., Germany, and other EU countries. One approach that is being used by industry and safety testing organizations Ijke UL to address safety issues of new technologies is to enter into colbaborative relationships with U.S. national laboratories and other government agencies. The aim of this collaboration is to transfer technology that has been developed with government funding to manufacturers for the design and evaluation of safety-critical products. By publishing standards for new technologies and conducting collaborative research, these efforts can assist manufacturers in developing state-of-theart practices for the safety design and evaluation of products. 


\title{
MANUFACTURING STANDARDS
}

\author{
Matthew K. McLean \\ U.S. Government Techunology Analyst
}

\section{Entroduction}

Have you ever tried to start your car with your house key? Have you ever tried to order a Big Mac at Wendy's? If so, you know the frustration which many manufacturers and their suppliers experience as they work with a wide variety of vendors and products, each with their own designs, formats, and protocols. The effort to get parts, tools, or data to work properly in a new or different system is expensive, time-consuming and often inadequate. The goal of data standardization is to establish a neutral file exchange mechanism, thereby creating an environment wherein various manufacturing systems can seamlessly accept, use, and send information between various vendors, suppliers, and manufacturers.

A number of industry joumals cite the ability to effectively and accurately exchange digital product information as the key element to vastly improve tomorrow's industrial productivity and competitiveness. Perhaps the most difficult challenge facing manufacturers today is not only the standardization of manufacturing processes, equipment, and computer data, but ultimately the integration of these technologies, as well. This problem is more than a challenge, however, $j$ is an opportunity. The inability to effectively and accurately communicate manufacturing information between unlike systems is a particularly sticky issue as it relates to computer-aided design and manufacturing (CAD/CAM) and other factory automation technologies. Although standardization encompasses much more than CAD/CAM, these tectunologies are the centerpiece of much of the manufacturing standardization effort. The most popular U.S. standard for exchanging mechanical design data is the Initial Graphics Exchange Standard (IGES). First published in 1980, IGES concentrates on neutral data formats for CAD systems. IGES, however, is generally not considered stritable for sapturing data for the entire product life cycle. According to a 1993 survey by DataQuest, new product data standards are needed as industry is not satisfied with current standards and means of transferring data.

\section{STEP}

The most significant movement underway to facilitate the standardization of manufacturing is the development and 
implementation of the Standard for the Exchange of Product Model Data, commonly referred to as "SFEP". STEP is an emerging international data exchange standard that goes far beyond accurate transfer and translation of CAD/CAM data. Using a computer language called EXPRESS, STEP seeks to encompass the entire life cycle of a product from design through manufacturing, testing and analysis, maintenance, and disposal. The initial development of STEP was focused on standardizing the definition of mechanical parts. It has since been expanded to applications in other product areas including electronics, architectural, construction, apparel, and chemical process industries. The fundamental components of STEP are the "application protocols", which are the integrated packages that translate and transfer data for a particular domain, such as drafting or numerical control.

\title{
Application Protocols Within STEP (Source: DataOuest)
}

\author{
Explicit Drafting \\ Associative Drafting \\ Mechanical Controlied Design \\ Mechanical Design using Boundary Representation \\ Mechanical Design using Wireframe Representation \\ Sheet Metal Die Planning and Design \\ Life Cycle Product Change Process \\ Design through Analysis of Composite and Metallic Structures \\ Electronic Printed Circuit Assembly: Design and Manufacture \\ Electronic Printed Circuit Assembly: Test, Integrated Diagnostic, \\ and Remanıfacture \\ Electrotechrical Plants \\ Numerical Control Process Plans for Machined Parts \\ Core Data for Automotive Mechanical Design Processes \\ Ship Arrangement \\ Ship Molded Forms \\ Ship Piping \\ Ship Structures \\ Inspection Process Plans
}

The STEP effort involves a number of organizations, consortia, and committees worldwide. Many U.S. industry and government organizations are actively pursting the development, testing, and implementation of manufacturing data standards, with a focus on STEP. The primary players for the United States include:

- The IGES/PDES Organization (IPO) was established to develop data standards and provide a forum for exchanging information regarding STEP by the American National Standards Institute (ANSI), 
- The international Standards Organization (ISO) is the international body which approves, establishes, and maintains industrial standards worldwide.

- The U.S. Product Data Association (USPRO) orgarizes and funds activities for the development, implementation, and testing of product data standards and specifications.

- The U.S. Techuical Advisory Group (USTAG) is a working group that defines the U.S. position and casts the U.S. vote on various ISO issues, including STEP. USTAG is a standing committee of USPRO'S IPO.

- National Initiative for Product Data Exchange (NIPDE) is an effort sponsored by high-level industry and government executives to coordinate the various efforts to develop, test, and implement data standards.

- PDES Inc. is an international consortium of more than $\mathbf{2 0}$ aerospace, automotive, defense, and computer firms for testing and promoting STEP. The National PDES Testbed coordinates U.S. implementation and testing of STEP.

- The National Institute of Standards and Technology (NIST) is part of the U.S. Department of Commerce which has development laboratories and testbed facilities to validate STEP concepts.

- The Process Data Exchange Institute (PDXI) is an American Institute of Chemical Engineers program to promote data standardization in chemical processing industries.

\section{Europe}

Europe is highly active in the development and deployment of standards and often specific standards are required by law in industrial activities. Indeed, much of the development and implementation of STEP is centered in Europe. For example, Germany recently introduced ProSTEP, a joint-venture to standardize the exchange of product model data among the approximately 110 different $\mathrm{CAD}$ systems used by German automobile manufacturer's. Germany's Federal Economics Ministry expects STEP to improve cooperation between small and medium-sized enterprises and large manufacturers and has contributed about one-third of the $\$ 6$ million cost to set-up ProSTEP. The Standard Exchange and Transfer (SET) standard is the French equivalent to STEP $r$ and the GOSET Association is the center for the country's STEP activities where it actively develops the EXPRESS computer language and the SET standard. The CAD-CAM Data Exchange Technical Center (CADDETC) is the center for product data exchange in the United Kingdom.

The Eufopean Uriton is also actively developing and promoting STEP development and implementation, primarily through its European Strategic Program for Research in Information Technology (ESPRIT). One 
ESPRIT program, the Advanced Information Technology (AIT) project is particularly significant. This $\$ 500$ million research consortium consists of 30 leading European aerospace and automobile manufacturers who are developing and standardizing factory automation data (particularly CAD/CAM systems) based on STEP. AIT's research is divided into five "work packages": product definition, product modeling, manufacturing engineering, production control and logistics support, and information management. The six-year project is currently mid-way through an 18month pilot phase funded at $\$ 28$ million- half coming from ESPRIT.

In addition to data standardization, Europe established the ISO 9000 standard in 1987 to standardize manufacturing processes with the goal of improving the quality of products produced. The serjes of ISO 9000 standards have been adopted in 95 countries with over 45,000 certifications granted worldwide, but only 4,000 in the U.S., according to industry journals. Although ISO 9000 is a priority for many comparies (more so with larger firms), some industry executives have expressed concerns about the standard. Registration costs typically run $\$ 35,000$ for three years, regardless of company size. Moreover, many U.S. companies suggest that the U.S. accreditation system for the American ISO 9000 program is behind that of the European program, and that European companies sometimes reject American certification on that basis. Contributing to this situation, the European ISO 9000 standard is reportedly being rewritten, which could impact U.S. companies trying to do business in Europe.

\section{Japan}

The standardization of manufacturing data is also being seriously pursued in Japan. In 1991, the Nippon Graphics Association (Nicograph) was commissioned by AIST (Japan's Agency of Industrial Science and Technology under the Ministry of (nternational Trade and industry) to establish the STEP Center to act as the lead for Japan's STEP activities. Nicograph's efforts include coordinating Japanese STEP activities with the U.S. and Europe, preparing Japanese-language versions of STEP, testing and evaluating data exchange research, and promoting STEP within Japanese industry. Last year, AIST launched a five-year, \$3 million program tasking Nicograph and the STEP Center to conduct further research on data conversion programs.

The Japan Automobile Manufacturers Association (JAMA, which is under MITI's Machinery and Information Industries Bureau) is sponsoring two industry working groups to coordinate data standardization efforts among the 13 member companies. The first working group, the JAMAIGES Strbset (JAMA-IS), focuses on imtrediate data exchange issues and problems through utilization of the IGES standard; IGES was selected as the means to work out present problems because it is currently the most 
widely accepted standard. The second working group, JAMA-STEP, focuses on the development and future direction of STEP within Japan's automobile industry. At the same time, Mitsubishi Heavy Industries is leading an effort with six other companies in Japan's shipbuilding industry to establish shipbuilding standards integrating STEP.

In the broader sense, the Japanese Industrial Standards (JS) Committee is responsible for setting various national standards across a wide range of Japanese industries, including the textile, chemical, construction, machinery, medical, shipbuilding, atomic energy, electronics, aircraft, and steel industries, among others. IIS has established over 8,000 standards which can be generally broken down into three areas: product standards, working methods standards, and basic standands (terminology, language, symbols, etc.) One of the primary goals currently being pursued is the accommodation and integration of products, processes, and practices due to the increased internationalization of industries and businessesparticularly in light of global recognition of GATT and its associated Standards Code.

\section{Conclusion}

Standardization activities actoss various industrialized countries are required to be highly linked because business and industry is becoming increasingly global. Indeed, most major incustrial standards emerging today- such as STEP- are being developed on a multilateral level with a high degree of cooperation among the researchers from the different nations. Industrial standards- especially those associated with electronic data in manufacturing and commurications- will play a critical role in manufacturing competitiveness. As large-scale, emerging standards are in development, the U.S. should be deeply involved in order to ensure U.S. industrial interests are represented in the final version of the standard. Perhaps more importantly, how well the standards are accepted and utilized will determine the efficiency of communications between manufacturers on a global scale and thus their ability to interact and compete. 


\section{Appendix: List of Contributing Experts}

\section{Product, Process and Enterprise Design}

Farrokh Mistree, Professor

Systems Realization Laboratory

Georgía Institute of Technology

Atlanta, Ceorgia 30332-0405

(404)894-8412

FAX(404)894-9342

farrokh.mistrokme.gatech.edu

\author{
David Rosen, Associate Professor \\ Systems Realization Laboratory \\ Georgia Institute of Technology \\ Atlanta, Georgia 30332-0405 \\ (404894-9668 \\ FAX (404) $894-9342$ \\ david.rosen mane-gatech.edu
}

The mission of the Systems Realization Laboratory is to develop the scientific foundation and the educational and university-industry infrastructures that will support people in designing, inanufacturing, deploying, and maintaining open engineering systems. Professor Mistree joined the Mechanical Engineering Department in 1992 and directs research in open engineering systems. He is particularly interested in enhancing the ability of human designers to make dexisions in the eatly stages of the product realization process. He has developed the Decision Support Problem Technique, the associated DSIDES software, and the DSPT Workbook for ímplementing unified design, manufacturing, and maintenance. Professor Mistree directed the Mechanical Engineering Design Program at the University of Houston from 1981 to 1992. He has published two books and 150 publications. Professor Rosen joined the Systems Realization Laboratory in 1992. His interests include product representation research which is being expanded to capture issues of product modularity and part integration in support of continuous quality improvement. He received a 1992 ASME Best Paper award and has coedited a special issue of the journal Research in Engineering Designt.

\section{Rapid Prototyping / Concurrent Engineering}

Allan J. Lightman, Professor

University of Dayton Research lnstitute

Dayton, $\mathrm{OH} 45 \times 69-0140$

(513) 229-3966

FAX(513)229-3433

lightman@udniudayton.edu

Dr. Lightman conducts research and development focused on advanced manufacturing technologies. He co-founded and continues as a director of the International Conference on Rapid Prototyping held annually in Dayton, is a founding board member of the Rapid Prototyping Association of SME, and is a member of the editorial board of the International Journal of Rapid Prototyping. Dr. Lightman has also been a keyrote speaker at rapid prototyping conferences in Europe and Japan. 


\section{Environmental Technologies}

Guna Selvad uray, Professor

Departnent of Materials Engineering

San Jose State University

San Jose, CA 95192-0086

(408)924-3874

FAX (408)924-4057

selvadur\%sjsuvm1.bitnetormsa. Berkeley.edu

\section{Safety and Health Design Considerations}

Peter J. Boden, Research Associate

Underwriters Laboratories Inc.

333 Pfingsten Road

Northbrook, llinois 60062-2096

(708) 272-8800ext42011

FAX(708)272-8129
M. Matthew Vlasaty, Research Associate Underwriters Laboratories Inc. 333 Pfingsten Road

Notthbrook, Illinois 60062-2096

(708) 272-8800 ex 43579

FAX $\{708) 272-8129$

Peter Boden and Matthew Vlasaty pursue engineering research on international safety skandardization and technology transfer to industry. The independent, not-for-profit organization provides extensive international engineering services and foreign safety certification information. Beyond product safety certification programs, the Underwriters Laboratory staff works closely with manufacturers, regulators, consumers, retailers, and insurance companies to identify appropriate product safety requirements.

\section{Chemical Processing}

John G. Wilder, Staff Engineer/Geologist

Lawtence Livermore National Laboratory

PO. Box 808 L-591

Livermore, CA 94550

(510) $422-2745$

FAX(510)422-3165

jwilderøilnl.gov

John Wilder is currently responsible for the molten salt destruction prototype system for DOE's Waste Remediation Program. He has worked on several technology programs at LLNL developing material fabrication. processes. His twenty years of engineering, development, and operations experience in energy research and production includes nuclear power plant emergency backup systems, ofishore/subsea petroleum development, and design and installation of reciprocating compressors, pumps, and diesel engines for the oil and gas industry. He has worked and traveled extensively overseas. 


\section{Workpiece Fabrication}

John Berkowitch, Ph.D. National Textile Center 3352 Momingside Road Wilmington, DE 19810

(302)478-00340

$\mathrm{FAX}(302) 478-0213$

berowjegrsoc.Inet.dupont.com

Dr. Berkowitch retired from DuPont Fibers, Techniçal Division, at the end of 1991 following a career of thirty-four years in a variety of staff and managerial positions. Primarily associated with the polyester enterprise and the organization responsible for the pioneering of novel fiber-based core technologies. Managed for the last decade a worldwide tectunology transfer program with emphasis on Japan, Europe and the U.S. National Laboratories. Presently associated with the National Textile Center, a university research consortium, operating under a grant admínistered by the U.S. Department of Commerce. Also an independent consultant and adjunct faculty at the Philadelphia College of Textiles and Science.

\section{Machining}

J. Tusty, Graduate Research Professor

Mecharical Engineering Department

University of Florida

Gainesville, FL 32611

(904) $392-7656$

FAX(904)392-1071

Professor Tlusty is Director of the Machine Tool Research Center at the University of Florida and President of Manufacturing Laboratories Inc. His research interests include high speed, high power machining and vibrations/controls during machining. His experience in the design, testing, and application of machining processes and machine tools spans fifty-three years. Professor Tlusty has contributed to machiring research in Czechoslovakia, England, Canada, Germany, and the United States and has received the 1954 Czechoslovak State Prize, the 1979 SME Gold Medal, the 1980 ASME Centennial Award, and the 1990 ASME Blackall Award. 


\section{Surface Coating and Modification}

Frank K. Ưban, Ph.D.

Professor, Electrical Engineering

Florida Intemational University

Miami, FL 33199

(305)348-2807

FAX(305)349-3707

urbanoservax.iu.edu

Professor Urban's research interests include new thin film depostion technologies, real-time in-situ film growth monitoring and control, and advanced numerical processing of microscopy imagery. He began working on thin film technologies in the semiconductor industry. After joining academia, Frank spent a year at Kyoto University working in this field and maintains contacts with researchers in Japanese and German universities working on related technologies. The laboratory he directs at FIU was the first in the U.S. and second in the world to produce intense cluster beams of a room temperature solid without using a carrier gas. He has also pioneered "real-time" ellipsometry solutions for film growth control tusing artificial neural network algotithms.

\section{Joining and Assembly}

John C. Lippold, Ph.D.

Edison Welding Institute

1100 Kinnear Road

Colurnbus, OH 43212-1152

(614) $486-9400$

FAX(614)486-9528

Dr. Lippold is a staff member of the Edison Welding Institute. The Institute is a nonprofit organization which develops and thangfers the latest materials joining technologies to industry. The members are dedicated to improving US. manufacturing through materials joiring technology by improved quality, increased productivity, reduced cost and extended product life. They have developed a multi-million dollar ongoing cooperative research and development program. 


\section{Test and Inspection}

James E. Helton, President and CEO

M\&M Precision Systems Corporation

300 Progress Road

West Carrollton, OH 45449

(513) $859-82.73$

FAX(513)859-4452

In $1988 \mathrm{Mr}$. Helton joined M\&M precision Systems, a manufacturer of metrology equipment, as President and C.E.O. Mr. Helton began his industrial career in 1963 serving a five year apprenticeship at Cincinnati Milacron and continued there in manufacturing, engineering, and sales positions. He later served in a variety of manufacturing and technical management positions with the Valeron Corporation and Eagle Picher Industries. He became President of Kysor Machine Tool, a manufacturer of manual and CNC metal cutting machine tools in 1979. He is a Certified Manufacturing Engineer in the Field of Material Removal and a Certified Robotics Engineer.

\section{Information Technologies}

Diane Culp

Howard Curtis

Tamami Davidson

Jackson Hwang;

The International Liaison Office

MCC

Austin, Texas

FAX(512)338-3898
(512)338-3229; culp(imcecom)

(512)338-3792; curts

(512)338-3228; davidson(mec.com)

(512)338-3350; hwang incc.com

MCC's International Liaison Office (ILO) monitors and reports to MCC member organizations on developments abroad in semiconductor packaging and interconnect, advanced electronic devices and computer components, computer architecture and design, software and software development environments, databases and intelligent information systems, and networking and telecommutrications. In addition to publishing the: monthly Global Technology Monitor, the ILO issues in-depth techrical reports on foreign technology trends; maintains two major electronic databases that track R\&D activity abroad; prepares and delivers technical briefings at member sites; provides translating services for technical literature; and assists members with international negotiations, the organization of study tours and fact-finding missions abroad, and the incorporation of improved information on foreign technology into member firms' own competitive analysis efforts. 


\section{Machine and Tool Technologies}

Thomas M. Batlow, Site Manager

National Machine Tool Partnership

Lawrence Livermore National Laboratory

P. O. Box 808 L-644

Livermore, CA 94550

(510)422-8200

EAX(510)423-7914

batjow101/nl.gov

Thomas M. Barlow is a Fellow in the American Society of Mechanical Engineers and currently serves as a Vice President in the Society. He was the principal author of the report, The National Machine Tool Partnership: Final Report and Recommendations of the Machie Tool Task Team, (Lawrence Livermore National Laboratory Report UCRL-LR-113247, April 1993), that recommended the current Department of Energy program. He is actively involved in the Partnership, serving as the program's LLNL site manager.

\section{Sensor and Control Technologies}

Del Tesar, Graduate Research Profesşor

Director, Robotics Research Group

University of Texas

Austin, TX

(512)471-3039

FAX(512)471-3987

fesarguts.cc.utexas.edu

Del Tesar received the Carol Cockrell Curran Chair in Engineering at the University of Texas at Austin in 1985. He established the Robotics Research Group which supports 33 graduate students and a permanent staff of six. Professor Tesar has pursued research in the machine system field for 35 years. Continuing research is centered in the areas of design control and operation of manufacturing systems. In 1992, he was appointed to the standing review committee of the National Research Council on the Space Station. In 1964 he was presented the ASME Machine Design Award. He has served on an Air Force Review committee for the MANTECH program, the Air Force Science Advisory Board, and national review panels on robotics for NIST, USAF, and NASA. 


\subsection{References}

[3.1] Jobst Conrad, Technological protest in West Germany: signs of a politicization of production? Industrial Crisis Quarterly 4(3) 1990: p.176.

[3.2] D. B. Welbourn, What has happened to CADCAM? Computer-Aided Eng. J. December, 1991: p. 229-232.

[3.3] Shunsuke Mori, Diffusion of Adranced manufacturing systems in Japan. Science/Technology/Industry Review 12, OECD, April, 1993: p.101-125.

[3.4] Manufacturing technology; the competitive edge, Report of the DOE Laboratories Mariufacturing Working Group, April 30, 1993.

[3.5] The Taxonomy is a joint product of the DOE Laboratories Manufacturing Working Group and NIST* 1993.

[3.6] F. Mistree, et al., Engineering Research Center for Open Engineering Systems. Proposal to the National Science Foundation, 1993.

[3.7] L. Dobbins and C. Crawford-Mason, Quality or Else. Houghton Mifflin, NY, 1991: p.10.

[3.8] ". . organizations where people continually expand their capacity to create the results they truly desire, where new and expansive patterns of thinking are nurtured, where collective aspiration is set free, and where people ate continually leaming how to learn together." (P. Senge, The Fifth Discipline: The Art \& Practice of the Learning Organization. Double Day, New York: 1990 ).

[3.9] D.E. Whitney, State of the Art is Japanese CAD Methodologies for Mechrical Products - Industrial Practice and Unioersily Research. Draper Laboratory Report CSDL-P-3126, Cambridge, Massachusetts: October. 1991.

[3.10] D.E. Whitney, Electro-Mechanical Design in Europe: Unizersity Research and Industrial Practice, Draper Laboratory CSDL-P-3226 Cambridge, Massachusetts: December, 1992. 